\title{
Structure of the crust and upper mantle beneath the Bransfield Strait (Antarctica) using $P$ receiver functions
}

\section{Joan Antoni Parera Portell}

Supervisors: Dr. Flor de Lis Mancilla Pérez

Dr. José Morales Soto

Master's thesis
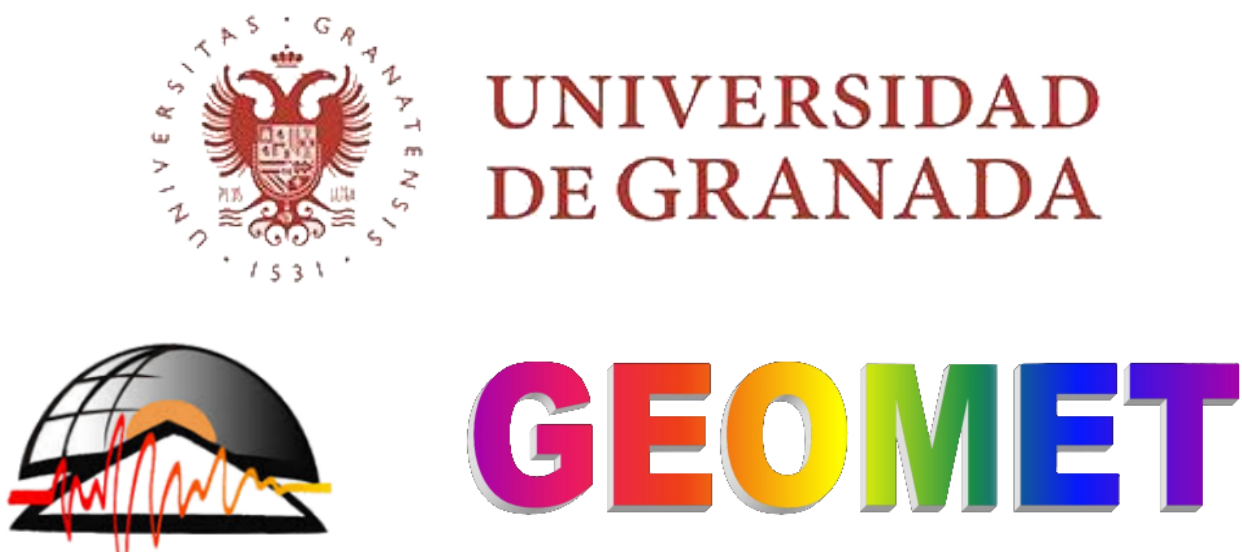

INSTITUTO NDALUZ DE CEOFISICA Y PREVENCIÓN DE DESASTRES SISMICOS

Máster en Geofísica y Meteorología

Departamento de Física Teórica y del Cosmos

Instituto Andaluz de Geofísica

8th September 2019 



\section{Contents}

1 Introduction 1

1.1 Goals ........................... 2

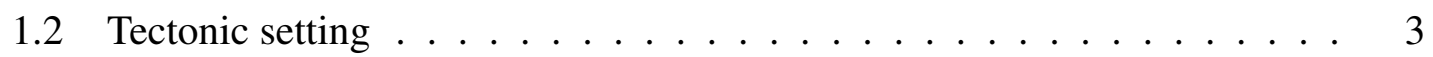

1.3 Receiver functions overview . . . . . . . . . . . . 6

1.4 Receiver functions in the Bransfield Strait . . . . . . . . . . . . 8

2 Materials and methods $\quad \mathbf{1 0}$

2.1 Seismic dataset . . . . . . . . . . . . . . . . . . 10

2.2 Data preparation . . . . . . . . . . . . . . . . . 11

2.3 Receiver function technique . . . . . . . . . . . . . . . . . 13

2.3.1 Component rotation . . . . . . . . . . . . . . 13

2.3.2 Iterative time-domain deconvolution method . . . . . . . . . . . 14

2.4 Stacking . . . . . . . . . . . . . . . . . . . 16

2.4.1 Time-domain stacking and moveout correction . . . . . . . 16

2.4.2 Common conversion point stacking . . . . . . . . . . . . 17

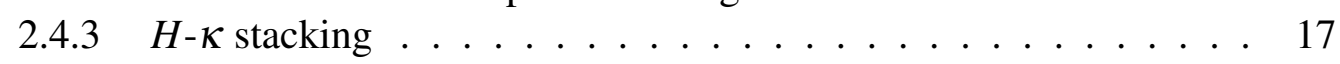

2.4 .4 Grid stacking . . . . . . . . . . . . . . . . . . 19

3 Results $\quad 21$

3.1 Lithosphere . . . . . . . . . . . . . . . . . . 21

3.1.1 Crustal thickness and $V_{P} / V_{S} \ldots \ldots \ldots \ldots$

3.2 Mantle Transition Zone (MTZ) . . . . . . . . . . . . . . . . . . . . . 29

4 Discussion $\quad 31$

4.1 Lithospheric structure . . . . . . . . . . . . . . . . . . . 31

4.2 Limitations and comparison of crustal thickness and $V_{P} / V_{S} \ldots \ldots . . .34$

4.3 Variability of the MTZ and its relationship to regional tectonics . . . . . . 37

5 Conclusions $\quad 41$

References $\quad 42$

A Computer programs i

B Time-domain stacks $x i v$

C $H$ - $\kappa$ stacks $\quad$ xxi 


\section{List of acronyms}

AP Antarctic Peninsula

BRAVOSEIS BRAnsfield VOlcano SEISmology

CCP Common Conversion Point Stacking

DFT Discrete Fourier Transform

ESR East Scotia Ridge

FFT Fast Fourier Transform

HFZ Hero Fracture Zone

IAG Instituto Andaluz de Geofísica

IRIS Incorporated Research Institutions for Seismology

LVZ Low Velocity Zone

MTZ Mantle Transition Zone

NEIC National Earthquake Information Center

NSR North Scotia Ridge

PR Phoenix Ridge

RF Receiver Function

SAC Seismic Analysis Code

SEPA Seismic Experiment in Patagonia and Antarctica

SFZ Shackleton Fracture Zone

SSB South Shetland Block

SSI South Shetland Islands

SSR South Scotia Ridge

SST South Shetland Trench

ST Sandwich Trench

WSR West Scotia Ridge 


\section{Acknowledgements}

I would like to acknowledge my two supervisors, Flor de Lis Mancilla and José Morales, for their help and support, as well as for all the hours I spent with Flor discussing the results and resolving my (many) questions and doubts. In addition, they gave me the opportunity to write this thesis at the Instituto Andaluz de Geofísica (IAG) in a very friendly environment.

My gratitude to anyone whom I spent time with at the IAG, including the GEOMET professors and the fellow students Eugènia and Saray; I have felt very comfortable. Special thanks to Roberto for the time we shared working together and discussing both this thesis and his. 


\begin{abstract}
The Bransfield Strait is a tectonically active region of the Antarctic Ocean comprising the waters located between the South Shetland archipelago and the Antarctic Peninsula. Nowadays the Bransfield region is characterised by the presence of an incipient oceanic spreading ridge possibly driven by ongoing subduction or slab rollback in the South Shetland Trench, to the northwest of the archipelago. A set of twelve seismic stations located in the region provide records of teleseismic earthquakes which allow the study of the deep earth structure, which is thought to be heterogeneous due to the complex tectonics. Here, we use those teleseismic events to obtain P-wave receiver functions in order to infer the structure and spatial variability of the main discontinuities in the crust and upper mantle, including the depth of the Mohorovičić (Moho) discontinuity, the crustal average $V_{P} / V_{S}$ ratio, and the thickness of the Mantle Transition Zone. Results indicate that the structure below the South Shetland Islands is laterally heterogeneous: crustal thickness reaches its minimum in Deception Island $(15 \mathrm{~km})$ and grows up to $30-32 \mathrm{~km}$ near the southwestern and northeastern ends of the archipelago. In contrast, crustal thickness in the Antarctic Peninsula is similar under all the stations with values between $33-35 \mathrm{~km}$. Average $V_{P} / V_{S}$ ratios display a similar variation than crustal thickness, being more variable in the South Shetland archipelago (1.69-2.19) than in the Antarctic Peninsula (1.68-1.82). A negative correlation between crustal thickness and average $V_{P} / V_{S}$ has also been observed, with high $V_{P} / V_{S}$ clustered around the thinnest crust at the centre of the rift basin, possibly indicating the presence of melts in accordance with the active volcanism in the area. Receiver functions in the South Shetland Islands hint the presence of at least another three seismic interfaces below the Moho, which are interpreted to represent magmatic underplating, a negative gradient-like discontinuity possible related with the mantle wedge, and the subducted slab. The negative gradient is also seen in the Antarctic Peninsula, and may indicate there is a low velocity zone in the upper mantle due to the presence of melts. The Mantle Transition Zone is not perturbed to the northwest of the South Shetland Archipelago, while it appears thickened below the islands and the Bransfield rift basin due to the interaction with the sinking slab. Results in the Antarctic Peninsula are not conclusive, but the Transition Zone could be thinner than usual.
\end{abstract}




\section{Introduction}

The Bransfield Strait is a body of water belonging to the Antarctic Ocean, located between the Antarctic Peninsula (AP) and the South Shetland Islands (SSI) archipelago (Fig. 1). The Strait is a seismically active region and is, in fact, a rift basin where incipient oceanic crust is developing (Gràcia et al., 1996). It displays active volcanism, both submarine (e.g. Gràcia et al., 1996; Lawver et al., 1996) and subaerial (e.g. Almendros et al., 1997; Smellie, 2002). Furthermore, an oceanic trench (South Shetland Trench (SST), Fig. 1) located immediately to the northwest of the SSI has been a focus of interest in past years, as the presence of an active subduction has been largely debated. The most recent seismic studies support the presence of a slowly sinking slab below the region (Robertson Maurice et al., 2003; Dziak et al., 2010; Park et al., 2012) which would be responsible, at least partially, of the active rifting in the Bransfield Basin. In this seismically active region the occurrence of earthquakes responding to such processes provide evidence of a complex tectonic setting (Robertson Maurice et al., 2003, see Fig. 1).

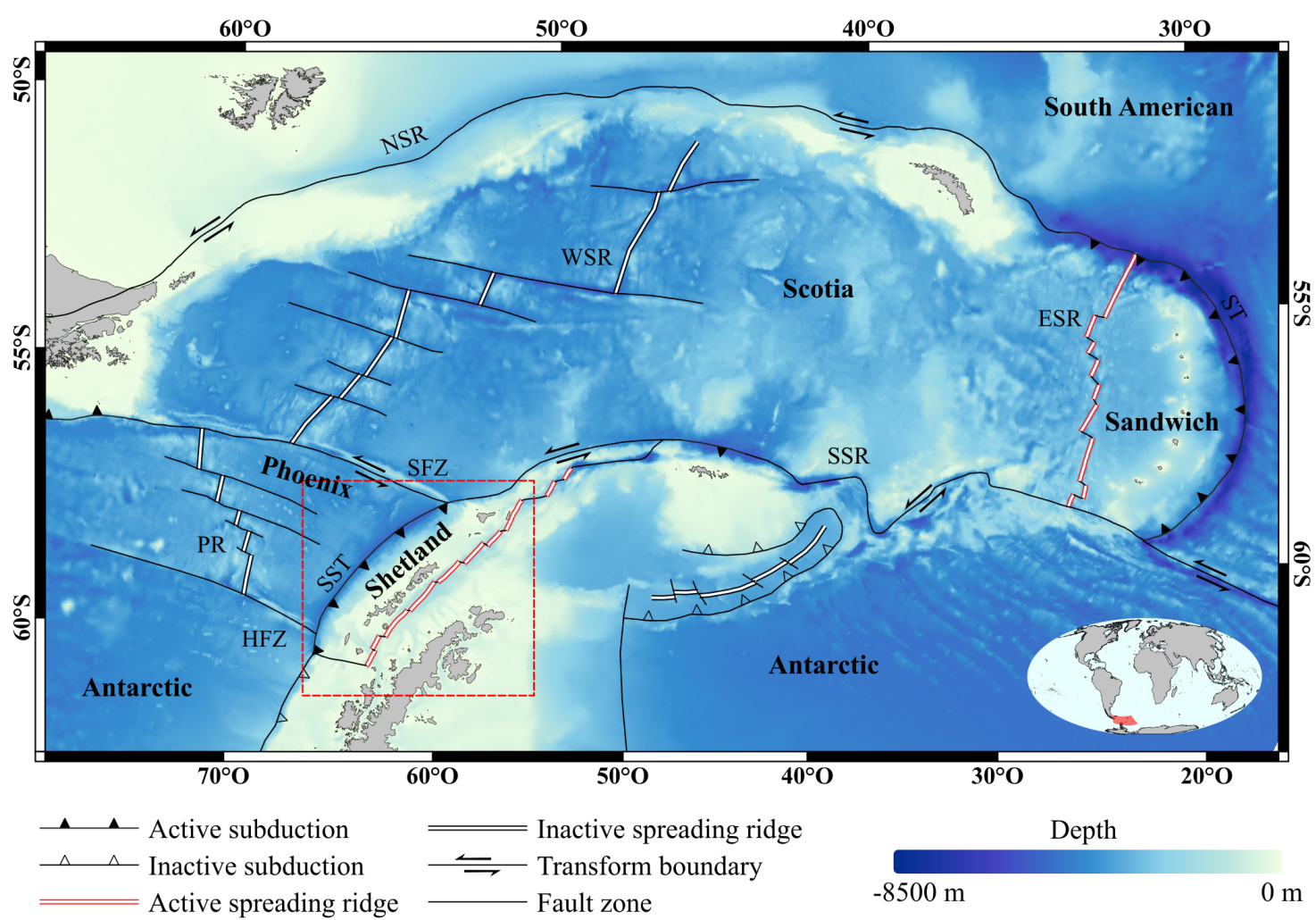

Figure 1: Tectonic setting of the study area (within the dashed red box). Bathymetry data was obtained from Ryan et al. (2009). Plate boundaries are based on USGS' ScienceBase catalogue data. All maps in this work are in South Pole Azimuthal Equidistant projection (WGS84 ellipsoid).

Multiple seismic stations are distributed at both sides of the Strait, both in the SSI and the AP (see Fig. 2). Although there are some limitations such as the geographical configuration of the emerged land and the harsh climate of the region, those stations do not only allow to study the local and regional seismicity, but also to detect distant earthquakes. Such distant or teleseismic earthquakes can be used to study the regional deep structure in multiple ways; here we focus on Receiver Function (RF) analysis, which is a method to obtain the impulse response of the Earth using teleseismic data (Vinnik, 1977; Langston, 
1979). As previous RF analyses have shown (e.g. Biryol et al., 2018), the tectonic features in Bransfield led to an heterogeneous structure which is still not well constrained, so further research is required.

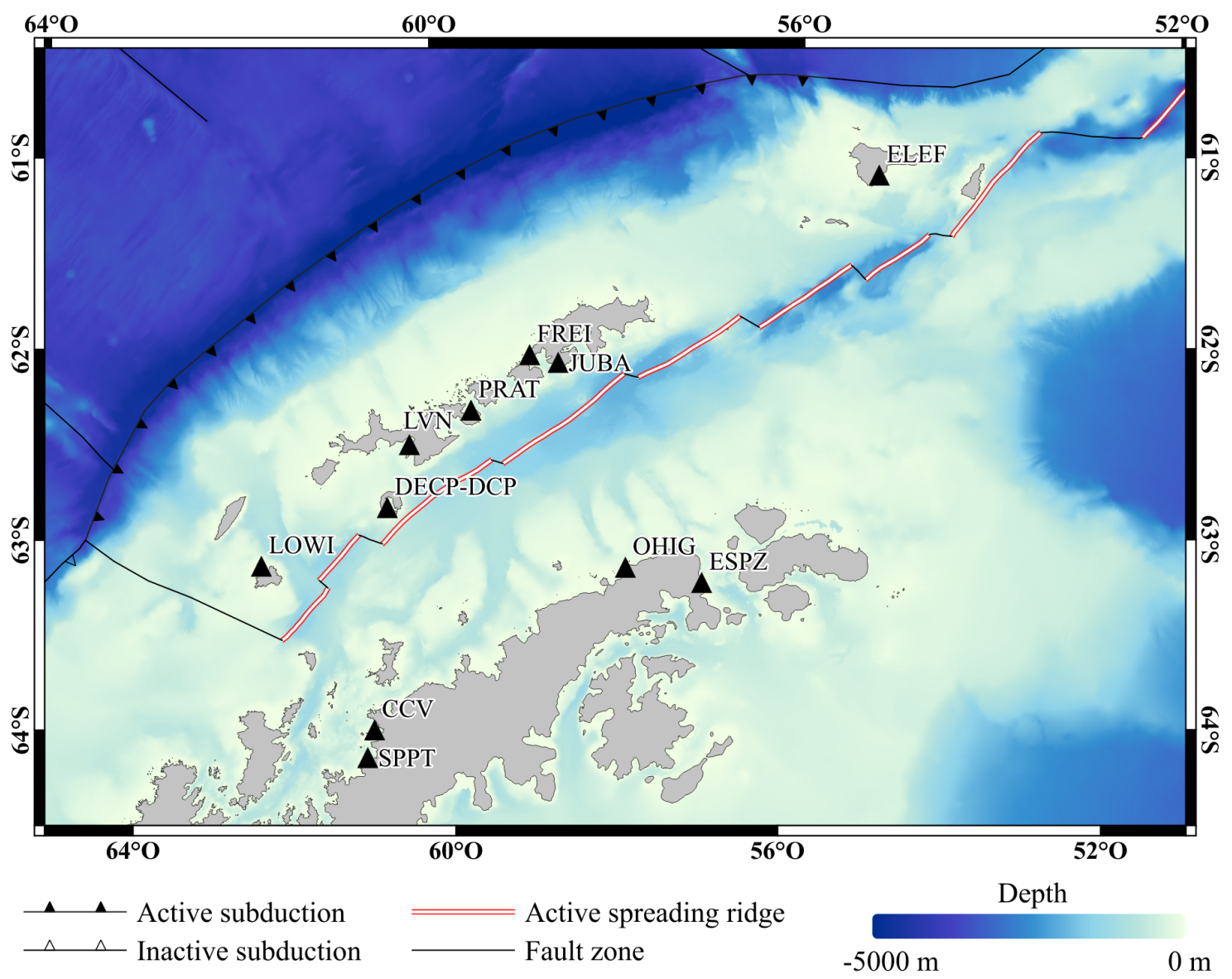

Figure 2: Tectonic features of the study area alongside the location of the 12 seismic stations.

Concerning the structure of this study, the rest of this section is dedicated to put forward our goals, to give a more extensive tectonic context, introduce the RF technique, and briefly review past RF geophysical studies in the Bransfield Strait. In the next section we describe in detail the dataset and used methodology, including a step-by-step explanation of the RF calculation and further analysis. The third section is devoted to present the results, while in the fourth section their implications on the structure and tectonic features in the area are discussed. Results are also compared to previous geophysical studies on Bransfield's deep structure, including RF analyses. Finally, in the last section the conclusions are exposed.

\subsection{Goals}

The aim of this work is to provide some insights on the deep earth structure of the Bransfield Strait region (including its crustal and upper mantle structure) in order to increase the current knowledge in its present tectonics and also in its tectonic evolution. To accomplish this we make use of $\mathrm{P}$ wave RFs methodology. This seismic technique allows to detect the depth and strength of the seismic interfaces and, thus, to constrain the depth 
of the Mohorovičić (Moho) discontinuity (i.e. the crustal thickness), the thickness of the Mantle Transition Zone (MTZ), and their spatial variations along the study area. This is particularly important due to the active rifting in the Strait, which suggests an heterogeneous crustal structure, while the subduction implies that the sinking slab possibly perturbs the MTZ. RFs are obtained from teleseismic records provided by twelve seismic stations in the area, nine belonging to international networks through Incorporated Research Institutions for Seismology (IRIS) organization and another three to the Instituto Andaluz de Geofísica (IAG), Universidad de Granada. With this large dataset we will be able to assess previous RF studies and to resolve more clearly the crustal and upper mantle structure below the Bransfield Strait region.

\subsection{Tectonic setting}

The Bransfield Strait, as seen in Figure 1, belongs to a region where multiple tectonic plates interact. Main plates in the region include the Antarctic, South American and Scotia plates, alongside the minor Sandwich, Shetland, and the former Phoenix plates. The main tectonic feature in the region is the eastwards-propagating Scotia Arc, comprising the North Scotia Ridge (NSR) and South Scotia Ridge (SSR) transform boundaries and the Sandwich Trench (ST), an active subduction zone with an associated volcanic island arc, the South Sandwich Islands. The Scotia Arc and the Shackleton Fracture Zone (SFZ) enclose the Scotia and Sandwich plates, which are separated by an active back-arc spreading centre known as East Scotia Ridge (ESR), that is linked to the subduction of the South American plate beneath the Sandwich plate at the ST (Dalziel et al., 2013). Current estimates set the ESR opening rate at $60-70 \mathrm{~mm} \mathrm{yr}^{-1}$ (Thomas et al., 2003). The two transform boundaries have a sinistral motion due to the relative velocity of the plates: in the NSR the Scotia plate is moving eastwards relative to the South American plate at $7.5 \mathrm{~mm} \mathrm{yr}^{-1}$, while in the SSR the Scotia plate moves to the west relative to the Antarctic and Shetland plates about 6-7 $\mathrm{mm} \mathrm{yr}^{-1}$ (Dalziel et al., 2013). At the NSR the seismic activity corresponds mainly to strike-slip events, however, the deformation at the SSR is not purely strike-slip (Thomas et al., 2003); there can be both transtensional and transpressive deformation. The Scotia plate also features the West Scotia Ridge (WSR), an inactive spreading centre thought to be responsible for the opening of the Drake Passage, i.e. the body of water between South America and the SSI, during the early Oligocene to late Miocene (Maldonado et al., 2014).

The Bransfield strait lies on a back-arc rift basin with an active spreading ridge that marks the boundary between the Antarctic and Shetland plates and separates two mainly continental crust blocks: the South Shetland Block (SSB) and the AP. To the north, the Shetland plate is bounded by the Scotia plate from the Shetland-Antarctic-Scotia triple junction to the SFZ. From the SFZ to the Hero Fracture Zone (HFZ) the Shetland plate bounds with Phoenix through the SST, where Phoenix is thought to be passively sinking (Ibáñez et al., 1997; Jabaloy et al., 2003; Robertson Maurice et al., 2003; Dziak et al., 2010; Yegorova et al., 2010; Park et al., 2012), although the current activity of the subduction is under debate (González-Casado et al., 2000; Jin et al., 2009). In the Bransfield Basin there is evidence of seafloor spreading through seamount volcanism and of prespreading back-arc rifting (Gràcia et al., 1996), although it has not yet evolved to the formation of normal oceanic crust (Lawver et al., 1996; Christeson et al., 2003). Currently the Bransfield Strait is opening at a rate of $7 \mathrm{~mm} \mathrm{yr}^{-1}$ according to Dietrich et al. 
(2004). Active volcanic edifices are found along the basin (Gràcia et al., 1996; Lawver et al., 1996), both submarine and emerged, with Deception Island being the most clear example due to its caldera shape. According to Smellie et al. (1984) the SSI have long been a magmatic region, first forming due to back-arc volcanism as evidenced by the volcano-sedimentary rocks and lava flows of Late Jurassic to Early Paleogene age outcropping there above the metasedimentary basement. Volcanic terrains can also be found in the AP.

Seismicity in the area concentrates generally in the SSB, along the SFZ, and near the volcanic edifices in the Bransfield rift basin, according to the USGS's National Earthquake Information Center (NEIC). There is also some shallow seismicity near the Phoenix Ridge (PR), although it is not caused by active extension but possibly by stresses produced by continuing subduction in the SST (Thomas et al., 2003). There are many evidences showing the PR is not experiencing extension any more and, thus, that Phoenix is now part of the Antarctic plate: paleomagnetic data shows the ridge stopped spreading around 3.3 Ma (Livermore et al., 2000), while the focal mechanisms of earthquakes located there show strike-slip motion not parallel to the fracture zones (Thomas et al., 2003).

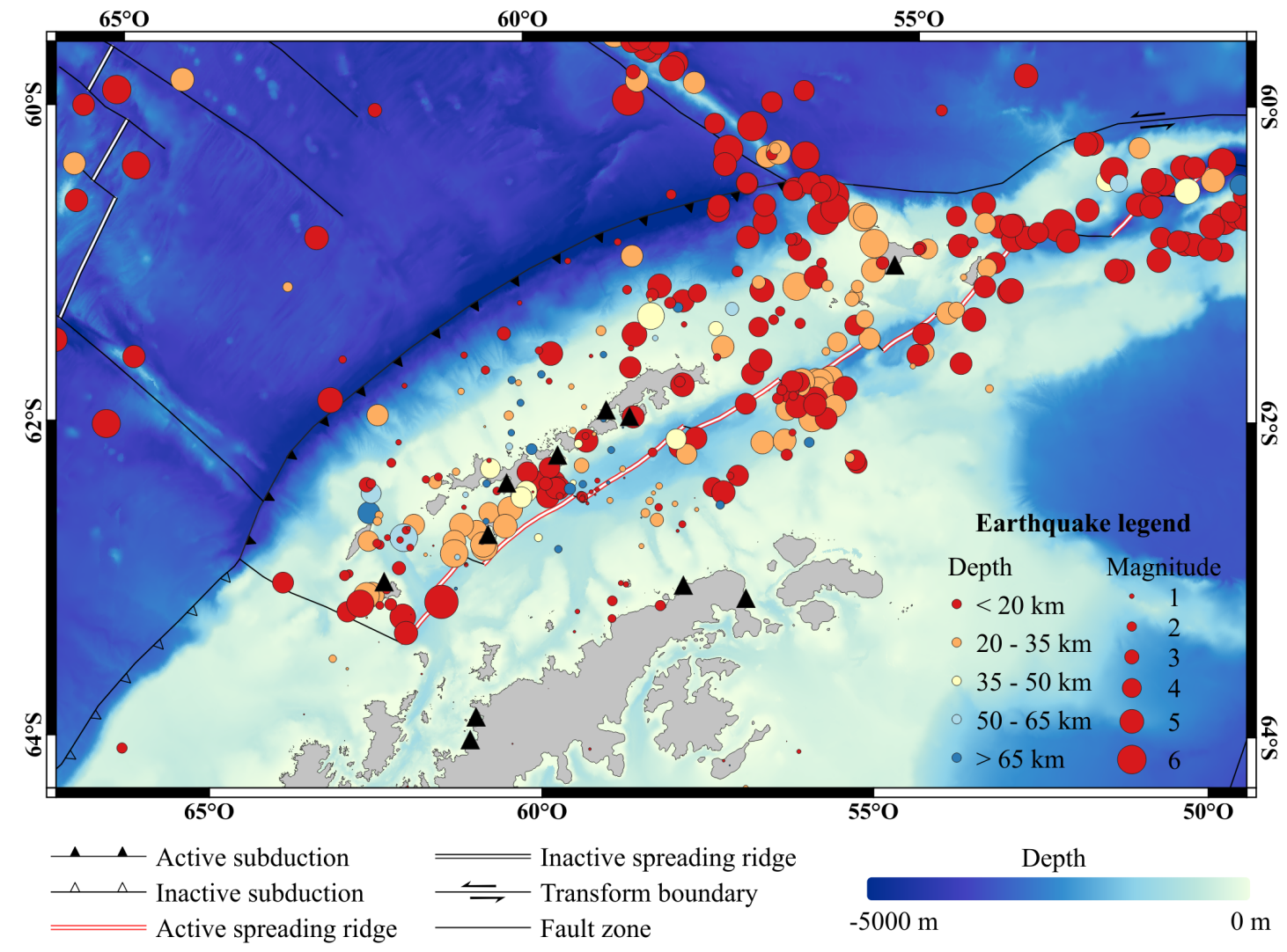

Figure 3: Epicenters of the earthquakes in the study area from 1930 to 2018 according to NEIC, alongside those located by Davoli (2019) from March 2018 to February 2019.

The NEIC database shows shallow events of magnitude 6 or larger in the Bransfield area in the depth range of 0 to $20 \mathrm{~km}$, but earthquakes with lower magnitude can occur at depths up to $72 \mathrm{~km}$. Ibáñez et al. (1997) suggest many earthquakes occurring below the SSI may not be detected due to the low magnitude, although they detected up to 15 intermediate-focus events using a seismic array which they argue represent mi- 
croseismicity produced by ongoing subduction. Further analysis by Robertson Maurice et al. (2003) indicates that there is a high level of seismicity with body-wave magnitude between 2 and 5. Using the Seismic Experiment in Patagonia and Antarctica (SEPA) seismometer deployment, the authors were able to locate accurately almost 150 earthquakes with depths mainly between 10 to $50 \mathrm{~km}$. Figure 4 shows some of the earthquakes analysed in Robertson Maurice et al. (2003) in a cross section orthogonal to the SST, from northwest to southeast across the Livingston Island. The authors suggest that the depth and location of the earthquakes may be indicative of shallow thrust faulting along an active subduction. The focal mechanisms represented in Figure 4 are also consistent with the tectonic setting: the intermediate-focus event displays almost pure compressive movement in a gently dipping plane, while the shallow event located to the southeast of Livingston Island clearly shows normal faulting with some strike-slip component. Davoli (2019) detected a high number of intermediate to deep earthquakes below the SSI, with a maximum depth of almost $175 \mathrm{~km}$. Those events commonly display local magnitudes between 1 and 3, and appear to delineate the slab. Robertson Maurice et al. (2003) argue this may be a case similar to the Cascadian Arc, with a young and slowly subducting slab reaching high temperatures at low depths, thus showing reduced seismic activity and absence of a clear Wadati-Benioff zone. This view supports the hypothesis that the Bransfield Basin is the product of back-arc spreading, which is also supported by the deformation and overthrusting of the youngest trench fill sediments in the SST (Jabaloy et al., 2003) and by magnetic and gravimetric models (Yegorova et al., 2010). In a more recent paper, Park et al. (2012) use P-wave tomography to image the structure below the SSB. Results show a positive anomaly in seismic velocity, indicating the position of a steeply dipping subducting slab which the authors suggest is causing slab pull and, therefore, back-arc extension. However, limitations in the dataset shown by their synthetic resolution tests must be considered.

Other authors (e.g. González-Casado et al., 2000; Jin et al., 2009) propose that compression in the SSI is caused by the sinistral movement between the Antarctic and the Scotia plates, which makes the SSB push the former Phoenix plate to the northwest. This way, convergence should take place at the SFZ to accommodate stresses in the region, and the opening of the Bransfield Basin would not be caused by back-arc rifting, but rather by the same simple sinistral shear that drives compression in the SSB.

Finally, some authors (e.g. Galindo-Zaldivar et al., 2004) suggest that the current dynamics in the Bransfield area are a combined effect of both slab roll-back and the shear stress process proposed by González-Casado et al. (2000). If we assume this complex setting, the tectonic evolution of the Bransfield Basin would be as follows: before the opening of the basin, the Antarctic margin featured an active subduction zone, where Phoenix subducted below the Antarctic plate (Larter et al., 2002; Jabaloy et al., 2003; GalindoZaldivar et al., 2004). Fast subduction was probably already active during the Cretaceous (Larter et al., 2002) and lasted until the collision between the HFZ and the SST (3.3 Ma) which caused a reduction in slab pull and the extinction of the PR (Livermore et al., 2000). This event also led to a lateral transition between an active to an inactive subduction zone in the vicinity of the HFZ (Jabaloy et al., 2003). From this point on, GalindoZaldivar et al. (2004) suggest that slab roll-back produced a northwestwards migration of the SSB which, along with the shear stresses caused by the Scotia-Antarctic plate boundary (González-Casado et al., 2000), started a process of back-arc rifting. Eventually, the 


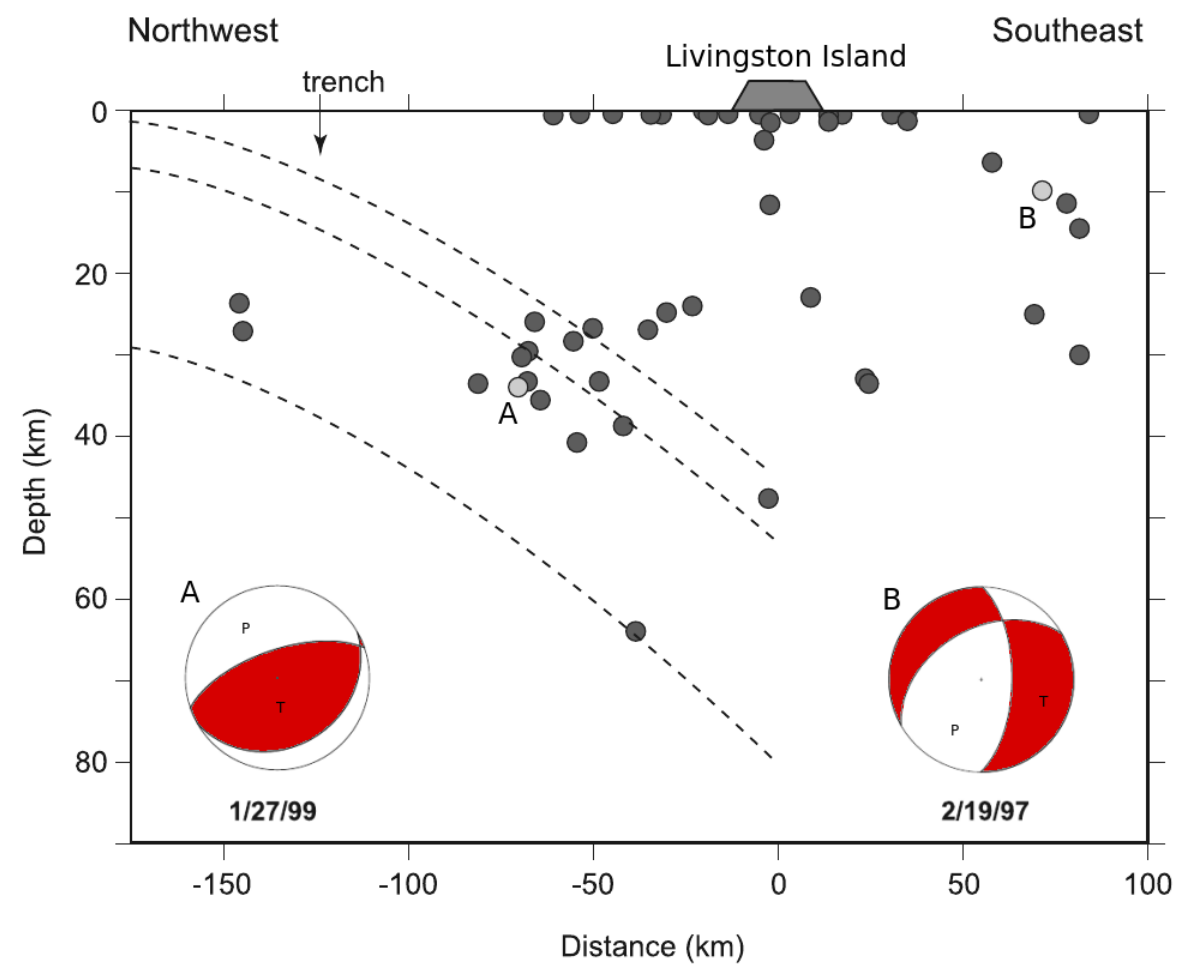

Figure 4: Cross-section perpendicular to the SST indicating the location of hypocenters with well-constrained depth. In dashed lines are represented the hypothetical locations of the crust and lithosphere of the subducting slab. Focal mechanisms are shown for two of the largest events. Figure modified from Robertson Maurice et al. (2003).

combination of both processes led to the incipient seafloor spreading seen today in the Bransfield Strait.

\subsection{Receiver functions overview}

Receiver functions, which were first introduced in Vinnik (1977) and Langston (1979), are time series of seismic wave conversions which can be regarded as the impulse response of the local Earth structure under the recording station, and are therefore used to study its internal structure. When a propagating body wave reaches a boundary between different seismic velocities with a non-normal incidence angle it may be refracted or reflected, and in both cases phase conversions may occur. Depending on the incoming body wave type, the conversions that will take place will be $\mathrm{P}$ to $\mathrm{S}$ waves (used in $\mathrm{P}$-wave RFs) or $\mathrm{S}$ to $\mathrm{P}$ waves (used in $\mathrm{S}$-wave RFs). $\mathrm{P}$ or primary waves display compressional motion along its propagation direction, being the fastest seismic waves; $\mathrm{S}$ or secondary waves are shear waves, that is, the particle motion is perpendicular to the wave propagation direction. The $\mathrm{S}$ waves cannot propagate through liquid mediums and travel slower than $\mathrm{P}$ waves. they are polarized into SV (vertical) and SH (horizontal) components. P waves can only be converted to SV waves or vice versa, while SH waves cannot be converted (Bormann et al., 2009). Consequently, if the seismic interface is horizontal and isotropic the energy of a $\mathrm{P}$ wave and its converted phases is contained within the vertical plane, i.e., the P-SV plane.

Figure 5 exemplifies a case of seismic waves reaching an interface from below. The 
wave identified as $\mathrm{Pp}$ is a $\mathrm{P}$ wave refracted at the interface, known as direct $\mathrm{P}$. Ps is the converted phase, which is transmitted as an SV wave upon reaching the discontinuity. PpPhp, PpPhs, PsPhs, and PpShs are called multiples, as they reverberate between the interface and the free surface, and so the lateral sampling becomes much larger than that of Ps phase (the converted phase). Note that due to their lower velocity and as a consequence of Snell's law $\mathrm{S}$ waves travel with a steeper angle than $\mathrm{P}$ waves after conversion. Figure 5 are obtained by deconvolving the vertical component from the horizontal components in the time window corresponding to the teleseismic P-wave arrival and its coda (Vinnik, 1977; Langston, 1979). Ideally, the deconvolution process removes the common signature of the source, the instrument response, and propagation effects before the phase conversion at the discontinuity, keeping only the information of the local structure below the seismic station in the resulting receiver function (Langston, 1979). Due to the difference in travel paths and between $\mathrm{P}$ and $\mathrm{S}$ wave velocities the converted phases reach the station at different times and amplitudes, thus giving P-RFs an appearance such as in Figure 6 . If the velocity contrast at the discontinuity is positive, meaning velocities above the interface are slower, the converted phases will be represented by a pulse of positive amplitude. On the contrary, the pulse will have negative amplitude if there is a negative velocity contrast. However, as predicted by the Zoeppritz equations, multiples involving the interaction of $\mathrm{S}$ waves with the free surface display inverted polarity.

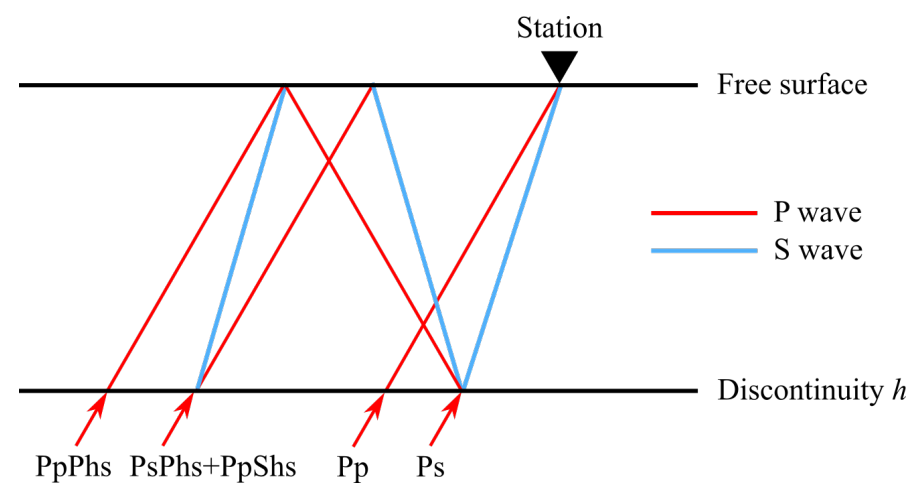

Figure 5: Sketch of $\mathrm{P}$ to $\mathrm{S}$ conversions at a discontinuity $h$ and the free surface. Modified from Ammon et al. (1990).

P-RFs use teleseismic events at epicentral distances between $30^{\circ}-90^{\circ}$, as at those distances seismic waves arrive with a steep incident angle and $\mathrm{P}$ motion is recorded mainly on the $\mathrm{Z}$ (vertical) component of seismometers, while $\mathrm{S}$ motion is recorded predominantly on the $\mathrm{N}$ (north) and $\mathrm{E}$ (east) components. This allows approximation of the P-SV plane with simple component rotations, which help maximize the amplitude of the converted phases. Additionally, $\mathrm{P}$ wave triplication below $30^{\circ}$ is avoided, and by setting the upper limit to $90^{\circ}$ the $\mathrm{P}$ wave shadow zone is excluded and waves resulting from the interaction with the core-mantle boundary are not detected.

However, the fundamental question regarding RFs is how is the Earth's impulse response obtained from the recorded waveforms. First, consider a waveform $D(t)$ belonging to a teleseismic P wave. Following the notation in Langston (1979), $D(t)$ is the product of the following convolution:

$$
D(t)_{i}=I(t) * S(t) * E(t)_{i}
$$




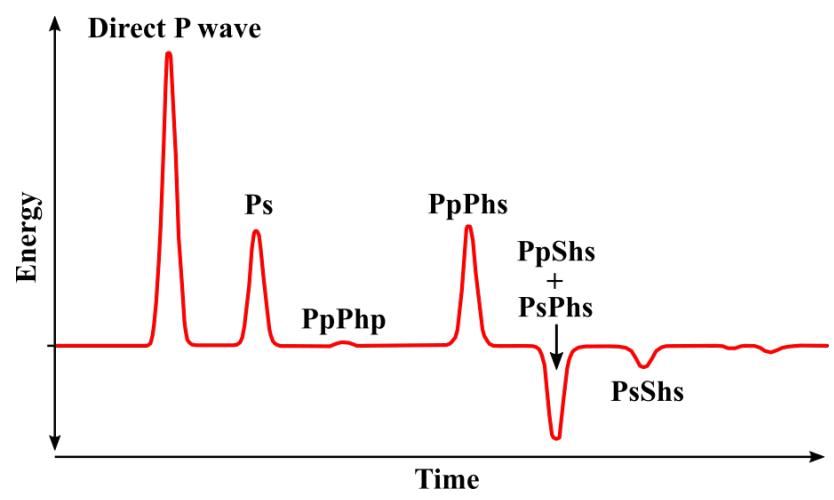

Figure 6: Sketch of a $\mathrm{P}$ receiver function (SV waves not completely isolated), with the spikes corresponding to converted phases at a discontinuity $h$. Adapted from Ammon et al. (1990).

where $i$ is any given component, $I(t)$ is the impulse response of the instrument, $S(t)$ is the source time function (the release of seismic moment as a function of time) of the earthquake, and $E(t)$ is the impulse response of the structure or, equivalently, the Green's functions of the medium. Moreover, there is an additional contribution caused by random noise. If the three components of a seismometer are available, then we have redundant information about the source, instrument, and path effects, which allows us to isolate $E(t)$, i.e. the receiver function, by deconvolving one component from another. This is the basis from which the deconvolution method used in this work departs (Ligorría and Ammon, 1999), as is further explained in subsection 2.3.

\subsection{Receiver functions in the Bransfield Strait}

Pevious RF analysis in the Bransfield Strait include the works of Vuan (2001) and Biryol et al. (2018). Both papers are briefly summarized below:

- Vuan (2001) used P-RFs from 70 teleseismic earthquakes recorded at two stations (PMSA and ESPZ) to deduce the lithospheric structure and to model seismic velocities beneath the AP. It was found that the Moho is somewhat deeper below PMSA $(40 \mathrm{~km})$ than ESPZ $(37 \mathrm{~km})$. However, the stations are far from each other and the author states that results are preliminary and that a larger earthquake database is needed due to the high noise levels. Moreover, the study does not include the northwestern side of the Bransfield Strait, so no information was obtained on the structure beneath the SSB.

- Biryol et al. (2018) carried out a more comprehensive P-RF analysis, including 10 seismic broadband stations (data at IRIS) and using 332 events. In Figure 7 are shown the RF for DECP and JUBA station (including in this study), with Ps arrivals clearly identifiable in the latter. Nevertheless, some stations show much less coherent waveforms where no converted phase can be unequivocally identified by visual examination, as in the case of DECP. The large amount of noise, alongside the different data availability between stations, may be responsible of the lack of coherent pulses. For instance, DECP data available at the IRIS catalogue comprises only from 1998 to 2000, while JUBA covers from 2002 to present. Moreover, the authors do not specify which signal to noise ratio $(S / N)$ threshold was used to discard noisy data. 

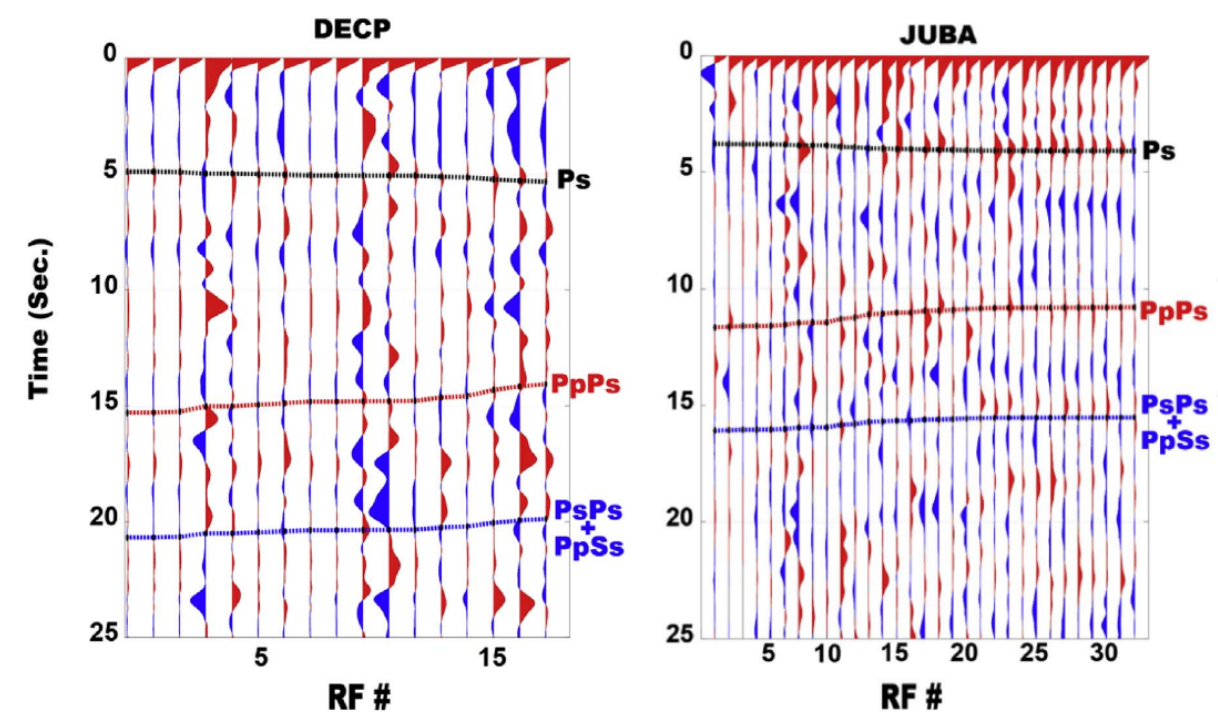

Figure 7: Receiver functions obtained for DECP and JUBA stations, on the SSB. The dashed lines indicate the theoretical arrival times of converted phases (Biryol et al., 2018).

Biryol et al. (2018) obtained estimates of the crustal thickness and the $V_{P} / V_{S}$ ratio, although some results may be unreliable in some stations due to the poorly identifiable phases in the RFs. Results indicate the SSB has a variable crustal thickness from 25 to $40 \mathrm{~km}$, while in the AP its values are much more consistent, being around $30 \mathrm{~km}$. The authors argue that the obtained $V_{P} / V_{S}$ ratios (around 1.82 to 1.96 ) agree well with an incipient seafloor spreading context and the presence of partial melts at depth. Crustal thickness and $V_{P} / V_{S}$ estimates were later used to migrate RF stacks from time to depth. Once again, results in Biryol et al. (2018) show much more variable crustal thickness in the SSB (Fig. 8) than in the AP. According to the authors, the crustal thickness variations in the SSB indicate the stalled slab and the rollback mechanism are controlling to an important extent the evolution of the rift basin: the thinnest crust is located in the central Bransfield Basin, below FREI and JUBA stations, where rollback is though to be more prominent (Biryol et al., 2018). Nonetheless, the Moho and slab depths should be interpreted cautiously due to the already mentioned lack of coherency in some stations, although the authors state that the slab is seen as clear arrivals between 70 and $80 \mathrm{~km}$. According to Biryol et al. (2018), these depths agree well with the imaged stalled slab in Park et al. (2012).

Hence, even though there are previous RF studies in the Bransfield Strait which can provide hints about its deep structure, results to date are still scarce and face many uncertainties. In this work we will use a more extensive seismic dataset and will perform two rotations to obtain L (longitudinal), Q (SV direction), and T (transverse) components, in contrast to Vuan (2001) and Biryol et al. (2018), which only applied a single rotation to Z, R (radial), and T. This way, we will test whether the structure in the Bransfield Strait can be more clearly resolved. 


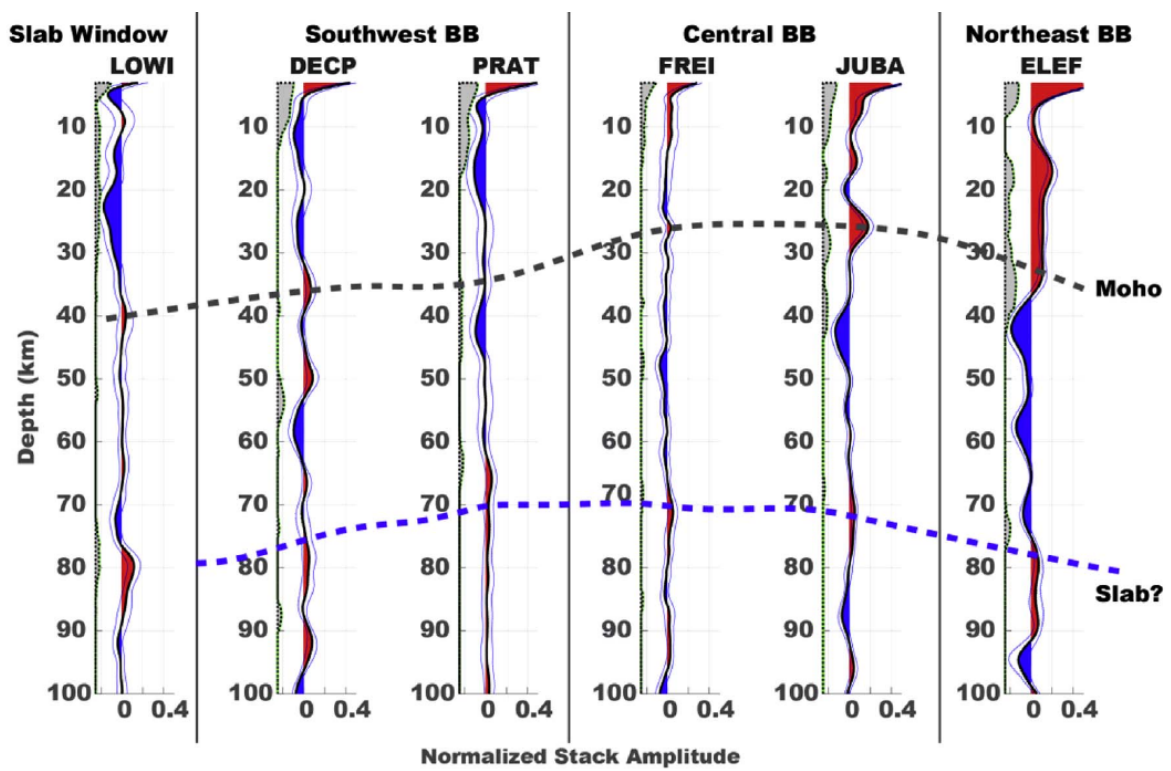

Figure 8: Depth migrated RF stacks for stations belonging to the SSB. BB stands for Bransfield Basin (Biryol et al., 2018).

\section{Materials and methods}

\subsection{Seismic dataset}

The data was recorded by twelve seismometers during different time lapses depending on the station. Eight of them are located in the SSI, while the remaining four are in the AP (Fig. 2. Nine instruments belong to international networks and their data are accessible through the IRIS online catalogue, with the other three seismometers belonging to the IAG. All instruments are high-gain broadband seismometers, with varying sample rate (from 20 to $40 \mathrm{~Hz}$ ) depending on the station and time. In Table 1 the station code, location, recorded time window, and geographical coordinates of each station have been summarized.

We use events with magnitude equal or larger than 5.5, located in the distance range between 30 and $90^{\circ}$ from each station, and with the three components available. Figure 9 shows the location of the stations on the map alongside rose diagrams indicating the backazimuth of the selected earthquakes after data preparation and preprocessing. The diagrams clearly exhibit one of the main limitations of the dataset, which is that backazimuth distributions are extremely heterogeneous, meaning recorded waveforms come from very limited directions. This is only dependent on the distribution of seismically active areas within the defined $30^{\circ}-90^{\circ}$ distance range. In our case, the dominant backazimuth has a NNW orientation, corresponding to earthquakes occurring in the Pacific margin of South America. A secondary dominant backazimuth has a SW orientation, and represents earthquakes originated in the Tonga-Kermadec subduction zone. Events with other backazimuths are practically non-existent. Another main issue concerning seismic data is its varying time availability depending on the station: some stations such as JUBA have been active for many years, while others like SPPT provide a very limited amount of teleseismic records. This, along with the noise levels, will determine how many RFs we can obtain and how well do they sample the structure beneath the stations. 
Table 1: Available time lapse and location of the stations used in this work.

\begin{tabular}{|c|c|c|c|}
\hline Station code & Station name and available time window & Latitude & Longitude \\
\hline \multicolumn{4}{|c|}{ IRIS dataset } \\
\hline DECP & $\begin{array}{c}\text { Deception Island, South Shetland Islands } \\
\text { 1997-01-30 to 1999-12-31 }\end{array}$ & $-62.9771^{\circ}$ & $-60.6699^{\circ}$ \\
\hline ELEF & $\begin{array}{l}\text { Elephant Island, South Shetland Islands } \\
\text { 1997-01-20 to 1999-12-31 }\end{array}$ & $-61.2198^{\circ}$ & $-55.1390^{\circ}$ \\
\hline ESPZ & $\begin{array}{l}\text { Esperanza Permanent Argentinean Antarctic Base } \\
\qquad 2005-01-26 \text { to present }\end{array}$ & $-63.3981^{\circ}$ & $-56.9964^{\circ}$ \\
\hline FREI & $\begin{array}{c}\text { Base Frei, South Shetland Islands } \\
1997-01-23 \text { to 2001-12-31 }\end{array}$ & $-62.1947^{\circ}$ & $-58.9841^{\circ}$ \\
\hline JUBA & $\begin{array}{l}\text { Carlini Permanent Argentinean Antarctic Base } \\
\text { 2002-03-05 to present }\end{array}$ & $-62.2373^{\circ}$ & $-58.6627^{\circ}$ \\
\hline LOWI & $\begin{array}{l}\text { Low Island, South Shetland Islands } \\
\text { 1997-12-27 to 1999-12-31 }\end{array}$ & $-63.2470^{\circ}$ & $-62.1808^{\circ}$ \\
\hline OHIG & $\begin{array}{c}\text { Base O’Higgins, Antarctica } \\
\text { 1997-01-28 to 2001-12-31 }\end{array}$ & $-63.3212^{\circ}$ & $-57.8982^{\circ}$ \\
\hline PRAT & $\begin{array}{l}\text { Base Prat, South Shetland Islands } \\
\text { 1997-01-16 to 1999-12-31 }\end{array}$ & $-62.4798^{\circ}$ & $-59.6641^{\circ}$ \\
\hline SPPT & $\begin{array}{c}\text { Sprint Point, Antarctica } \\
1998-12-08 \text { to } 1999-12-31\end{array}$ & $-64.2955^{\circ}$ & $-61.0514^{\circ}$ \\
\hline \multicolumn{4}{|c|}{ IAG dataset } \\
\hline $\mathrm{CCV}$ & $\begin{array}{l}\text { Cierva Cove, Antarctica } \\
\text { 2008-03-01 to 2015-12-31 }\end{array}$ & $-64.1500^{\circ}$ & $-60.9500^{\circ}$ \\
\hline DCP & $\begin{array}{l}\text { Deception Island, South Shetland Islands } \\
\text { 2008-03-01 to 2015-12-31 }\end{array}$ & $-62.9833^{\circ}$ & $-60.6833^{\circ}$ \\
\hline LVN & $\begin{array}{l}\text { Livingston Island, South Shetland Islands } \\
\text { 2008-03-01 to 2012-12-31 }\end{array}$ & $-62.6500^{\circ}$ & $-60.3833^{\circ}$ \\
\hline
\end{tabular}

\subsection{Data preparation}

Data preparation has been carried out with Seismic Analysis Code (SAC) commands and FORTRAN77 or C code controlled and automatized through bash scripts under a Unix (Linux) system. The workflow is detailed below:

1. Data and event information download. IRIS data is downloaded in SAC format using PyWEED, which is an application based on Python used to retrieve data from the IRIS database. Once both the IRIS and IAG datasets are ready, information of the events is retrieved from the NEIC catalogue, including origin time, latitude, longitude, depth, and magnitude.

2. Evaluation of azimuth, backazimuth, epicentral distance, $P$ and $S$ travel times, take off angles, attenuation, and geometrical spreading with the EDABAC program, by R. B. Herrmann. This FORTRAN77 program requires input data from 


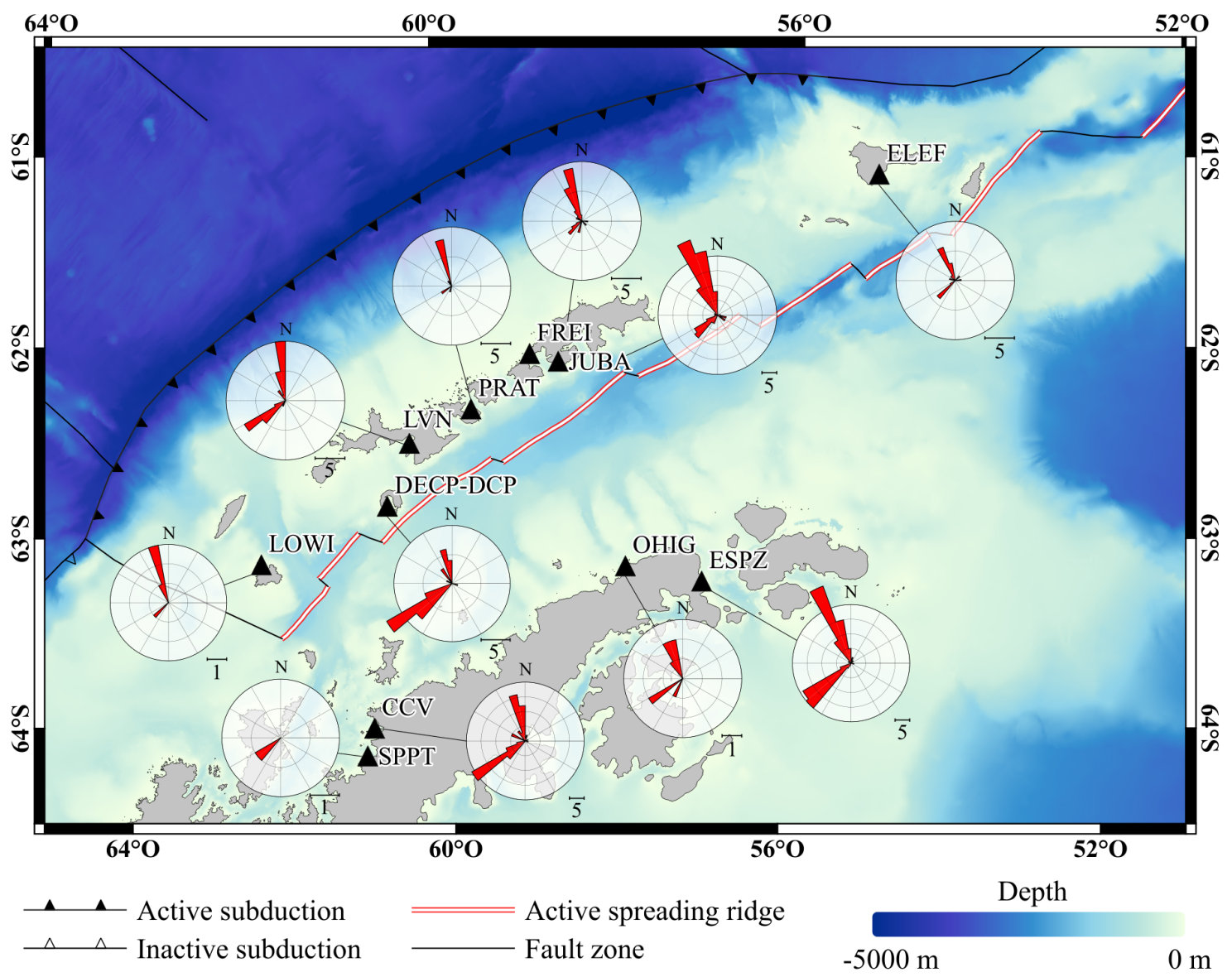

Figure 9: Location of the stations alongside rose diagrams showing the backazimuth of the events from which a RF was obtained.

the downloaded NEIC information, which is provided automatically through a bash script. Such parameters are calculated according to the IASP91 Earth model (Kennett and Engdahl, 1991), and are later stored in the header of the SAC files as they will be necessary during the following processes. The mathematical basis of the code is explained in Herrmann (1987).

3. SAC file headers . To store the EDABAC calculations in the SAC headers a bash script has been modified to solve some unhandy filename patterns, as the files downloaded from PyWEED are named based on the selected initial time while in NEIC they are named according to the origin time. In this case the initial time corresponds to the $\mathrm{P}$ wave arrival time minus $60 \mathrm{~s}$. Every file has to be matched with the associated NEIC event so the script knows which EDABAC information to append: the script uses the $\mathrm{P}$ arrival times computed by EDABAC to search for SAC files containing the same time minus $60 \mathrm{~s}$ with $\mathrm{a} \pm 3 \mathrm{~s}$ error margin. Once there is a match in $\mathrm{P}$ wave arrival times the script tests whether the three components are available, otherwise discarding the files. Then the script modifies the headers and the files are renamed according to the station name, year, and number of event for the sake of simplicity.

4. Signal processing. This is done via SAC commands and bash scripting. First, the maximum peak to peak amplitude and $S / R$ ratio are obtained. Data is cut by setting a time window from $20 \mathrm{~s}$ before to $120 \mathrm{~s}$ after the $\mathrm{P}$ wave arrival time. Next, the 
signal is detrended by obtaining a straight line by least-squares fit and later subtracting the trend and intercept from the data. A taper is also applied: tapering consists in applying a symmetric window function with values between 0 and 1 within our selected time interval. The window function is zero-valued outside the interval and for its first and last data points, while it increases smoothly and symmetrically towards the middle point of the interval. The taper is intended to reduce the effect of the data edges in the following processes. Next, the signal is filtered using a high-pass Butterwoth filter with corner frequency $0.05 \mathrm{~Hz}$ and two passes so the phase remains unchanged. Later, the mean is subtracted from the waveforms and they are decimated to 10 samples per second. Original data has sample rates between $20-40 \mathrm{~Hz}$, but the Gaussian pulses that will be used to compute the RFs (see subsubsection 2.3.2) have a maximum frequency of $\sim 1 \mathrm{~Hz}$. A sampling rate of $10 \mathrm{~Hz}$ is enough for pulses up to the Nyquist frequency $(5 \mathrm{~Hz})$.

5. Removal of data with $S / R<2$. If a station has few data, a bash script is run to manually check the discarded files in order to keep as many as possible. Once this step is done, data is ready for rotation and deconvolution.

\subsection{Receiver function technique}

\subsubsection{Component rotation}

Component rotation is an essential part of receiver function computation because the motion of each wave type ( $\mathrm{P}, \mathrm{SV}$, and $\mathrm{SH})$ has to be isolated into different components as much as possible. However, waves arrive from many directions and with varying incidence angles, while seismic stations are oriented to the north and parallel to the local surface. Thus, in most cases each component records energy coming from different wave types. To isolate $\mathrm{P}, \mathrm{SV}$, and $\mathrm{SH}$ motion two rotations are applied using SAC commands:

In the first place, $\mathrm{Z}, \mathrm{N}$, and $\mathrm{E}$ components are rotated to $\mathrm{Z}, \mathrm{R}$, and $\mathrm{T}$ using the event's backazimuth $(\beta)$ :

$$
\left[\begin{array}{l}
Z \\
R \\
T
\end{array}\right]=\left[\begin{array}{ccc}
1 & 0 & 0 \\
0 & -\cos \beta & -\sin \beta \\
0 & \sin \beta & -\cos \beta
\end{array}\right]\left[\begin{array}{l}
Z \\
N \\
E
\end{array}\right]
$$

This rotation confines the $\mathrm{SH}$ motion to the $\mathrm{T}$ component, while $\mathrm{P}$ is predominantly recorded in $\mathrm{Z}$ and $\mathrm{SV}$ in $\mathrm{R}$, although not entirely.

A second rotation is performed to obtain a seismic ray oriented coordinate system. Z, $\mathrm{R}$, and $\mathrm{T}$ components are rotated to $\mathrm{L}, \mathrm{Q}$, and $\mathrm{T}$, according to the incidence angle $(i)$ of the seismic ray:

$$
\left[\begin{array}{l}
L \\
Q \\
T
\end{array}\right]=\left[\begin{array}{ccc}
\cos i & \sin i & 0 \\
-\sin i & \cos i & 0 \\
0 & 0 & 1
\end{array}\right]\left[\begin{array}{l}
Z \\
R \\
T
\end{array}\right]
$$

In the ideal case, all $\mathrm{P}$ and $\mathrm{SV}$ motion should be respectively contained in the $\mathrm{L}$ and Q components, while SH motion should be left in the T component. However, if the 
structure beneath the seismic station is not horizontal and isotropic the different wave types will not be completely isolated.

\subsubsection{Iterative time-domain deconvolution method}

The deconvolution is the base of the RF methodology. RF are obtained by deconvolving the vertical component from the horizontal components in the time window corresponding to the teleseismic P-wave arrival and its coda (Langston, 1979). The deconvolution process removes the common signature of the source, the instrument response, and propagation effects before the phase conversion, keeping only the information of the local structure below the seismic station in the resulting receiver function. In this study we use the iterative time-domain deconvolution method described in Ligorría and Ammon (1999). The main advantage of this method is that, in contrast to other deconvolution techniques, it does not need the setting of parameters such as smoothing and damping, although there is an increase in computational cost. Additionally, it outputs stable results in the presence of noise. The method is based on the assumption that signal recorded in the direction of $\mathrm{SV}$ motion, i.e. $Q(t)$, is entirely constituted of $\mathrm{P}$ to $\mathrm{S}$ conversions. Therefore, $Q(t)$ results from the following convolution:

$$
Q(t)=L(t) * R F(t)
$$

where $L(t)$ is the waveform in the direction of $\mathrm{P}$ wave propagation and $R F(t)$ is the receiver function. Then, a predicted $Q(t)$ waveform can be obtained by convolving $L(t)$ with an estimated $R F(t)$, which can be iteratively updated from the largest pulse to the smallest until the misfit between the observed and predicted $Q(t)$ is minimized. This way, the final $R F(t)$ will be the succession of pulses that, convolved with $L(t)$, gives the best $Q(t)$ estimate. The same principle is used to deconvolve $T(t)$ because if the medium is not isotropic and laterally homogeneous there might be energy belonging to $\mathrm{P}$ to $\mathrm{S}$ conversions left in the transverse component. This method can only be applied if the three components are available, otherwise the source and path effects would have to be considered (recall Equation 1).

The first step in the deconvolution process is to compute the cross-correlation of $L(t)$ with $Q(t)$ to estimate the time lag of the spike that will be introduced in $R F(t)$. Crosscorrelation is calculated using the Fast Fourier Transform (FFT) of both $L(t)$ and $Q(t)$. Previously data has been zero-padded so the number of samples is a power of two, thus making the FFT algorithm more computationally efficient. The Discrete Fourier Transform (DFT) of $L(t)$ is

$$
L(f)=\sum_{n=1}^{N-1} L(t)_{n} \cdot e^{-\frac{i 2 \pi}{N} f n}
$$

where $f$ is the frequency, $N$ is the number of samples in the seismogram, and $n$ is each one of the data points. Next, cross-correlation in the frequency domain is calculated by

$$
(L \star Q)_{f}=L(f) \cdot Q(f)^{*}
$$

where $Q(f)^{*}$ is the complex conjugate of the DFT of $Q(t)$. Then, the inverse DFT of 
$(L \star Q)_{f}$ is computed, obtaining cross-correlation in the time domain:

$$
(L \star Q)_{n}=\frac{1}{N} \sum_{f=1}^{N-1}(L \star Q)_{f} \cdot e^{\frac{i 2 \pi f n}{N}}
$$

If $\partial t$ is the time difference between samples, time lag $\tau$ at point $n$ is $\tau=n \cdot \partial t$. The time lag which maximizes $(L \star Q)_{n}$ is then used to set the location of the receiver function spike, obtained as a Gaussian pulse:

$$
G(t)=e^{\frac{-t^{2}}{4 a^{2}}}
$$

where $a$ is the Gaussian width factor. The amplitude of the pulse is calculated by solving the following equation (Kikuchi and Kanamori, 1982):

$$
A=(L \star Q)\left[n_{\tau}\right] /(L \star L)[0]
$$

where $n_{\tau}$ is the data point of maximum cross-correlation and $(L \star L)[0]$ is the zero-time autocorrelation of $L(t)$. Then, the receiver function estimate at iteration $m$ is

$$
R F(t)=\sum_{i=1}^{m} A_{i} \cdot G\left(t-\tau_{i}\right)
$$

with $A_{i}$ and $\tau_{i}$ being the amplitude and time lag at iteration $i$. Next, FFT is used again to perform convolution, as multiplication in the frequency domain results in convolution in the time domain. If $R F(f)$ is the DFT of the receiver function, then

$$
(L * R F)_{f}=L(f) \cdot R F(f)
$$

and convolution in the time domain is

$$
Q_{p}(t)=(L * R F)_{n}=\frac{1}{N} \sum_{f=1}^{N-1}(L * R F)_{f} \cdot e^{\frac{i 2 \pi f n}{N}}
$$

The misfit between observation $Q(t)$ and prediction $Q_{p}(t)$ is obtained with the leastsquares method:

$$
\Delta_{Q}=\sum_{n=1}^{N}\left[Q(t)_{n}-Q_{p}(t)_{n}\right]^{2}
$$

Finally, the prediction is subtracted from $Q(t)$ :

$$
Q_{i}(t)=Q(t)-Q_{p}(t)
$$

where $Q_{i}(t)$ is the waveform that will be used in the next iteration. The iteration continues until a $\Delta_{Q}$ threshold or the maximum number of iterations is reached.

The original FORTRAN77 code by C. Ammon (version 1.04) has been used, set to 200 iterations and using two different Gaussian width factors: 2.5 and 0.5 . The best resolution is provided by $a=2.5$, which is roughly equivalent to a $1 \mathrm{~Hz}$ pulse. RFs with $a=2.5$ are used to study the lithosphere, but as high frequencies suffer more attenuation the 400 and $660 \mathrm{~km}$ discontinuities are difficult to detect. Instead, $a=0.5$ is used to study the MTZ. 


\subsection{Stacking}

\subsubsection{Time-domain stacking and moveout correction}

Single RFs may contain significant amounts of white noise which hinder their interpretation. RF stacking is a way to work around this issue due to the random nature of noise, as the summation of many RF for a given station ideally cancels noise and amplifies the signal. However, the wave arrival times in the RF will be dependent on the event's epicentral distance (i.e. incident angle) and, therefore, phases in different RF cannot be coherently stacked. Time moveout correction is applied to resolve this issue: it consists in compressing or stretching the RF in function of how arrival times obtained with the event's ray parameter $p$ compare to predicted times for a chosen reference $p$ (ray parameter). This way, the original RF is rewritten according to a new time vector.

In this case, moveout has been performed according to Ps arrival times with a reference $p=0.065 \mathrm{~s} \mathrm{~km}^{-1}$ (or, equivalently, a distance of $66^{\circ}$ ), using a FORTRAN77 program by F. Mancilla which assumes the IASP91 Earth model (Kennett and Engdahl, 1991). To simplify the calculations the Earth model is transformed to a flat half-space model using the following transformations (Muller, 1971):

$$
\begin{gathered}
z^{\prime}=r \cdot \ln \left(\frac{r}{r-z}\right) \\
V^{\prime}=V \cdot \frac{r}{r-z}
\end{gathered}
$$

where $z^{\prime}$ is the transformed depth $z, V^{\prime}$ is any transformed body wave velocity $V$, and $r$ is the Earth's radius in $\mathrm{km}$. Then, thanks to the ray theory and the Snell's law the incidence angle $i$ of the seismic ray can be obtained using the local velocity $V^{\prime}$ and the ray parameter $p$, which is constant for any given event and depends only on the epicentral distance:

$$
p(\text { const. })=\frac{\sin i}{V^{\prime}}
$$

$V^{\prime}$ and $i$ allow the calculation of the wave travel time along a given model layer. This is the basis from which the time difference between the reference and a given Ps arrival is obtained to stretch or compress the RF.

After moveout correction RFs may be grouped by station and stacked. A common approach is to plot all single RFs ordered by backazimuth alongside the summation trace or linear stack. This is a good method to assess the RFs in a general way, but may not be the best way to detect the multiples of the converted phases. In this case it is preferable to stack RFs by the ray parameter, summing the RFs falling into given intervals. As the time difference between the spikes of the converted phases and multiples increases as the ray parameter decreases, plotting the different stacks by ray parameter order may help to distinguish converted phases from mulitples. Another way to perform time-domain stacking is to stack by backazimuth where, like in the stacking by ray parameter, RFs inside a defined backazimuth interval are summed. Then the stacks are plotted by backazimuth order, thus allowing to detect more clearly the effects of anisotropy or dipping seismic interfaces. 


\subsubsection{Common conversion point stacking}

The Common Conversion Point Stacking (CCP) may be considered a 2D RF mapping method, as it is used to stack depth-migrated RFs along a profile line. To do this the profile-depth plane is divided into cells, the amount of which is restricted by the vertical resolution of the RFs. The resolution is limited by the wavelength $\lambda$ of the seismic waves sampling the structure, which depends on their frequency and the velocity of the medium, and only seismic velocity gradients thicker than $\lambda / 2$ can be detected. $S$ waves in the crust and upper mantle are commonly around $\lambda=4 \mathrm{~km}$ for a frequency of $1 \mathrm{~Hz}$, which is the frequency equivalent to $a=2.5$ (Mancilla et al., 2012). This means the maximum resolution of the RFs is about $2 \mathrm{~km}$. The value for a given cell is the stacked amplitude of the RFs at the corresponding position, after being transformed from time-domain to depth. The depth migration relies on the use of an Earth model to backproject the RFs according to their backazimuth and ray parameter. Similarly to the procedure in the moveout correction explained in subsubsection 2.4.1, the one dimensional Earth model has to be transformed to a flat and layered half-space model, which is used to calculate the travel path of the incoming converted waves with the Snell's law. As each RF is backprojected from its corresponding station, the sampled areas beneath the stations will have a conical appearance with decreasing amplitudes and coherence at depth due to the spreading of the RF paths.

To perform CCP, FORTRAN77 code by X. Yuan and the IASP91 Earth model have been used, as in the moveout correction.

\subsection{3 $H-\kappa$ stacking}

$H$ - $\kappa$ stacking is a grid-search stacking method used to estimate crustal thickness $H$ and $V_{P} / V_{S}$ ratio (i.e. $\kappa$ ) below a given station. This methods use the relative arrival times for the Pms (converted phase at the Moho discontinuity), Ppps, Ppss+Psps phases with respect to the direct $\mathrm{P}$ arrival. These relative arrival times can be employed to constrain the thickness and the average $\mathrm{Vp} / \mathrm{Vs}$ ratio of the crust, provided that the average $\mathrm{P}$-wave velocity for the crust is known. We apply a receiver function stacking technique developed by Zhu and Kanamori (2000) ( $H-\kappa$ stacking technique). This technique, $H-\kappa$ stacking, consists in maximizing the amplitude of the RF in the $H$ - $\kappa$ domain, or $R F(H, \kappa)$ :

$$
R F(H, \kappa)=w_{1} \cdot R F\left(t_{P S}\right)+w_{2} \cdot R F\left(t_{P p P S}\right)-w_{3} \cdot R F\left(t_{P p S s}\right)
$$

where $w_{1}, w_{2}$, and $w_{3}$ are three weighting factors summing up to 1 , while $R F\left(t_{P S}\right)$, $R F\left(t_{P p P S}\right)$, and $R F\left(t_{P p S s}\right)$ are the amplitudes of a given RF at the predicted delay times of $\mathrm{Ps}$, PpPs, and PpSs+PsPs after the direct $\mathrm{P}$ arrival, respectively. Times are calculated as follows:

$$
\begin{gathered}
t_{P S}=H \cdot\left(\sqrt{V_{S}^{-2}-p^{2}}-\sqrt{V_{P}^{-2}-p^{2}}\right) \\
t_{P p P s}=H \cdot\left(\sqrt{V_{S}^{-2}-p^{2}}+\sqrt{V_{P}^{-2}-p^{2}}\right) \\
t_{P p S s}=2 H \cdot \sqrt{V_{S}^{-2}-p^{2}}
\end{gathered}
$$


with $p$ being the ray parameter. We use grid-steps of $0.1 \mathrm{~km}$ and 0.01 for $\mathrm{H}$ and $\mathrm{Vp} / \mathrm{Vs}$, respectively. This way, $R F(H, \kappa)$ will achieve its maximum when a given $H$ and $\kappa$ value make the amplitudes of the converted and multiple phases stack coherently using all the available RF. The maximum amplitude achieved after searching the whole parameter space using a pair of $H$ and $\kappa$ values in each step, will indicate the best crustal thickness and average $V_{P} / V_{S}$ ratio estimates for the crust. $H$ dependence on $V_{S}$ is much stronger than on $V_{P}$ (Zhu and Kanamori, 2000), so different $\kappa$ values are generated by varying $V_{S}$ while keeping $V_{P}$ constant. The final stack will be simply the normalized sum of each computed $R F(H, \kappa)$. As many RF are being stacked corresponding to seismic rays coming from many azimuths and with many incidence angles, the final result represents average $H$ and $\kappa$ values below the station (Zhu and Kanamori, 2000).

To test the accuracy of $H$ - $\kappa$ stacking we have used the bootstrap method, after Efron and Tibshirani (1986). This method is basically a Monte Carlo algorithm, using many iterations through random samples to obtain an estimate of the standard error. If we have a number $X$ of $R F(H, \kappa)$, then we have to obtain a bootstrap sample containing $X$ randomly selected $R F(H, \kappa)$, thus ensuring there will be replacement. Then, sampled $R F(H, \kappa)$ are stacked and the $H$ and $\kappa$ estimates are obtained. This is repeated over a given number of iterations, which Efron and Tibshirani (1986) suggest should be between 50 and 200, and that in our case is 100 . The estimated standard error of $H$ after $N$ iterations is:

$$
\sigma_{H}=\sqrt{\frac{\sum_{n=1}^{N}\left(H_{n}-\bar{H}\right)^{2}}{N-1}}
$$

where $H_{n}$ is depth at iteration $n$ and $\bar{H}$ is the average depth. The same operation is repeated to obtain $\sigma_{\kappa}$.

The $H$ - $\kappa$ stacking and bootstrap processes have been automatized using three $\mathrm{C}$ programs, a Python script, and a bash script which have all been written from scratch. The first C program (hkstacking.c) transforms a time-domain RF to $H-\kappa$ domain following the method by Zhu and Kanamori (2000) described above. The second program (hk_sum.c), stacks $R F(H, \kappa)$ and normalizes the resulting stack. Next, a third $\mathrm{C}$ program is used to perform bootstrap (bootstrap.c) and output both standard errors and correlation. This program also contains a linear congruential generator to obtain the pseudo-random numbers used for bootstrap sampling, defined by the recurrence equation

$$
x_{n+1}=\left(A x_{n}+C\right) \% M
$$

where $x_{n}$ is the seed at recursion $n, A$ is the multiplier, $C$ is the increment, $M$ is the modulus, and \% is the modulo operator. We have used the Borland parameters, so $A=22695477, C=1$, and $M=2^{32}$. Then, the pseudo-random number $k$ scaled between $[0, \mathrm{~m}]$ will be $k=m \cdot x_{n+1} / M$.

Results of hk_sum.c and bootstrap.c are passed to a Python script (hk_plot.py) to plot data. This script does not only plot the $H$ - $\kappa$ stack, it also computes the error ellipse from $\sigma_{H}, \sigma_{\kappa}$, and the correlation $\rho_{H \kappa}$. Given the covariance matrix

$$
S(H, \kappa)=\left[\begin{array}{ll}
\sigma_{H}^{2} & \sigma_{H \kappa} \\
\sigma_{H \kappa} & \sigma_{\kappa}^{2}
\end{array}\right]
$$


where the covariance $\sigma_{H \kappa}$ is obtained as $\sigma_{H \kappa}=\rho_{H \kappa} \cdot \sigma_{H} \cdot \sigma_{\kappa}$, we can obtain the semimajor $(a)$ and semi-minor $(b)$ axes of the ellipse from eigenvalues $\lambda_{1}$ and $\lambda_{2}$. This way, $a=2 \sqrt{\lambda_{1}}$ and $b=2 \sqrt{\lambda_{2}}$. Then, we can calculate the counter-clockwise tilt $\theta$ of the ellipse as

$$
\theta=\frac{1}{2} \arctan \left(\frac{2 \sigma_{H \kappa}}{\sigma_{H}^{2}-\sigma_{\kappa}^{2}}\right)
$$

The three $\mathrm{C}$ programs and the Python script are controlled through a bash script (do_hk.sh), which passes the variables such as the RF files, minimum and maximum $H$ and $\kappa, V_{p}$, and weights. All code is available in Appendix A and may be downloaded at https://github.com/Parera-Portell.

The minimum uncertainty of the $H$ and $\kappa$ results is equal to the maximum resolution of the RFs. As explained in subsubsection 2.4.2, this is approximately $2 \mathrm{~km}$ when using RFs with $a=2.5$. A fixed $V_{p}=6.5 \mathrm{~km} \mathrm{~s}^{-1}$ was set, which is a typical crustal average (Christensen and Mooney, 1995). As $H$ is highly dependent on $\kappa$ (Kikuchi and Kanamori, 1982), potential disagreement of the selected $V_{P}$ with the crustal average must be considered: changing $V_{P}$ by $0.1 \mathrm{~km} \mathrm{~s}^{-1}$ resulted in $H$ variations less than $1 \mathrm{~km}$, while a change of $0.3 \mathrm{~km} \mathrm{~s}^{-1}$ produced $H$ variations up to $1.8 \mathrm{~km}$. The presence of a dipping Moho can also affect $H$ and $\kappa$ (see examples in Lombardi et al. (2008); Mancilla et al. (2012)), with increasing dip angle translating to larger error. Lombardi et al. (2008) calculated theoretical $H$ and $\kappa$ errors produced by a dipping Moho using synthetic RFs and numerous dip angles with the aim of providing general error estimations in such situations. Results indicate that for an average continental crust, with $H$ between 20 and $40 \mathrm{~km}$ and moderate dip angles, the depth of the Moho appears about $1 \mathrm{~km}$ shallower than it is, while $\kappa$ increases about 0.02 for a dip angle of $5^{\circ}$. The authors discourage the use of the $H$ - $\kappa$ stacking methodology if the dip of the Moho is greater than $15^{\circ}$ because the converted phase becomes much stronger than the multiples so $H$ and $\kappa$ cannot be accurately constrained. Error may also increase if the crust-mantle boundary is not a sharp discontinuity but a gradient, or if there are intracrustal interfaces between sediments and bedrock (Mancilla et al., 2012). In the first case the method would be unreliable due to the lack of a clear converted phase or its multiples, while in the second case the converted waves generated at the intracrustal interfaces might overlap with the converted phase at the Moho. As for the weighting scheme, Kikuchi and Kanamori (1982) suggest $w_{1}=0.7, w_{2}=0.2$, and $w_{3}=0.1$, although according to Lombardi et al. (2008) this leads to poorly resolved $H$ and $\kappa$ values if there is a strong Ps pulse. Therefore, weights were set to $w_{1}=0.4$, $w_{2}=0.4$, and $w_{3}=0.2$ so the multiples are used to a greater extent in the algorithm.

\subsubsection{Grid stacking}

Time-domain and $H-\kappa$ stacking are useful methods to infer the lithospheric structure from RFs, but difficulties arise when deeper layers are to be studied. Here the piercing points of the seismic rays must be considered: those are the geographic points where a seismic ray crosses (or pierces) at depth a given discontinuity. At depth ranges such as those of the Moho discontinuity, the piercing points fall very close to the station where the events were recorded, so the structure sampled by the rays at those depths is very similar and RFs can be stacked coherently. However, the piercing points of phases converted at deeper discontinuities may be located in zones which are not representative of the structure beneath 
the station, and thus single-station stacking may not be a good approximation instead we use a geographical cell or bin stacking.

Grid stacking is a kind of time-domain stacking and, as such, moveout correction is required. The difference, though, is that RFs are not grouped by stations. Instead, they are grouped according to the location of the piercing points, depending if they fall into a same geographical cell or not. In our case, five cells have been defined (Fig. 10): cell A is located in the Phoenix plate, B covers the western SSI, C includes mainly the Bridgeman and Nelson islands in the eastern SSI, and cells D and E are on the AP. We decided not to define a regular grid due to the heterogeneous density of piercing points, as it would cause many cells to be empty or occupied by piercing points belonging only to depths either of 410 or $660 \mathrm{~km}$. In such cases the stacks would not be helpful to study the MTZ: focusing only on a single converted phase at such depths is not a good approach to detect changes in the depth of the interface, as the delay times may be influenced by velocity anomalies above the discontinuity that are not considered in the reference IASP91 model used in the moveout correction. This would cause the discontinuity to appear deeper or shallower than it really is. Therefore, our cells have been manually placed in areas where piercing points at both the 410 and $660 \mathrm{~km}$ discontinuities are found. Piercing points have been obtained with the TauP toolkit (Crotwell et al., 1999), also assuming the IASP91 Earth model.

It may be the case that, for a given $\mathrm{RF}$, only a single piercing point corresponding to either the $410 \mathrm{~km}(\mathrm{P} 410 \mathrm{~s})$ or $660 \mathrm{~km}$ (P660s) converted phases falls inside a cell. This implies stacking cannot be performed on the entire RF because one of the conversions has occurred in a different region or cell. Therefore, P410s and P660s are stacked separately and only within the time window corresponding their theoretical arrivals \pm 10 s, as ob-

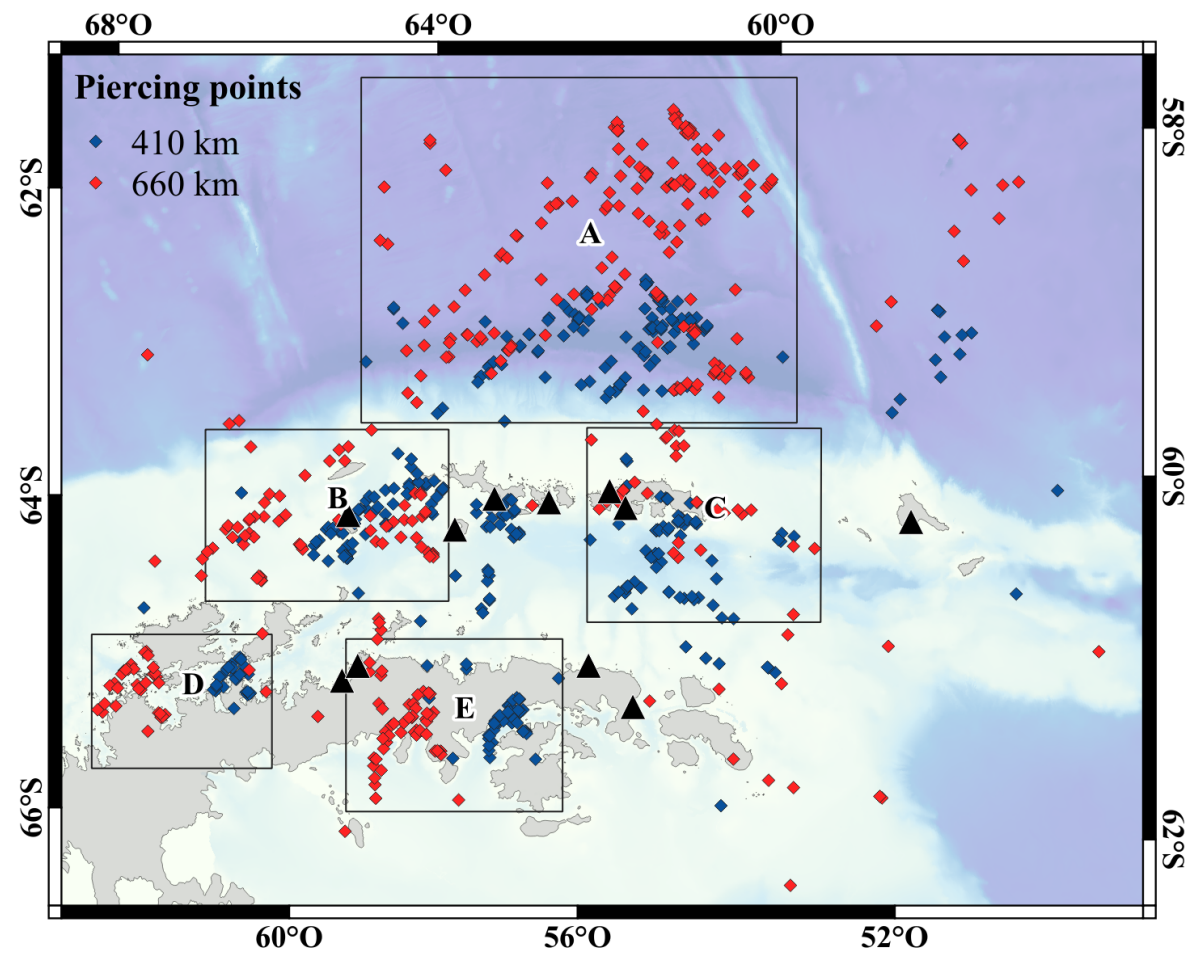

Figure 10: Location of piercing points at 410 and $660 \mathrm{~km}$ and the five stacking cells. 
tained with TauP. This results in two different summation traces per cell, which we use to estimate the state of the MTZ by comparing the delay times of the two converted phases respective to the direct $\mathrm{P}$ arrival. Additionally, only RFs with a Gaussian width of 0.5 have been used for grid stacking, as higher frequencies cannot correctly detect the MTZ due to the larger attenuation. However, resolution and Gaussian width decrease together, so the RFs will provide coarser results.

\section{Results}

\subsection{Lithosphere}

A total of 455 RFs (for a Gaussian parameter $a=2.5$ ) have been obtained. In Table 2 are summarized the number of processed events and RFs obtained by station, with the corresponding $H$ and $\kappa$ estimates and the predicted delay times of the converted phase at the Moho (Pms) and its principal multiples (PpPms and PpSms). Note that DECP and DCP have been treated as a single station, as they are geographically very close to each other. Both the number of events and of RFs varies greatly by station: fewer than $10 \mathrm{RFs}$ have been obtained from LOWI, OHIG, and SPPT, so the results lack the robustness of other stations such as ESPZ and JUBA which provided more than 100 RFs. In the case of SPPT the extremely limited data implies results should be taken cautiously and be always interpreted alongside those in the adjacent station of CCV. The number of RFs is not only conditioned by the time a station has been active, but also by its noise levels. For instance, 109 RFs were obtained in ESPZ from a total of 1553 processed events, while almost the same number of RFs (110) were obtained in JUBA from 1812 events, meaning waveforms in JUBA are noisier and few of them are suitable for deconvolution. Notwithstanding the vast differences in available events for processing, as mentioned in subsection 2.2 we set a threshold of $S / R \geqslant 2$ to ensure minimum quality levels at the expense of leaving some stations with very few RFs.

Table 2: Final number of RFs with a Gaussian width of 2.5 obtained per station, alongside the $H$ and $\kappa$ estimates for $V_{P}=6.5 \mathrm{~km} \mathrm{~s}^{-1}$ and weights $w_{1}=0.4, w_{2}=0.4$, and $w_{3}=0.2$. Delay times are calculated according to the $H-\kappa$ estimates with $p=0.065 \mathrm{~s} \mathrm{~km}^{-1}$.

\begin{tabular}{crrrrrrr}
\hline Station & Events & $\mathrm{RFs}$ & $\mathrm{H}(\mathrm{km})$ & $V_{P} / V_{S}$ & $t_{P S}(\mathrm{~s})$ & $t_{P p P S}(\mathrm{~s})$ & $t_{P p S S}(\mathrm{~s})$ \\
\hline CCV & 875 & 85 & $33.3 \pm 2.4$ & $1.82 \pm 0.07$ & 4.4 & 13.7 & 18.1 \\
DECP/DCP & 1118 & 41 & $15.1 \pm 2.2$ & $2.08 \pm 0.11$ & 2.6 & 6.8 & 9.5 \\
ELEF & 126 & 19 & $31.5 \pm 2.7$ & $1.69 \pm 0.08$ & 3.5 & 12.3 & 15.9 \\
ESPZ & 1553 & 109 & $35.4 \pm 3.5$ & $1.68 \pm 0.09$ & 3.9 & 13.8 & 17.7 \\
FREI & 261 & 30 & $28.3 \pm 2.7$ & $1.76 \pm 0.22$ & 3.5 & 11.4 & 14.9 \\
JUBA & 1812 & 110 & $25.7 \pm 0.7$ & $1.95 \pm 0.02$ & 3.9 & 11.1 & 15.1 \\
LOWI & 79 & 5 & $30.3 \pm 1.3$ & $1.77 \pm 0.04$ & 3.8 & 12.2 & 16.0 \\
LVN & 742 & 34 & $21.9 \pm 0.3$ & $2.19 \pm 0.04$ & 4.2 & 10.3 & 14.5 \\
OHIG & 176 & 8 & $35.0 \pm 1.0$ & $1.76 \pm 0.03$ & 4.3 & 14.1 & 18.4 \\
PRAT & 132 & 12 & $27.6 \pm 2.0$ & $1.95 \pm 0.10$ & 4.2 & 11.9 & 16.2 \\
SPPT & 45 & 2 & $33.1 \pm 3.4$ & $1.80 \pm 0.07$ & 4.3 & 13.5 & 17.8 \\
\hline
\end{tabular}


A first general glimpse at the structure of the Bransfield Strait may be obtained from the examination of the summation traces. Figure 11 reveals that the general pattern of the waveforms in the SSB is quite different from that in the AP. In the SSB all stations display very strong pulses near $t=0 \mathrm{~s}$, which in the case of LOWI, PRAT, and JUBA appear slightly displaced towards larger delay times: those are probably converted phases at very shallow intracrustal discontinuities, although if the medium is not horizontal and isotropic part of the direct $\mathrm{P}$ energy could be present. The largest spike after those arrivals can usually be identified as the converted wave at the Moho (Pms), although with the exception of JUBA and ELEF the pulse displays two peaks, the first being larger in all cases but FREI. Predicted delay times suggest the first peak truly corresponds to the Pms. Its delay times range from a minimum of $2.6 \mathrm{~s}$ in DECP/DCP to a maximum of $4.2 \mathrm{~s}$ in $\mathrm{LVN}$; the delay times of the secondary peak fluctuate from approximately $4.5 \mathrm{~s}$ in PRAT to $5.4 \mathrm{~s}$ in LVN. A large positive spike before Pms in ELEF may indicate the presence of another important intracrustal interface besides the one located near $t=0 \mathrm{~s}$.

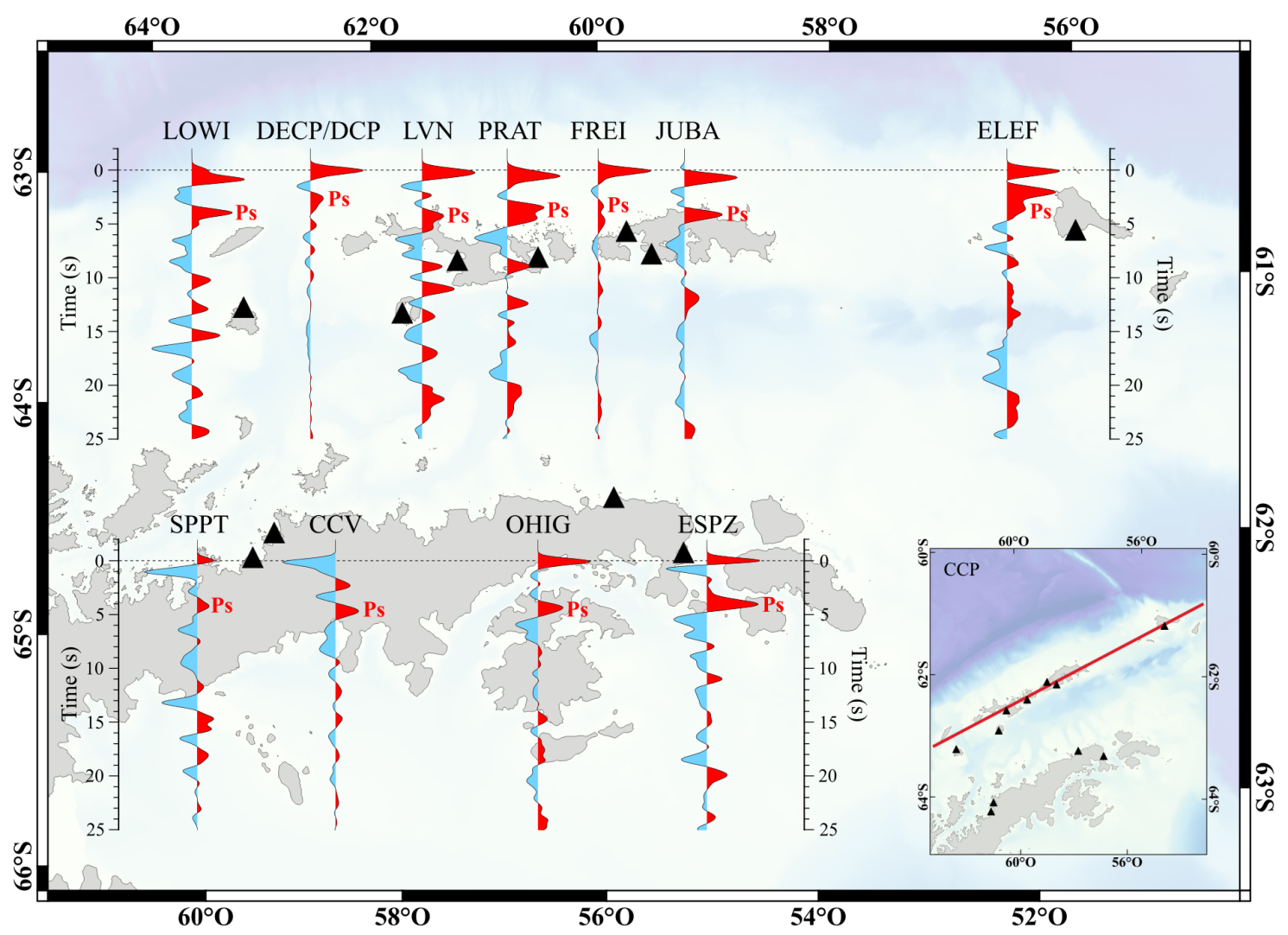

Figure 11: Normalized time-domain stacks (i.e. summation traces of the Q RF components) by station. The map at the lower right indicates the position of our CCP profile.

In the AP, OHIG and ESPZ display strong pulses near time 0, also indicating very shallow intracrustal conversions or the presence of $\mathrm{P}$ wave energy. In CCV the same pulse appears but with negative amplitude, probably meaning the seismometer is not correctly oriented to the north. A second and fainter positive pulse before Pms is also present in ESPZ, OHIG, and CCV, being specially prominent in the latter. In SPPT this pulse is identifiable but does not reach positive amplitudes. Pms is very coherent from station to station, with delay times found between $3.9 \mathrm{~s}$ in ESPZ and $4.4 \mathrm{~s}$ in CCV, being somewhat larger than in most SSB stations and thus hinting a deeper Moho. The delay times in 
SPPT are be very consistent with those in the other stations of the AP, in spite of only consisting of two RFs.

Examples of RFs ( $\mathrm{Q}$ and $\mathrm{T}$ components) sorted by backazimuth, stacks by ray parameter, and stacks by backazimuth are given in Figure 12 and Figure 13, to illustrate RFs in the SSB and the AP, respectively. Those include the stations of DECP/DCP, JUBA, CCV, and ESPZ. The rest of the time-domain stacks can be found in Appendix B. In general, a common characteristic of the RFs in all stations is that the T component contains almost as much energy as the $\mathrm{Q}$ component, indicating that the underlying layered medium is not horizontal or isotropic presenting lateral heterogeneities (e.g. dipping layer or seismic anysotropy).

One of the most striking features in Figure 12 is the difference in amplitude between the RFs in DECP/DCP and JUBA, making the RFs in DECP/DCP appear much noisier as a consequence of the unconsolidated volcanic materials in Deception Island. Pms arrivals in the SSB are clear but are accompanied by the overlapping spike, and multiples can be generally identified easily. In Figure 12, PpPms and PpSms can be both seen along the predicted delay time lines. In general, PpPms is clearly recognizable and agrees closely with predicted times in all stations in the SSB, at least in the stacks by ray parameter. A problematic station in this sense is ELEF, because even though the PpPms pulses may be identified pretty easily in the stacks by ray parameter there are pulses that mask the spike in the summation trace. PpSms is also usually detectable and in most cases agrees with the predicted delay time lines as closely as PpPms. However, it cannot be unequivocally identified in PRAT.

Other coherent pulses can be detected in the RFs, which can belong to other converted phases or even to other multiples that have not been considered, such as PpPmp if the medium is not horizontal or isotropic. For instance, in DECP/DCP, LVN, PRAT, and FREI the pulse overlapping Pms is present in almost every single RF and is clearly identifiable in the stacks by ray parameter. In LOWI this peak is not so clear due to the lack of data. A strong and wide negative pulse around a delay time of 6 to $8 \mathrm{~s}$ is found in all stations of the SSB, which is easily identifiable in JUBA (see Fig. 12) and may be indicative of conversions at a negative velocity gradient. Again all SSB stations feature a positive spike at $8-10 \mathrm{~s}$ just after the negative pulse, which in some cases may display amplitudes larger than PpPms and that might be another converted phase. Other sets of coherent positive and negative pulses may be identified after PpSms, of which the positive one arriving between 20 and $25 \mathrm{~s}$ is specially outstanding. However, it is beyond the scope of this study to identify and interpret most of those features and to discern whether they are converted phases or multiples.

Additionally, all stations in the SSB display clear signs of lateral heterogeneities, as there is significant energy contained within the $\mathrm{T}$ component. The pulses corresponding to the intracrustal discontinuities and the Moho may suffer polarity inversions within certain backazimuth ranges in the $\mathrm{T}$ component showing lateral heterogeneities as dipping layer or anisotropy. Moreover, the multiples in the $\mathrm{Q}$ component may approach or move away from the Pms spike depending on the backazimuth, indicating waves may reach the station faster within some backazimuth ranges. In Figure 12 both effects are visible, being specially clear in JUBA as the Pms and multiples are quite spaced. JUBA shows a 

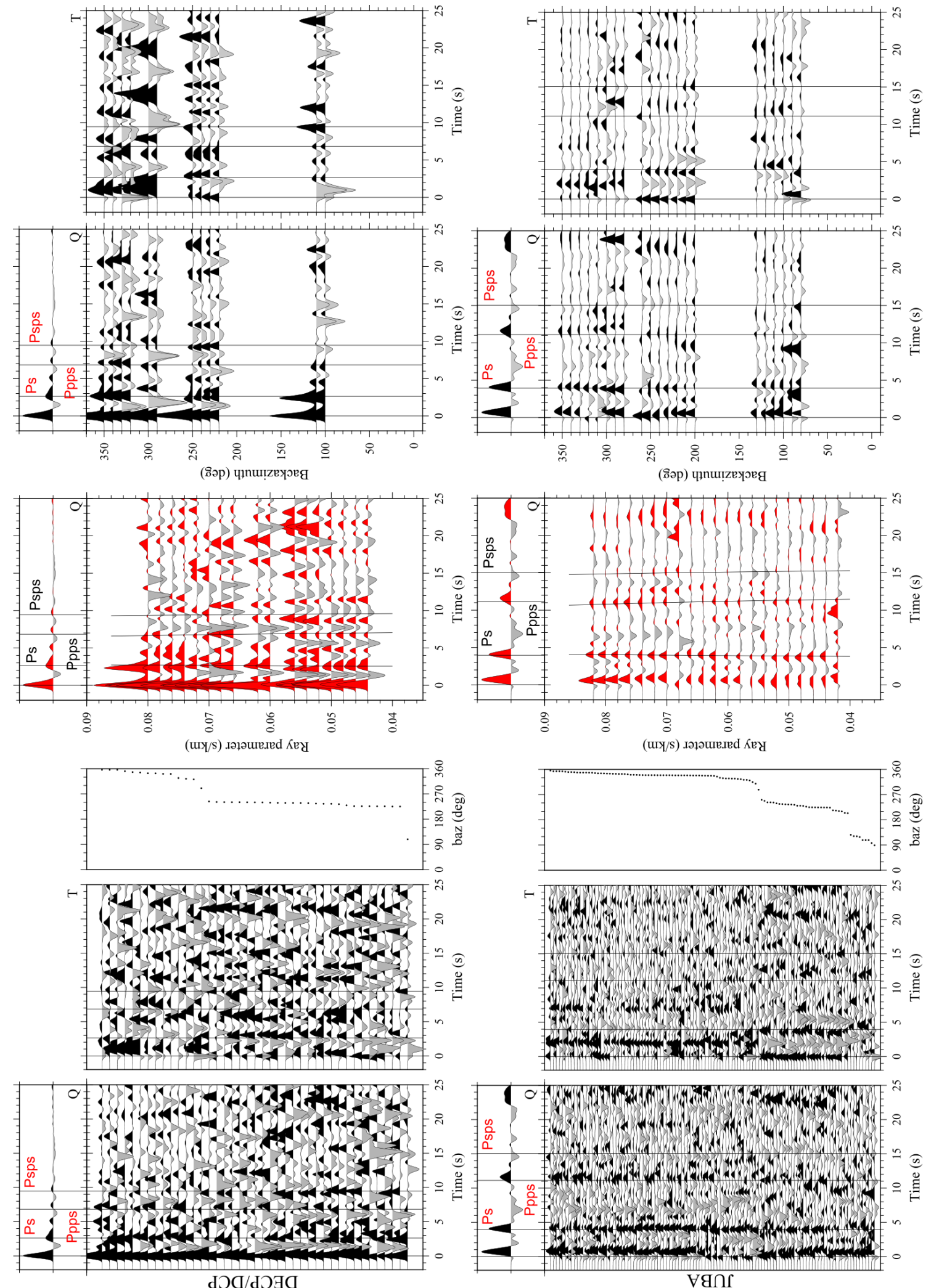

Figure 12: RFs ordered by backazimuth (left), stacks by ray parameter (centre), and stacks by backazimuth (right) of DECP/DCP and JUBA stations (SSB). The delay times of the converted phase and its multiples are indicated by solid black lines. 

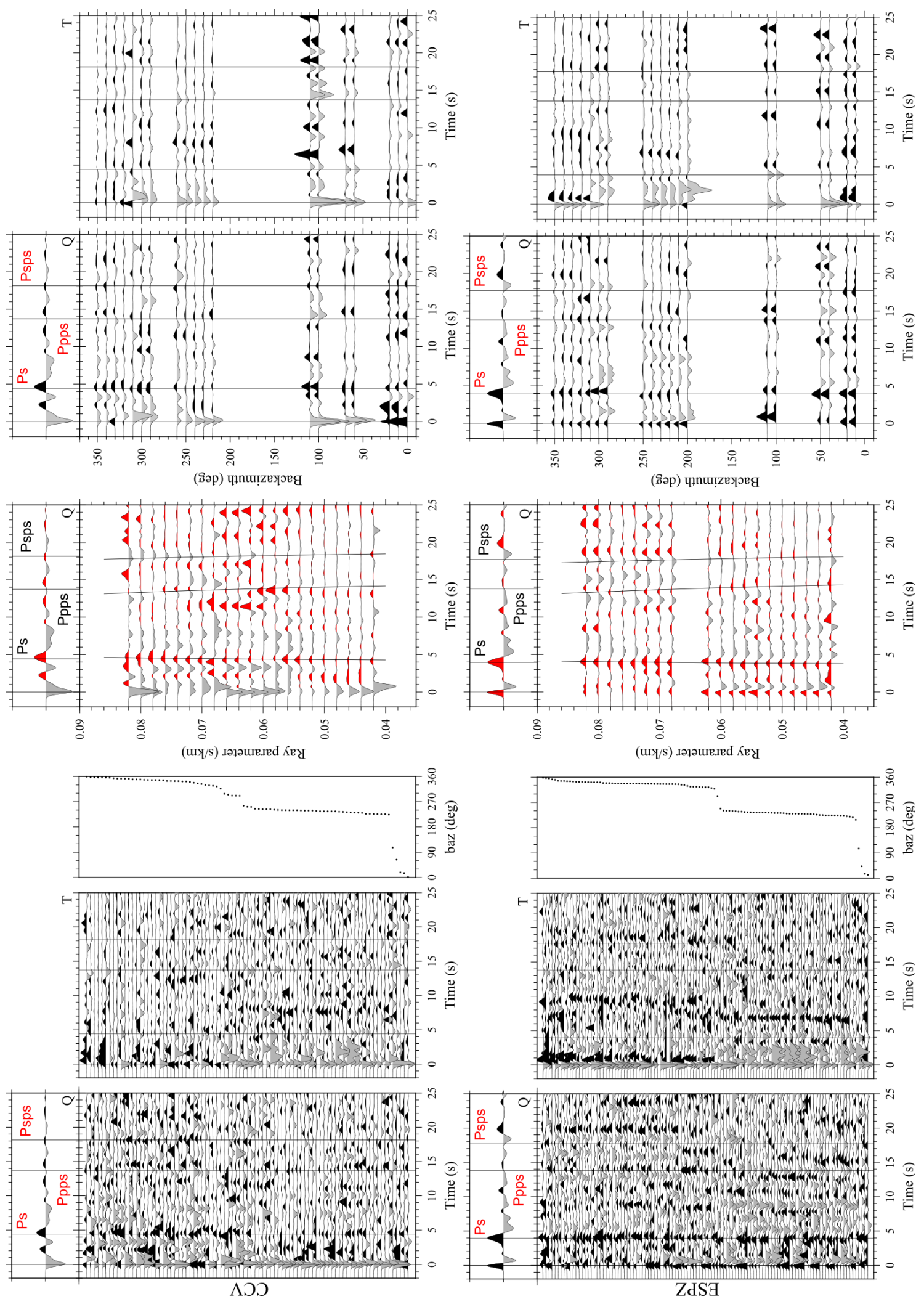

Figure 13: Same than Figure 12, showing CCV and ESPZ stations (AP). 
clear polarity inversion of the crustal conversions at $270^{\circ}$, which extends approximately down to a a backazimuth of $90^{\circ}$. A similar behaviour may be seen in other stations, being also very clear in LVN. Deducing if these polarity inversions are caused by anisotropy, a dipping interface or both requires additional techniques which are not used in the present study, so this analysis is left for further investigations.

In the AP, the RFs of the different stations generally resemble very much. Pms is seen as a single pulse and has the largest positive amplitude in the summation traces with the exception of OHIG. PpPms closely agrees with the predicted delay times in the stacks by ray parameter, although if the RFs are sorted by backazimuth it may appear displaced from the theoretical times due to the movement of the pulses caused by anisotripy or dipping. In SPPT this is caused by the lack of data. The case is almost identical for PpSms.

Intracrustal pulses are present in all stations, and other pulses are present after the Pms phase. In Figure 13 it is shown that those pulses are almost identical in CCV and ESPZ, even though they are more than $200 \mathrm{~km}$ away. As in the case of the SSB there is a wide area with strong negative pulses between approximately $5 \mathrm{~s}$ to $8 \mathrm{~s}$ which may indicate a negative velocity gradient. Between those arrivals and PpPms there are two positive and two negative pulses which are clearly seen and that, as happens with PpPms and PpSms, move towards smaller or greater delay times in function of the backazimuth. This is a clear sign of anisotropy or dipping interfaces and indicates those pulses are probably multiples, although their identification requires additional research. Additionally, both in CCV and ESPZ there are perfectly clear polarity changes in the T component.

The CCP has been done along the profile line shown in Figure 11 only in the SSB due the higher station density. Results are illustrated in Figure 14, featuring two major coherent and continuous areas: the positive amplitudes around depths of $30 \mathrm{kms}$ corresponding to Pms and the negative amplitudes between $50 \mathrm{~km}$ to $70 \mathrm{~km}$ corresponding to the wide negative pulse seen in all RFs around 6-8 s. The CCP indicates the Moho is shallower below DECP/DCP (approximately $20 \mathrm{~km}$ ), while in the rest of the SSB it varies slightly around $30 \mathrm{~km}$. However, as the CCP uses the reference IASP91 Earth model and therefore there are no lateral variations of seismic velocities, we expect the $H-\kappa$ stacking to provide better crustal thickness estimates. The coherence and large amplitudes of the negative pulse may be indicative that it truly represents another converted wave at a gradient-like seismic discontinuity with a negative velocity contrast, maybe hinting the presence of a low velocity zone. Below that region there are no coherent and continuous pulses, probably as a result of the lack of data. Moreover, there are large unsampled areas due to the uneven distribution of the stations, especially between the ELEF station and the rest of the islands.

\subsubsection{Crustal thickness and $V_{P} / V_{S}$}

Results of the $H-\kappa$ stacking are summarized in Table 2. Four examples are given in Figure 15, corresponding to the same stations in Figure 12 and Figure 13. All the $H$ - $\kappa$ stacks are available in Appendix $C$. The stacks usually show a dominant maximum where the best $H-\kappa$ estimates are located alongside secondary maximums which make the standard error increase and further exemplify the complexity of the RFs. Those secondary maxim- 


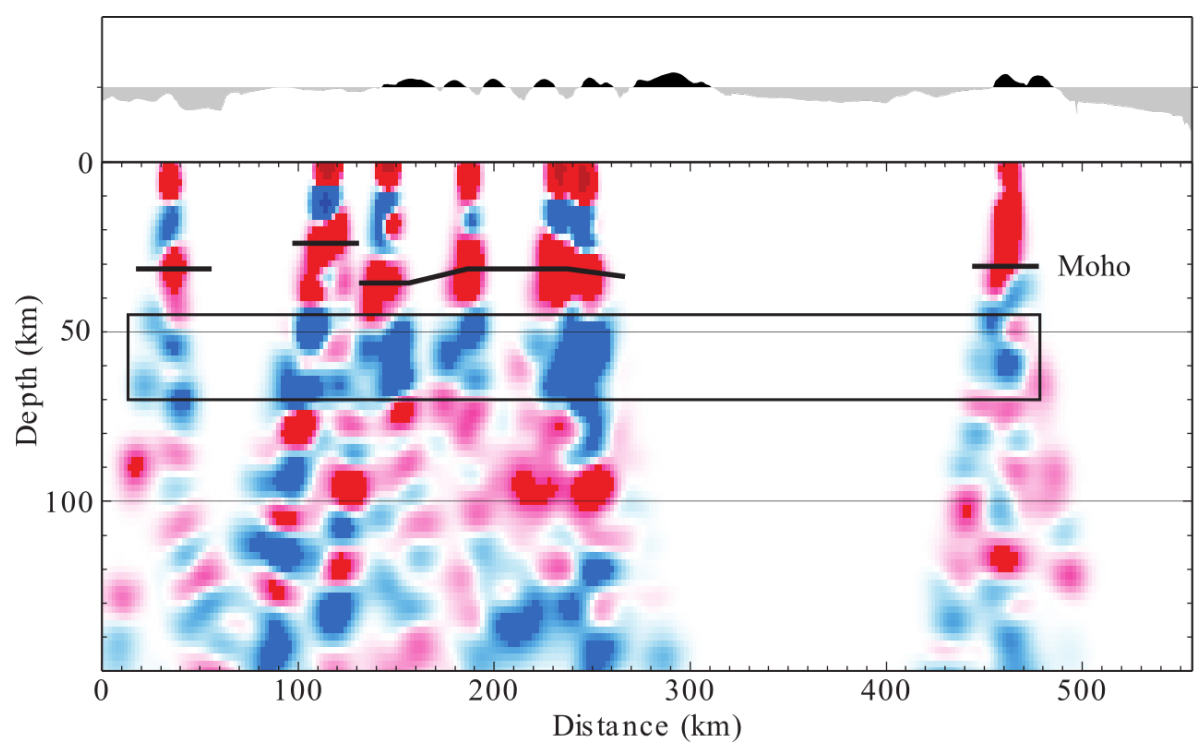

Figure 14: CCP along the profile in Figure 11. Red and blue indicate positive and negative amplitudes, respectively.

ums are caused by the intersection of the Pms line with coherently stacked pulses other than PpPms or PpSms. The ESPZ plot in Figure 15 is a clear example of such cases, displaying a clear and isolated secondary maximum approximately centred at $H=28 \mathrm{~km}$ and $\kappa=1.88$. Stations such as DECP/DCP (also shown in Fig. 15) and LVN display parallel regions containing high amplitude values, one of which is clearly dominant and provides the $H$ - $\kappa$ estimates. In some iterations during the bootstrap calculation those maximums become the primary peak, thus enlarging the error and causing the $1 \sigma$ ellipses to stretch along the direction between the two peaks. However, sometimes the dominant maximum may not represent the best estimates, so a convenient approach is to open the plotted $\mathrm{H}-\kappa$ space as much as possible to detect all peaks. Next, the space can be progressively narrowed down to exclude peaks representing implausible $H$ and $\kappa$ values. In section 4 the cases of PRAT and ELEF will be discussed in detail, as considerable narrowing has been done to obtain $H$ and $\kappa$ estimates in accordance with a priori knowledge (Barker et al., 2003) and to maintain coherence with the adjacent stations and the tectonic context.

Figure 16 confirms there is a clear difference between the crustal structure in the SSB and the AP, and shows there is an inverse correlation between $H$ and $V_{P} / V_{S}$. Crustal thickness in the SSB is more heterogeneous, achieving a minimum of $15.1 \pm 2.2 \mathrm{~km}$ in DECP/DCP and maximums at both edges of the archipelago, with $31.5 \pm 2.7 \mathrm{~km}$ in ELEF and $30.3 \pm 1.3 \mathrm{~km}$ in LOWI. A similar but inverted pattern is observed in $V_{P} / V_{S}$, with values ranging from a minimum of $1.69 \pm 0.08$ in ELEF to a maximum of $2.19 \pm 0.04$ in LVN. In this case high $V_{P} / V_{S}$ and low $H$ appear to be clustered in the area surrounding Deception Island, to the centre of the rift basin. ELEF and LOWI display the deepest Moho and the lowest $V_{P} / V_{S}$ in the SSB. PRAT, JUBA, and FREI are found in an intermediate situation regarding both $H$ and $V_{P} / V_{S}$. The high $V_{P} / V_{S}$ ratio in the central SSB results in a shallower Moho than expected with the CCP.

On the other hand, $H$ and $V_{P} / V_{S}$ in the AP are much more stable. $H$ has been found to be always larger than in the SSB, with a minimum of $33.1 \pm 3.4 \mathrm{~km}$ in SPPT and a maximum of $35.4 \pm 3.5 \mathrm{~km}$ in ESPZ. $V_{P} / V_{S}$ values reach a minimum of $1.68 \pm 0.09$ in 

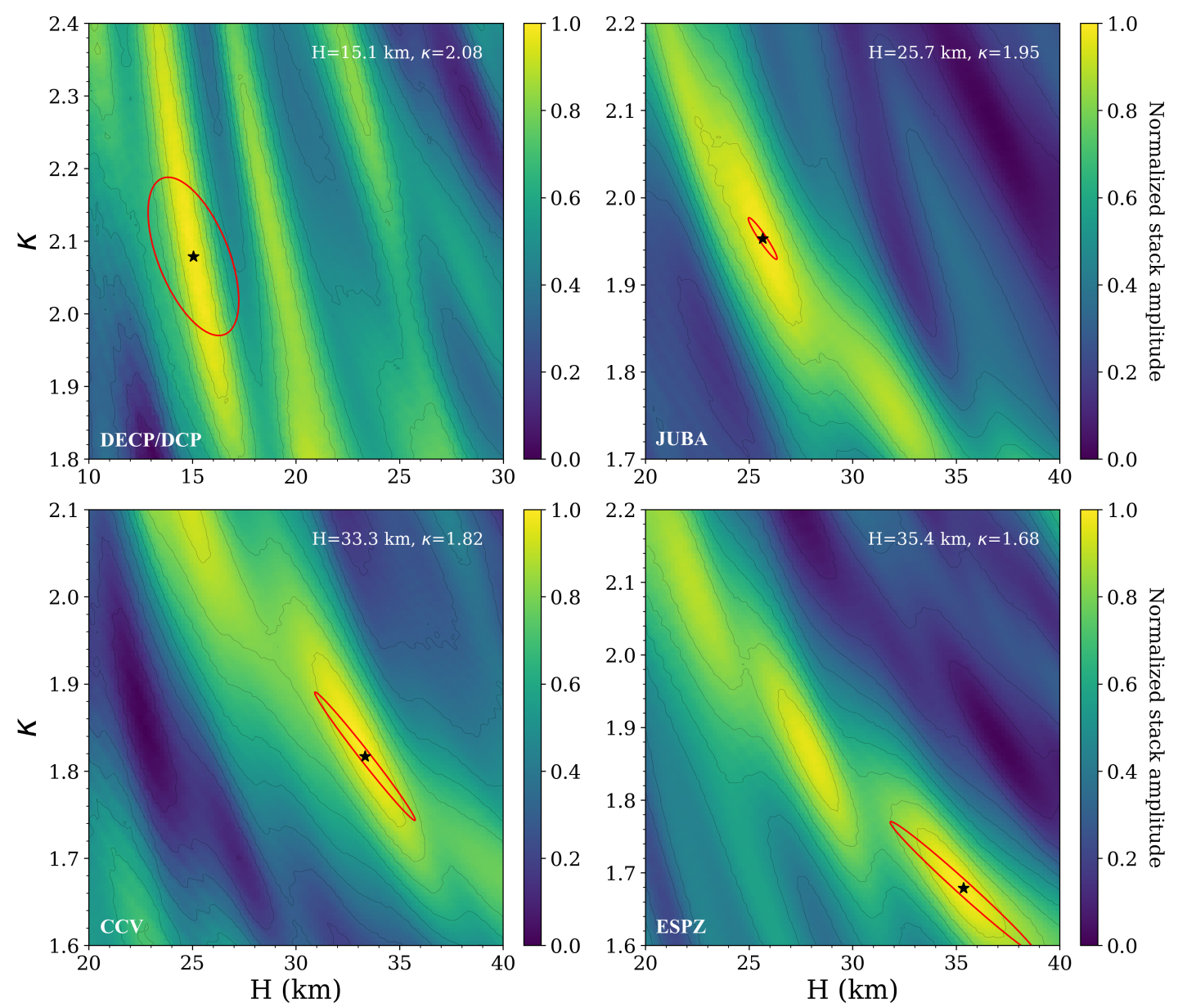

Figure 15: $H-\kappa$ stacks of DECP/DCP and JUBA (top, SSB); CCV and ESPZ (bottom, AP). $1 \sigma$ ellipses are shown in red.

ESPZ and a maximum of $1.82 \pm 0.07$ in CCV. Generally, $H$ and $V_{P} / V_{S}$ values in the AP resemble those in LOWI and ELEF. The described spatial distribution of $H$ and $V_{P} / V_{S}$ in the study area is shown in Figure 17.
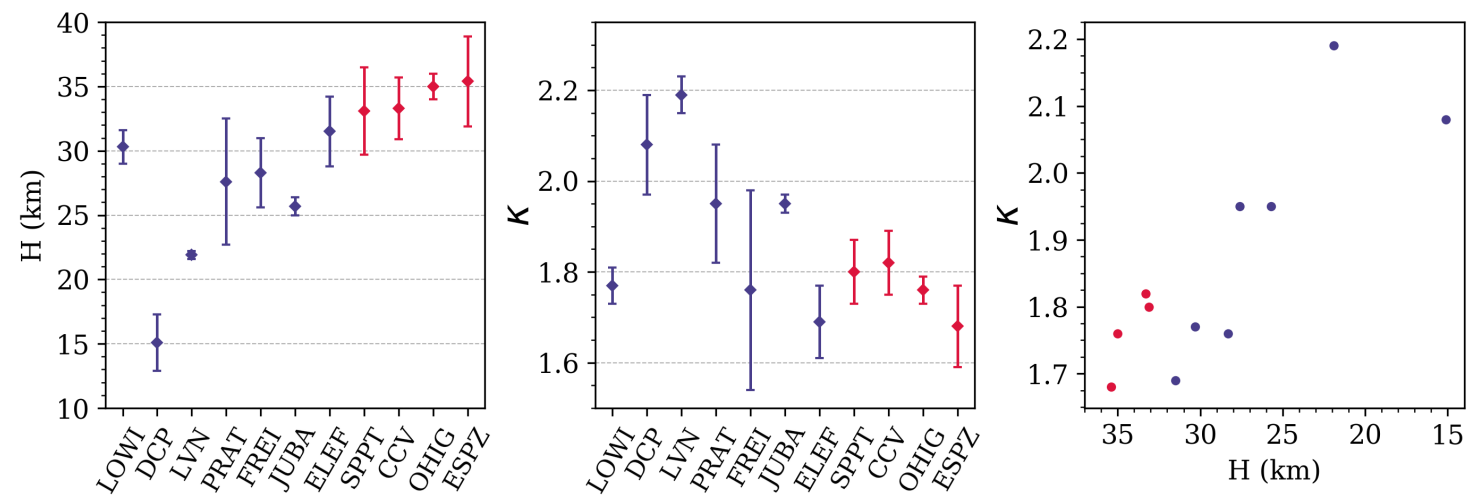

Figure 16: $H$ and $\kappa$ estimates along with the standard error. In dark blue and red are shown stations in the SSB and the AP, respectively. 


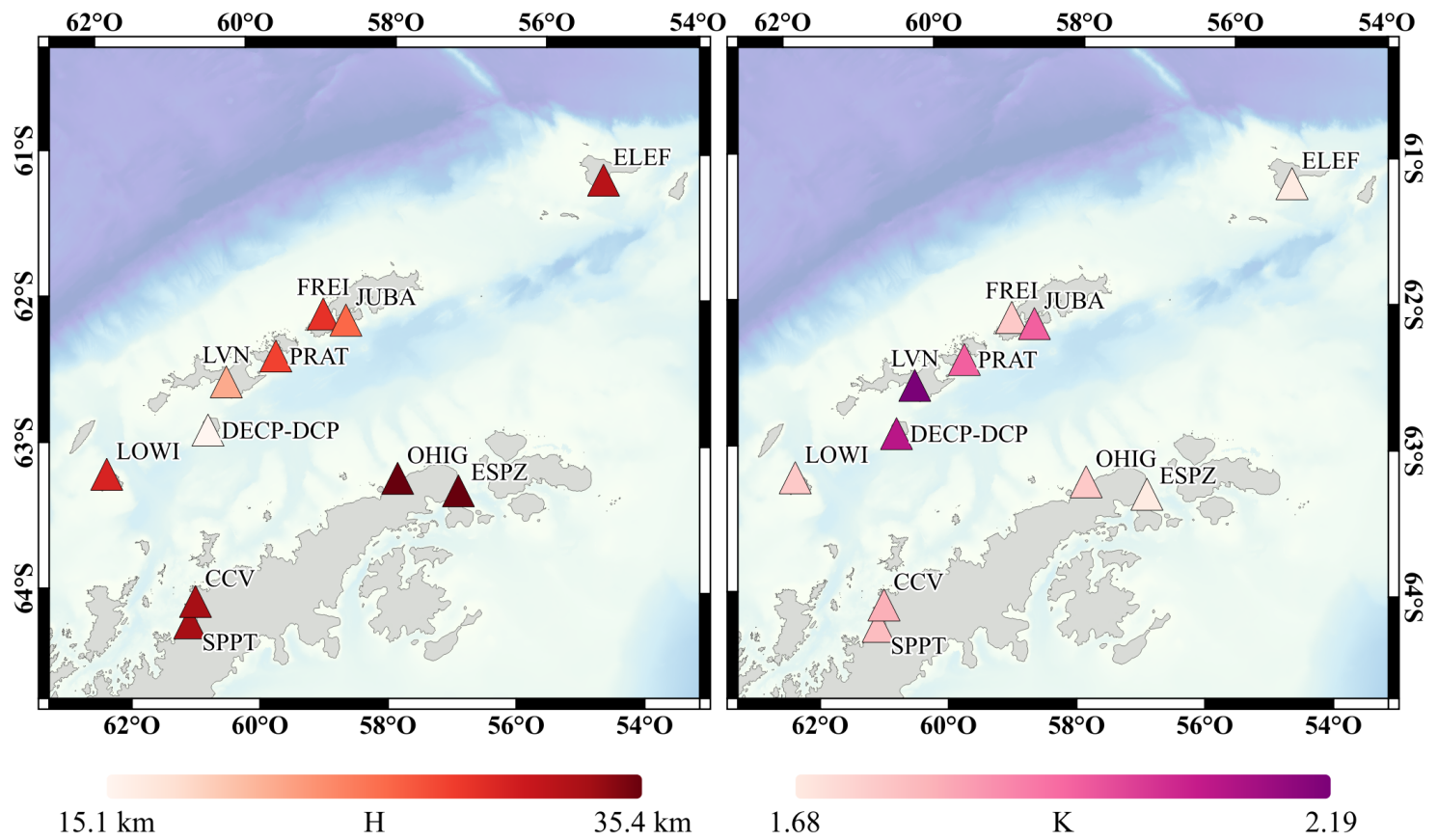

Figure 17: Spatial distribution of $H$ and $\kappa$ estimates in the Bransfield Strait.

\subsection{Mantle Transition Zone (MTZ)}

To study the MTZ the RFs $(a=0.5)$ have been stacked following the methodology described in subsubsection 2.4.4. In Table 3 are listed the number of traces per cell and discontinuity as well as the observed delay times and $\triangle M T Z$. This last value represents the thickness increment (in seconds) of the observed MTZ respective to a standard and not perturbed MTZ with discontinuities exactly at depths of $410 \mathrm{~km}$ and $660 \mathrm{~km}$. Theoretical arrival times of P410s and P660s are calculated with TauP (Crotwell et al., 1999) assuming the IASP91 Earth model. The resulting stacks are shown in Figure 18. All the RFs alongside the stacks are available in Appendix B.

Table 3: Number of RFs per cell and depth alongside grid stacking results. Theoretical P410s and P660s times are $44.1 \mathrm{~s}$ and $68.0 \mathrm{~s}$, respectively.

\begin{tabular}{rcrrrrr}
\hline Cell & Discontinuity & $\mathrm{RFs}$ & $t(\mathrm{~s})$ & $t-t_{\text {IASP91 }}(\mathrm{s})$ & $t_{660}-t_{410}(\mathrm{~s})$ & $\Delta M T Z(\mathrm{~s})$ \\
\hline \multirow{2}{*}{$\mathrm{A}$} & 410 & 127 & 43.0 & -1.1 & 23.5 & -0.4 \\
& 660 & 183 & 66.5 & -1.5 & & \\
$\mathrm{~B}$ & 410 & 67 & 47.5 & +3.4 & 26.7 & +2.8 \\
& 660 & 64 & 74.2 & +6.2 & & \\
$\mathrm{C}$ & 410 & 71 & 48.8 & +4.7 & 25.5 & +1.6 \\
& 660 & 33 & 74.3 & +6.3 & & \\
$\mathrm{D}$ & 410 & 33 & 47.4 & +3.3 & 19.5 & -4.4 \\
& 660 & 36 & 66.9 & -1.1 & & \\
$\mathrm{E}$ & 410 & 49 & 48.6 & +4.5 & & $?$ \\
& 660 & 50 & $?$ & $?$ & & $?$ \\
\hline
\end{tabular}

P410s and P660s arrivals appear to be clearest in the SSB, not only in the stacks in 
Figure 18, but also when examining the overall pattern of the RFs in Appendix B. Cell B shows two clear peaks in the 660 stack, possibly indicating a double interface, but the tectonic setting as well as results in cell $\mathrm{C}$ suggest the peak at $74.2 \mathrm{~s}$ may correspond to P660s. Both cells also display a clear pulse between 35 and $40 \mathrm{~s}$ which is seen in almost all the RFs. In the Phoenix plate the arrivals are not very coherent, as what we think are the converted waves in the RFs are sometimes overlapped by negative pulses. This may be a consequence of the large area that the cell A is covering, implying RFs may be more heterogeneous. Nevertheless, both peaks are seen in the stacks. Converted waves in the AP are not obvious, with the exception of P410s in cell E, which is accompanied by another pulse which could also indicate a double interface. No clear pulses belonging to P660s are found in the RFs of cell $\mathrm{E}$ and no peak can be seen on the summation trace. In cell D there are no clear pulses either, nor in the 410 nor the $660 \mathrm{~km}$ RFs. However, peaks are observed on the summation traces, maybe indicating the position of the converted phases. This cell also has the limitation of containing fewer piercing points than the rest.

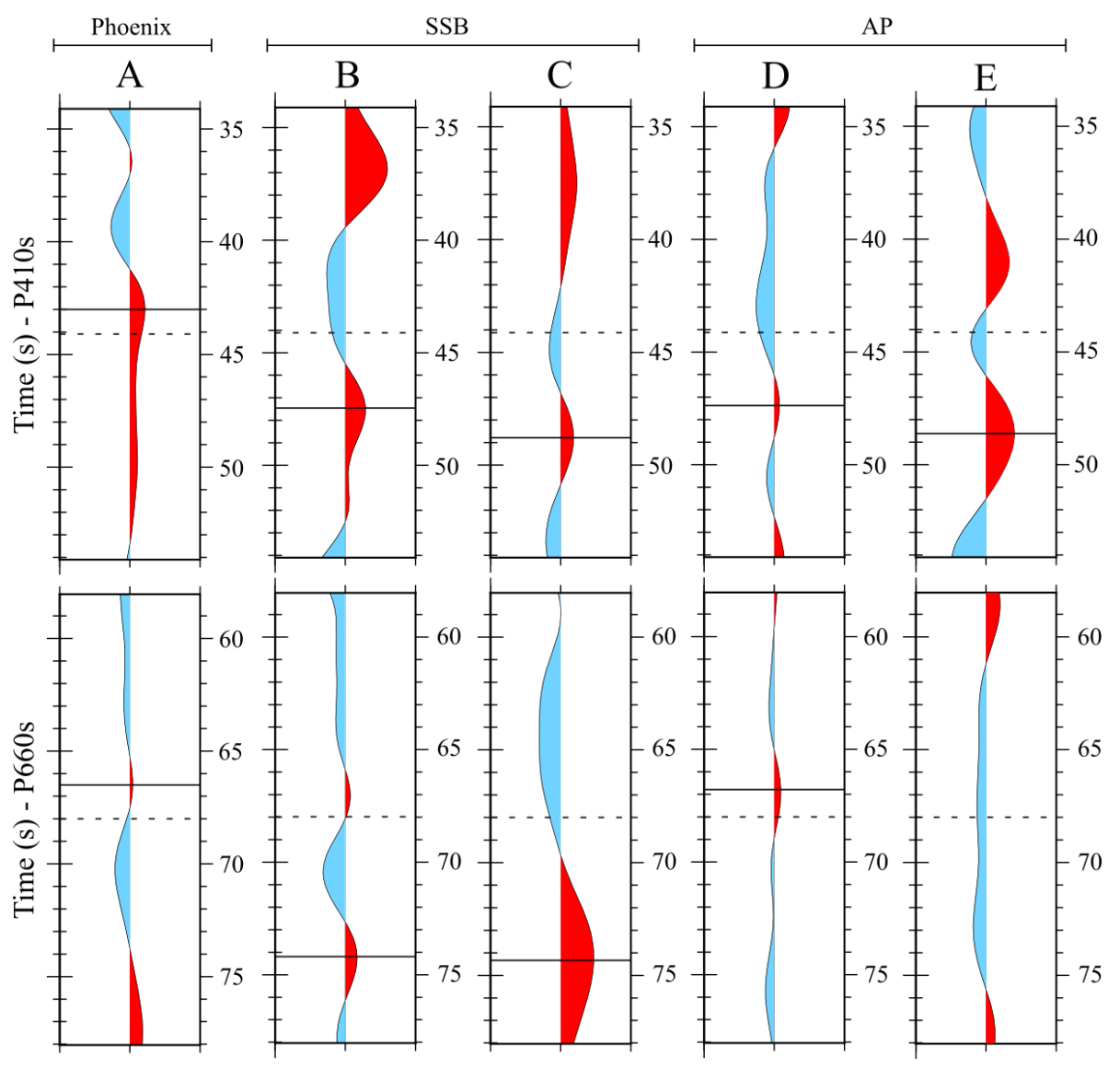

Figure 18: Grid stacking results, with black solid lines indicating P410s and P660s. Time windows are centred at the theoretical arrivals (dashed lines) using the IASP91 model.

By picking the delay times where the maximum amplitude of the selected pulses is achieved the time difference between both arrivals was determined. Cells in the SSB display the largest time differences $\left(t_{660}-t_{410}\right)$, being $26.7 \mathrm{~s}$ in cell $\mathrm{B}$ and $25.5 \mathrm{~s}$ in cell $\mathrm{C}$. $\triangle M T Z$ indicates a thickened MTZ, especially in cell B $(2.8 \mathrm{~s})$ and to a lesser extent in cell $\mathrm{C}(1.6 \mathrm{~s})$. Converted phases in both cells appear displaced to the right of the theoretical arrival times, so apparently both interfaces are deeper than $410 \mathrm{~km}$ and $660 \mathrm{~km}$. On the 
contrary, in the Phoenix plate (cell A) the converted phases are displaced to the left, indicating apparently shallower discontinuities. There the MTZ appears to be thinner, with a time difference of $23.5 \mathrm{~s}$. The estimated $\triangle M T Z$, however, is only $-0.4 \mathrm{~s}$, indicating the thickness of the MTZ is not perturbed. Additionally, if the peaks in cell D really correspond to the arrivals of converted phases, it would mean that the thinnest MTZ is found below the AP, with a $\triangle M T Z$ estimate of $-4.4 \mathrm{~s}$. The position of $\mathrm{P} 410 \mathrm{~s}$ in cell $\mathrm{D}$ agrees quite well with that in cell $\mathrm{E}$, in which the arrival is perfectly clear. However, due to the lack of a P660s spike in the summation trace of cell E results in cell D cannot be compared, and so the hypothesis that the MTZ is thinnest there remains unclear.

\section{Discussion}

\subsection{Lithospheric structure}

In section 3 the converted phase at the Moho discontinuity (Pms) and its two main multiples are identified and used to obtain the crustal thickness and average $V_{P} / V_{S}$. The identification of the multiples is a key step to interpret the regional structure of the lithosphere, as they might mask or interfere with other pulses corresponding to Ps phases. Generally, PpPms is the clearest multiple and PpSms is more difficult to detect, but it also has been consistently identified in almost all stations. Moreover, there are many features indicating there is anisotropy and/or dipping seismic interfaces below the Bransfield Strait, so the P to $\mathrm{S}$ conversions are not correctly isolated and some $\mathrm{P}$ wave energy might be left in the RFs. Therefore, the theoretical delay times of PpPmp have also been taken into account, although the multiple has not been satisfactorily identified. Note that the amplitude of the multiples in the summation traces can also be affected, as they move relative to Ps in function of the backazimuth and thus the pulse loses coherence. In Figure 19 all identified phases in the SSB are shown along the profile used in the CCP.

As discussed earlier in section 3 all summation traces display peaks near $t=0 \mathrm{~s}$ which could represent either converted phases or part of the $\mathrm{P}$ wave energy. Other pulses before the Pms arrival are also seen, but they could also be converted phases or multiples of the first pulse. Identification is difficult without a priori knowledge of the crustal structure, and therefore it remains unknown what do these pulses represent. However, in ELEF a pulse has been identified as an intracrustal converted phase (Pcs), as it is found considerably away from $t=0 \mathrm{~s}$ and its amplitude is larger than the Pms. Moreover, one of its multiples is detected (PpPcs). Future investigations should include joint inversion using both surface wave tomography and RFs to study the shallow structure. This would avoid the non-uniqueness of RF-only inversions caused by the multiple thickness-velocity solutions (Ammon et al., 1990) and would provide basic information to interpret the pulses seen in Figure 19.

The first converted phase identified after Pms is labeled as $\mathrm{Ph}_{1} \mathrm{~s}$, which corresponds to the pulse near Pms in LOWI, DECP/DCP, LVN, PRAT, and FREI. No identified multiple arrives near this pulse in any station, indicating it may really represent a seismic interface. The blue shaded area below $\mathrm{Ph}_{1} \mathrm{~s}$ corresponds to the negative pulse already discussed in section 3, which is identified as a converted phase $\left(\mathrm{Ph}_{2} \mathrm{~S}\right)$ generated at a gradient-like discontinuity due to its large width. $\mathrm{Ph}_{2} \mathrm{~S}$ occasionally displays a positive pulse within the shaded area due to the interference with multiples (PpPms in DECP/DCP and PpPcs in 
ELEF), but it is still clearly recognizable throughout the profile. In LOWI, LVN, PRAT, FREI, and JUBA it should interfere with PpPmp, although this multiple is not seen at all. $\mathrm{Ph}_{3} \mathrm{~s}$, in contrast, avoids any interaction with the multiples, suggesting it represents a sharp seismic discontinuity. Only in ELEF it matches almost exactly the predicted delay time of PpPmp, although whether this multiple is truly present or not remains unclear.

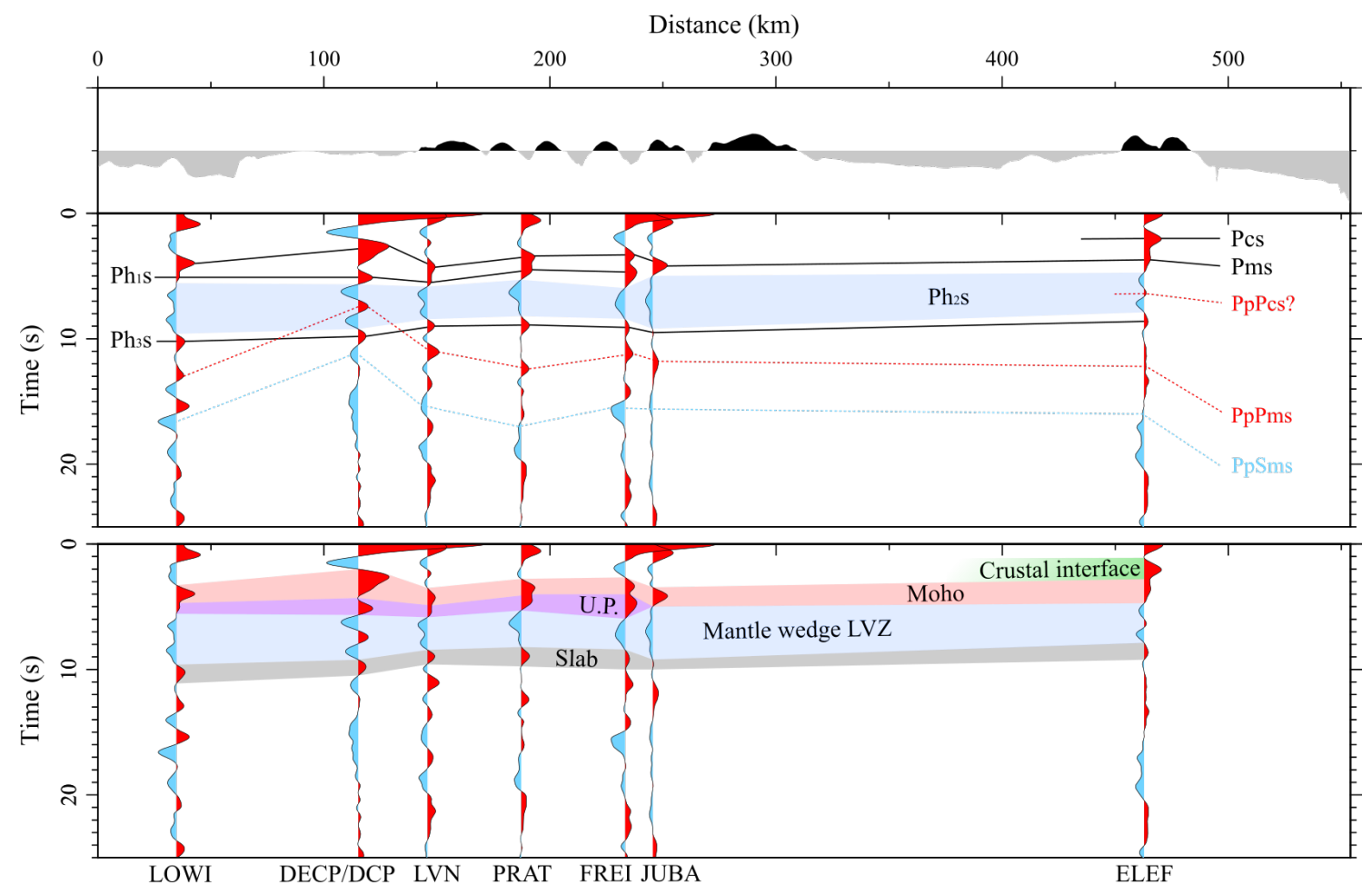

Figure 19: Interpretation for the major pulses identified in the summation traces of the SSB, projected onto the profile in Figure 11

$\mathrm{Ph}_{1} \mathrm{~s}$ is interpreted to be a case of magmatic underplating (see Fig. 20). Underplating occurs when magmas produced by partial melting in the upper mantle rise, as they are less dense than the surrounding mantle material. However, the magmas are still denser than the crust, so they get trapped and accumulate below the Moho discontinuity. This generates an additional positive seismic velocity contrast at the bottom of the underplating, which can appear as a positive pulse in the RFs. The presence of magmatic underplating is coherent with the active volcanism in the region, and has been documented via RF analysis in other volcanic regions such as the Canary Islands (Lodge et al., 2012) and the Hawaii archipelago (Leahy et al., 2010).

$\mathrm{Ph}_{2} \mathrm{~s}$ could be a Low Velocity Zone (LVZ) within the mantle wedge, and the width of the pulse indicates there is a negative velocity gradient rather than a sharp contrast. The LVZ may be caused by partial melting due to the water released by the subducted Phoenix slab in the mantle wedge, or to decompression caused by the extensional tectonics in the Bransfield Basin, or both. Slab driven magmatism is unlikely to be the only factor generating the hypothetical melts, as the LVZ is also found below the AP. The combined effect of both kinds of magmatism could be responsible for the diverse (and sometimes anomalous) geochemical signatures that the recent volcanic rocks show in the region (Fisk, 1990; Keller, 2002). Additionally, the LVZ could be the source of the melts in the underplating 


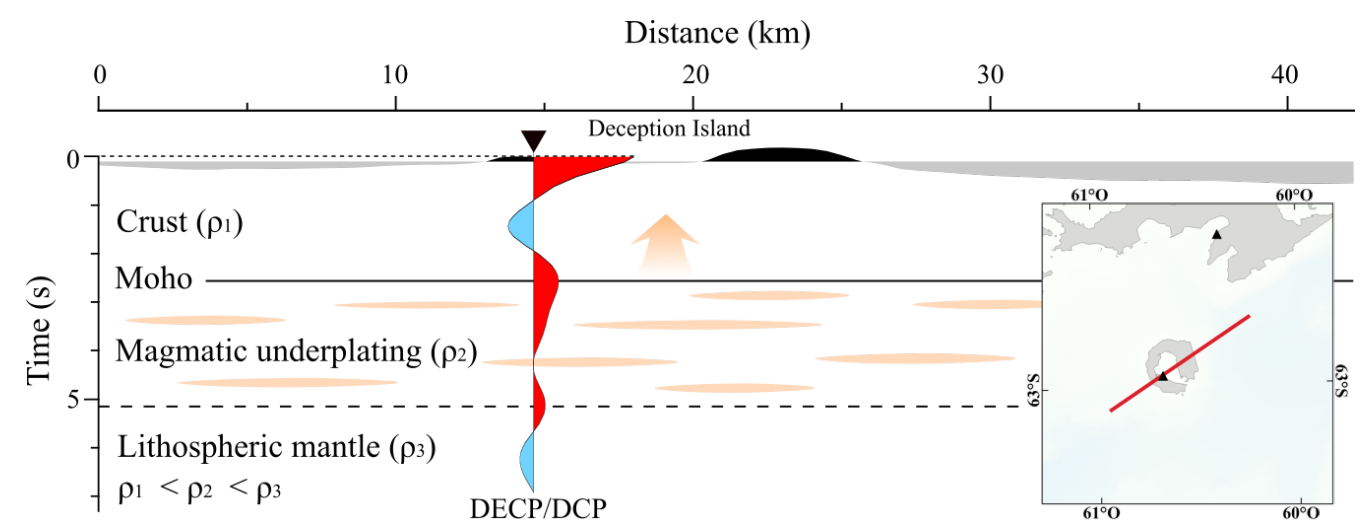

Figure 20: Sketch of the interpreted structure along a profile crossing Deception Island, showing magmatic underplating.

layer, as is thought happens in the Canary Islands (Martínez-Arévalo et al., 2013).

$\mathrm{Ph}_{3}$ s may represent the subducted Phoenix slab, which would cause seismic velocities to increase sharply and generate a positive pulse in the RFs. The pulse appears to be the same that was identified as the slab by Biryol et al. (2018) around 70 to $90 \mathrm{~km}$ (see Fig. 8). The depth of $\mathrm{Ph}_{3} \mathrm{~s}$ in the CCP (see Fig. 14) also matches the focal depths of the intermediate seismicity reported by Ibáñez et al. (1997), that reach a maximum depth of approximately $90 \mathrm{~km}$. Moreover, it also agrees with the preliminary results of the seismological study by Davoli (2019), which shows many recent earthquakes within similar depth ranges.

In the AP the structure is apparently simpler (Fig. 21). As in the SSB, strong arrivals near $t=0 \mathrm{~s}$ indicate there are shallow intracrustal interfaces and/or some $\mathrm{P}$ wave energy left. Again, a priori knowledge of the shallow structure would be necessary to interpret those pulses. Nevertheless, in all the AP stations there is a clear pulse at approximately $t=2 \mathrm{~s}$ which could correspond to a converted phase, and thus has been labeled as Pcs. Below Pms again a wide and strong set of negative pulses are detected, which may be the equivalent of $\mathrm{Ph}_{2} \mathrm{~S}$ in the SSB. Here, this area is labeled $\mathrm{Ph}_{1} \mathrm{~s}$. After $\mathrm{Ph}_{1} \mathrm{~s}$ there are multiple coherent pulses which, as explained in section 3, move towards smaller or larger delay times in function of the backazimuth, and thus are interpreted as multiples. However, there is not enough information to identify which multiples do those pulses represent. The PpPms and PpSms arrivals are found after those pulses, and appear at very similar delay times in all stations.

Pcs has been interpreted as an intracrustal interface of intermediate depth, as is shown in Figure 21. Below the Moho, the shaded area occupied by $\mathrm{Ph}_{1}$ s may indicate the presence of a LVZ, much like in the SSB. Here the LVZ cannot be explained as a product of a subduction, at least with our current knowledge of the structure of the Bransfield Strait. The apparent absence of a converted wave after the LVZ in Figure 21, the lack of intermediate to deep seismicity in the AP except in James Ross island (Davoli, 2019), the delay times of P410s and P660s (as is explained later in subsection 4.3), and previous seismic tomography (Park et al., 2012) strongly suggest the slab sinks very steeply and does not reach the AP. Therefore, no converted wave is expected immediately after the LVZ, with the exception of the pulse that could be generated at its lower boundary. 

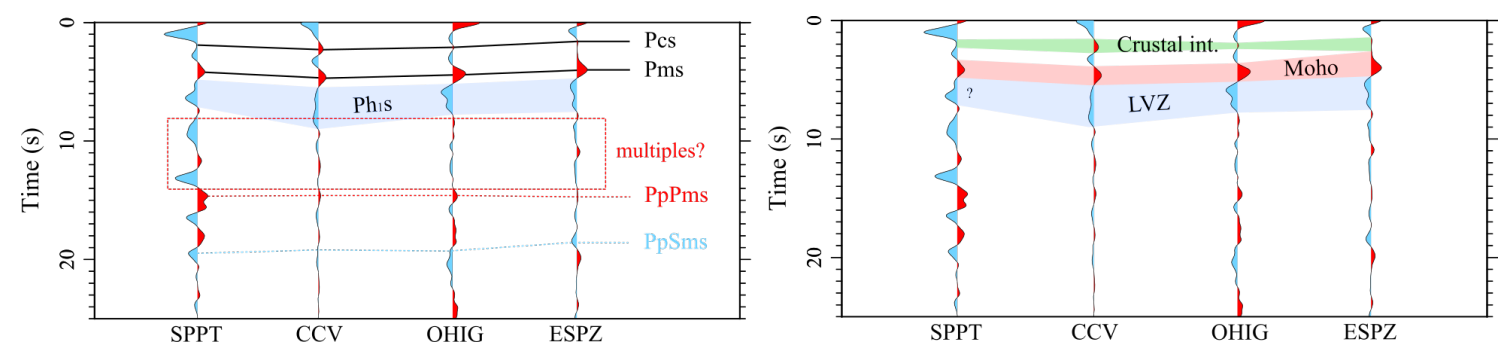

Figure 21: Interpretation for the major pulses identified in the summation traces of the AP. The traces have not been projected onto a profile due to the extremely large unsampled areas in between.

\subsection{Limitations and comparison of crustal thickness and $V_{P} / V_{S}$}

$H-\kappa$ stacking yielded some results with very small standard errors, especially in LVN and JUBA, but this is only indicative of the coherence and similarity of the RFs. As explained in subsubsection 2.4.3, the maximum resolution of RFs with $a=2.5$ is approximately $2 \mathrm{~km}$, so a minimum error of $2 \mathrm{~km}$ has to be assumed. Error introduced by a potentially dipping Moho or by potential $V_{P}$ disagreement between the Earth model and the medium must also be accounted for: error caused by a $V_{P}$ disagreement of $0.3 \mathrm{~km} \mathrm{~s}^{-1}$ was estimated to be always below $2 \mathrm{~km}$ in $H$ and to have almost no effect on $V_{P} / V_{S}$, while according to Lombardi et al. (2008) a gently dipping Moho would introduce an error of about $1 \mathrm{~km}$ in $H$ and about 0.02 in $V_{P} / V_{S}$. However, those values fall in most cases within the estimated bootstrap standard errors. Uncertainty is also increased by coherent pulses in the RFs other than the multiples, such as the spike overlapping Pms in the SSB.

Our $H$ and $V_{P} / V_{S}$ estimates (see Table 2) agree well with previous seismic refraction experiments in the Bransfield Strait (Barker et al., 2003), but may conflict with the RF analysis by Biryol et al. (2018). The spatial clustering in Figure 17 shows a shallower although more variable Moho below the SSB, while in the AP it is much more homogeneous, being always deeper than $30 \mathrm{~km}$. The more heterogeneous depth in the SSB reflects the active rifting of the region. Barker et al. (2003) report Moho depths around 14-16 km in the vicinity of Deception Island, around $26 \mathrm{~km}$ next to PRAT, and $22-24 \mathrm{~km}$ south of JUBA and FREI. Those values are perfectly compatible with the Moho depths obtained in this study. High $V_{P} / V_{S}$ values are found in the stations closer to the incipient spreading ridge, with the highest values clustered around the Deception Island area. This may be possibly suggesting the presence of partial melts and/or a heavily fractured medium, which is consistent with the tectonic setting involving active rifting and volcanism and may explain the inverse correlation between $H$ and $V_{P} / V_{S}$ seen in Figure 16.

Results in Biryol et al. (2018) are for some stations drastically different from our results, especially in the SSB. To test whether this is an effect of the selected $V_{P}$ we obtained additional $H$ and $V_{P} / V_{S}$ estimates using the velocities specified in Biryol et al. (2018). Results are compared in Table 4.

Crustal thickness in ELEF, FREI, JUBA, and SPPT reported in Biryol et al. (2018) closely agrees with our results, falling inside $1 \sigma_{H}$ error. ESPZ displays similar values, but not within $1 \sigma_{H}$. Vuan (2001) obtained a crustal thickness around $37 \mathrm{~km}$ in ESPZ, which is in accordance with our estimation. The rest of stations display significant differ- 
Table 4: Comparison between $H$ and $\kappa$ results in Biryol et al. (2018) and our estimates using both the $V_{P}$ scheme in Biryol et al. (2018) and a fixed $V_{P}$ of $6.5 \mathrm{~km} \mathrm{~s}^{-1}$. The authors set the following $V_{P}: 6.9 \mathrm{~km} \mathrm{~s}^{-1}$ in DECP and ELEF; $6.8 \mathrm{~km} \mathrm{~s}^{-1}$ in OHIG and SPPT; $6.7 \mathrm{~km} \mathrm{~s}^{-1}$ in PRAT; $6.6 \mathrm{~km} \mathrm{~s}^{-1}$ in FREI and JUBA; $6.0 \mathrm{~km} \mathrm{~s}^{-1}$ in ESPZ and LOWI. Weights were all set to $w_{1}=0.4, w_{2}=0.4$, and $w_{3}=0.2$. Only IRIS stations were used in Biryol et al. (2018), so CCV and LVN are not listed.

\begin{tabular}{crrrrrr}
\hline \multicolumn{2}{c}{ Biryol et al. (2018) } & \multicolumn{2}{c}{$V_{P}$ in Biryol et al. $(2018)$} & \multicolumn{2}{c}{$V_{P}=6.5 \mathrm{~km} \mathrm{~s}^{-1}$} \\
\hline Station & $H(\mathrm{~km})$ & $V_{P} / V_{S}$ & $H(\mathrm{~km})$ & $V_{P} / V_{S}$ & $H(\mathrm{~km})$ & $V_{P} / V_{S}$ \\
\hline DECP/DCP & $36.0 \pm 0.7$ & $1.94 \pm 0.03$ & $16.1 \pm 3.1$ & $2.08 \pm 0.15$ & $15.1 \pm 2.2$ & $2.08 \pm 0.11$ \\
ELEF & $33.0 \pm 0.8$ & $1.83 \pm 0.04$ & $33.3 \pm 3.4$ & $1.70 \pm 0.08$ & $31.5 \pm 2.7$ & $1.69 \pm 0.08$ \\
ESPZ & $31.0 \pm 0.9$ & $1.74 \pm 0.04$ & $31.7 \pm 2.8$ & $1.70 \pm 0.09$ & $35.4 \pm 3.5$ & $1.68 \pm 0.09$ \\
FREI & $26.5 \pm 0.5$ & $1.93 \pm 0.02$ & $28.9 \pm 2.9$ & $1.75 \pm 0.22$ & $28.3 \pm 2.7$ & $1.76 \pm 0.22$ \\
JUBA & $26.0 \pm 0.5$ & $1.96 \pm 0.02$ & $26.3 \pm 0.7$ & $1.94 \pm 0.02$ & $25.7 \pm 0.7$ & $1.95 \pm 0.02$ \\
LOWI & $40.0 \pm 0.5$ & $1.94 \pm 0.02$ & $27.3 \pm 1.1$ & $1.80 \pm 0.05$ & $30.3 \pm 1.3$ & $1.77 \pm 0.04$ \\
OHIG & $29.0 \pm 0.5$ & $1.74 \pm 0.03$ & $36.8 \pm 1.0$ & $1.75 \pm 0.03$ & $35.0 \pm 1.0$ & $1.76 \pm 0.03$ \\
PRAT & $34.5 \pm 0.5$ & $1.82 \pm 0.02$ & $28.3 \pm 2.1$ & $1.97 \pm 0.09$ & $27.6 \pm 2.0$ & $1.95 \pm 0.10$ \\
SPPT & $32.5 \pm 0.5$ & $1.74 \pm 0.02$ & $34.8 \pm 3.6$ & $1.79 \pm 0.07$ & $33.1 \pm 3.4$ & $1.80 \pm 0.07$ \\
\hline
\end{tabular}

ences respective to Biryol et al. (2018) way beyond our standard error, being exceptionally large in DECP/DCP. It is worth noting that the authors only used data corresponding to the DECP station: only five usable RFs from this station were obtained in the present study due to the large amount of noisy data with $S / R$ ratio below 2 . Back in Figure 7 it was already shown that RFs belonging to DECP in Biryol et al. (2018) were not coherent, so we suspect the estimated crustal thickness of $36 \mathrm{~km}$ may be the product of noise. No peak was observed in the $H-\kappa$ space near the values reported by the authors using our data. $H$ in LOWI also strongly disagrees with our estimates. As in DECP, this station has limited data and is largely affected by noise. Again, only five reliable RFs were obtained and no peak was observed in the stack near the values indicated by the authors. Differences are also large in PRAT, although the $H$ - $\kappa$ stack in this station is complex and displays multiple peaks, one of which is close to the values reported in Biryol et al. (2018). Nevertheless, our estimates are in accordance with results in Barker et al. (2003) and are consistent with the crustal thicknesses and $V_{P} / V_{S}$ in the neighbouring stations (Fig. 17). Biryol et al. (2018) acknowledge the crustal thickness of the southwestern Bransfield Basin in their work appears to be uncharacteristically thick, but they attribute it to isostatic adjustments in the region.

All $H$ and $V_{P} / V_{S}$ estimates using the $V_{P}$ scheme in Biryol et al. (2018) fall very close to the results that were obtained using a fixed $6.5 \mathrm{~km} \mathrm{~s}^{-1}$ velocity. This further proves the consistency of our $\mathrm{H}-\kappa$ stacks, and throws additional doubt on the exceptionally deep Moho, given the tectonic context, that Biryol et al. (2018) report in DECP and LOWI. Generally, $V_{P} / V_{S}$ is more difficult to constrain and variations may be larger. In this case, ESPZ, JUBA, OHIG, and SPPT display values very similar to those in Biryol et al. (2018), while error in FREI is very large no matter the $V_{P}$ used. A surprising feature of the results given in Biryol et al. (2018) is the exceptionally low standard error in all $H$ and $V_{P} / V_{S}$ estimates. For instance, no station displays an error in $H$ larger than $1 \mathrm{~km}$, and errors in $V_{P} / V_{S}$ are always below 0.05 . This contrasts with our estimations, which can have large 
standard errors remarking the complexity of the stacks (take FREI or ESPZ as examples).

Two of the $H-\kappa$ stacks were specially problematic due to the large number of maximums that appear in the plotting space. Those are PRAT and ELEF, which are illustrated in Figure 22. In the case of ELEF most peaks can be easily discarded due to the extremely low $\kappa$ values where the maximum amplitude is located. The maximum around $H=15 \mathrm{~km}$ would also be an unrealistic solution because the tectonic setting of ELEF suggests crustal thicknesses more like those in the Antarctic Peninsula, as already reported in Biryol et al. (2018). Therefore, we narrowed down the $H-\kappa$ space so that the peak indicated in Figure 22 becomes dominant. In PRAT the situation is more difficult, as there are three amplitude maximums which include plausible $H$ and $\kappa$ ranges. The maximum to the upper left would lead to a poorly resolved solution, and opening even more the $H$ - $\kappa$ space would yield extremely high $\kappa$ values, even higher than those in DECP/DCP and LVN. Moreover, the peak found about $\kappa=1.65$ and $H=32 \mathrm{~km}$ would provide a $V_{P} / V_{S}$ ratio which is very low if compared to the neighbouring stations, and would be even lower than those in the AP. We interpret the maximum indicated in Figure 22 corresponds to the best solution, as it is coherent with the tectonic setting and the neighbouring stations. The obtained crustal thickness $(27.6 \mathrm{~km})$ is close to that reported in Barker et al. (2003) in the submerged areas near PRAT $(\approx 26 \mathrm{~km})$.

The delay times of the Pms, PpPms and PpSms phases obtained with the $H$ - $\kappa$ estimates were also compared with Biryol et al. (2018). In Figure 23 three plots by ray parameter are shown, displaying different levels of disagreement. In the first case ELEF yielded very similar results both in this work and in Biryol et al. (2018), and this translates to a good agreement between the respective delay time lines. In OHIG $V_{P} / V_{S}$ is very similar, but $H$ differs by $5-6 \mathrm{~km}$. However, the delay time lines display significant differences, with the multiples following completely different pulses. The Pms line corresponding to Biryol et al. (2018) appears displaced from the pulse. Finally, DECP/DCP shows the worst agreement, with the Pms delay time line from Biryol et al. (2018) even following a spike more than $2 \mathrm{~s}$ away from what we identified as the Pms arrival.
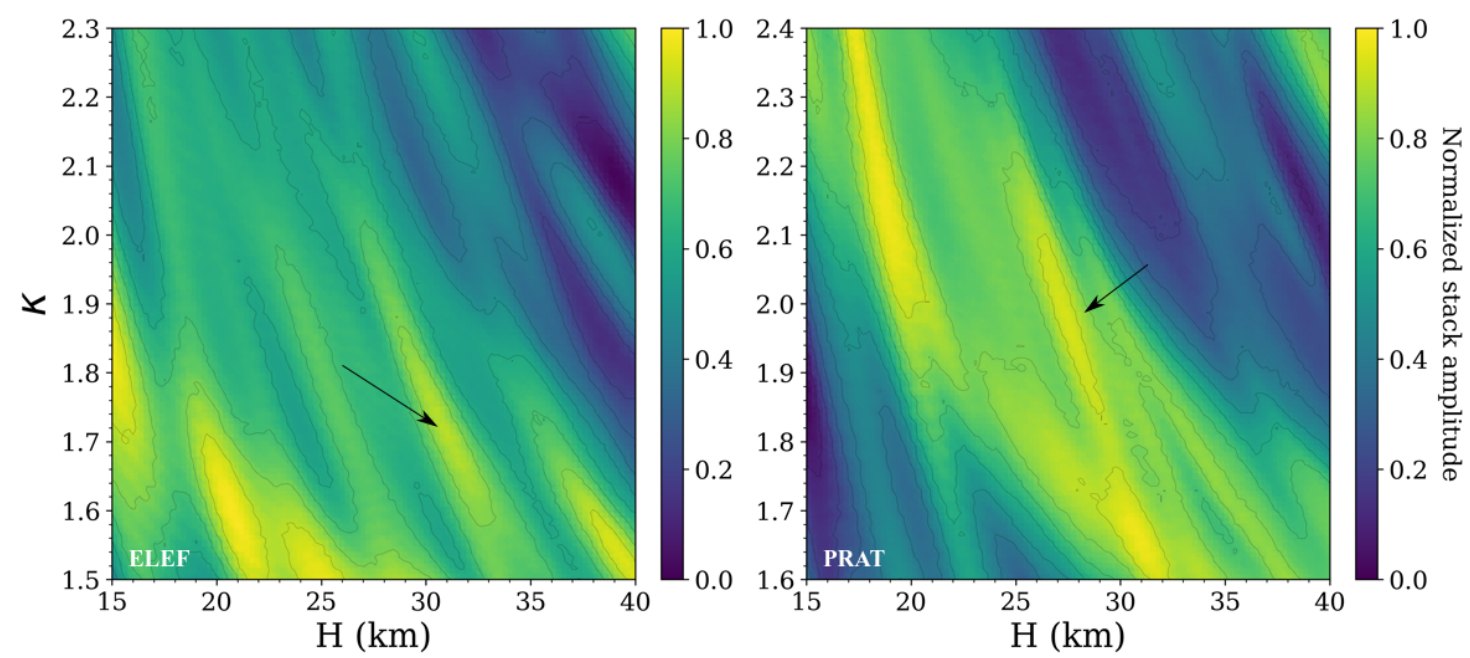

Figure 22: $H-\kappa$ stacks of ELEF and PRAT. The $H-\kappa$ space has been opened to represent a wide range of values and multiple maximums. The arrows indicate the peaks corresponding to the values in Table 2, but the estimates have not been obtained from these plots. 

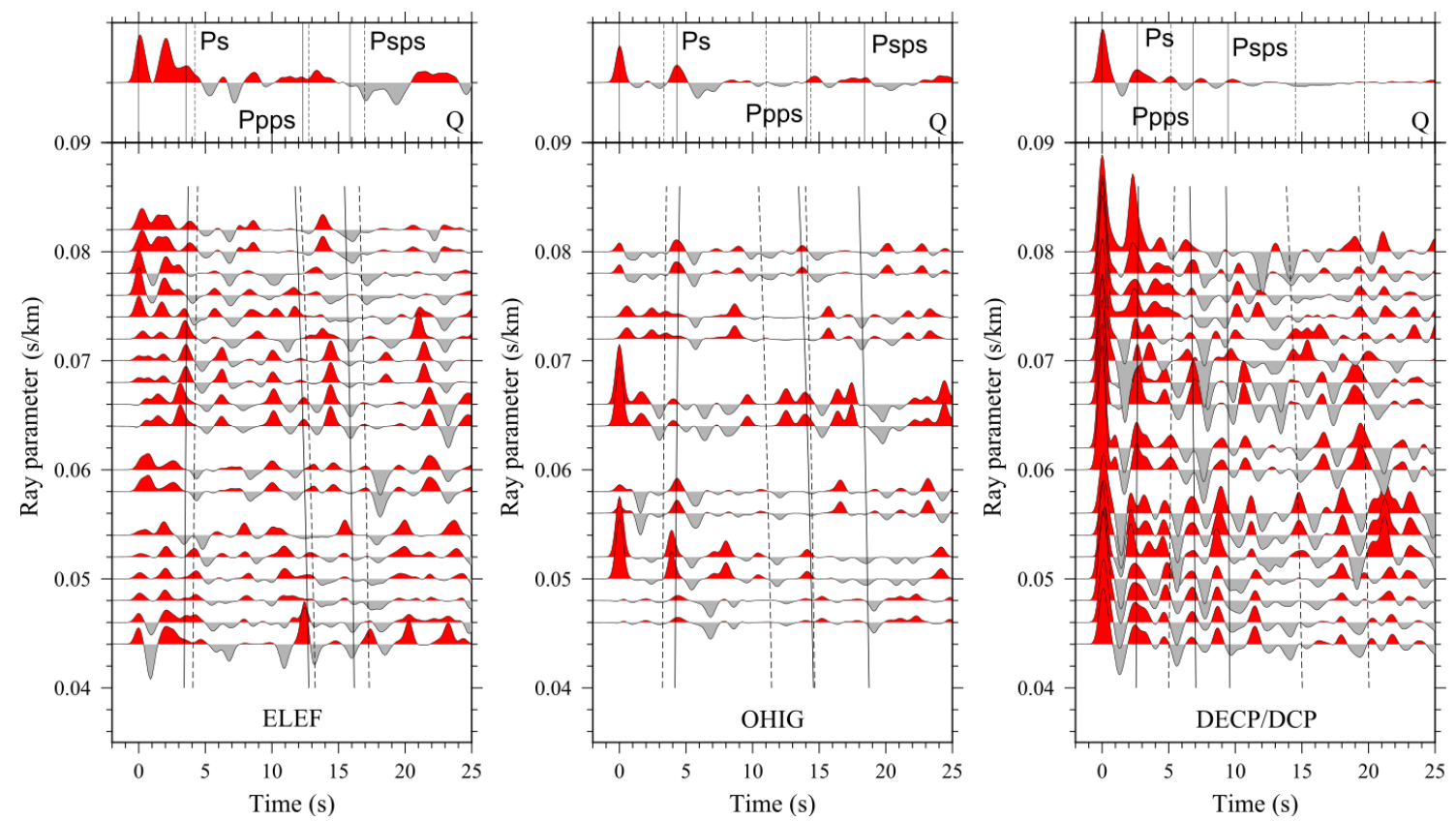

Figure 23: Comparison between predicted delay times according to our $H$ and $\kappa$ estimates (solid line) and according to the values suggested in Biryol et al. (2018) (dashed line). Three examples have been selected to show cases from good (ELEF) to bad agreement (DECP/DCP).

\subsection{Variability of the MTZ and its relationship to regional tectonics}

The thickness of the MTZ is controlled mainly by the thermodynamics of the phase transitions that take place in this portion of the mantle, a hypothesis which is supported by experimental work (Fei and Bertka, 1999). Those phase transitions only involve changes in the crystalline structure, but not compositional changes. The dominant mineral in the upper mantle is magnesium-rich olivine (forsterite), or $\alpha$-olivine. The $410 \mathrm{~km}$ discontinuity marks the end of the upper mantle and the start of the MTZ. In this discontinuity $\alpha$-olivine suffers a phase transition into $\beta$-olivine (wadsleyite), a reaction which has a negative Clapeyron slope (Fig. 24): this means that the pressure needed for the phase transition increases as the temperature also increases. Around $520 \mathrm{~km}$ another phase transition with negative Clapeyron slope may sometimes occur. In this case, $\beta$-olivine is transformed into $\gamma$-olivine (ringwoodite). The $660 \mathrm{~km}$ discontinuity constitutes the lower limit of the MTZ, bounding with the lower mantle. Here, a phase transition with a positive Clapeyron slope occurs: $\gamma$-olivine rearranges into a perovskite structure (bridgmanite) plus iron-magnesium oxides (magnesiowüstite). This phase transition behaves in the inverse manner than those in the $410 \mathrm{~km}$ and $520 \mathrm{~km}$ discontinuities: as temperature increases, pressure necessary for the reaction decreases (Fei and Bertka, 1999; Schmerr, 2015).

Due to the different Clapeyron slopes of the phase transitions at $410 \mathrm{~km}$ and $660 \mathrm{~km}$ thermal anomalies in the MTZ will affect differently the seismic discontinuities (Fei and Bertka, 1999; Schmerr, 2015). Figure 25 exemplifies this different behaviour: a negative temperature anomaly makes the $410 \mathrm{~km}$ discontinuity become shallower, but the $660 \mathrm{~km}$ interface gets deeper. Therefore, a thickened MTZ is expected when the region is colder 


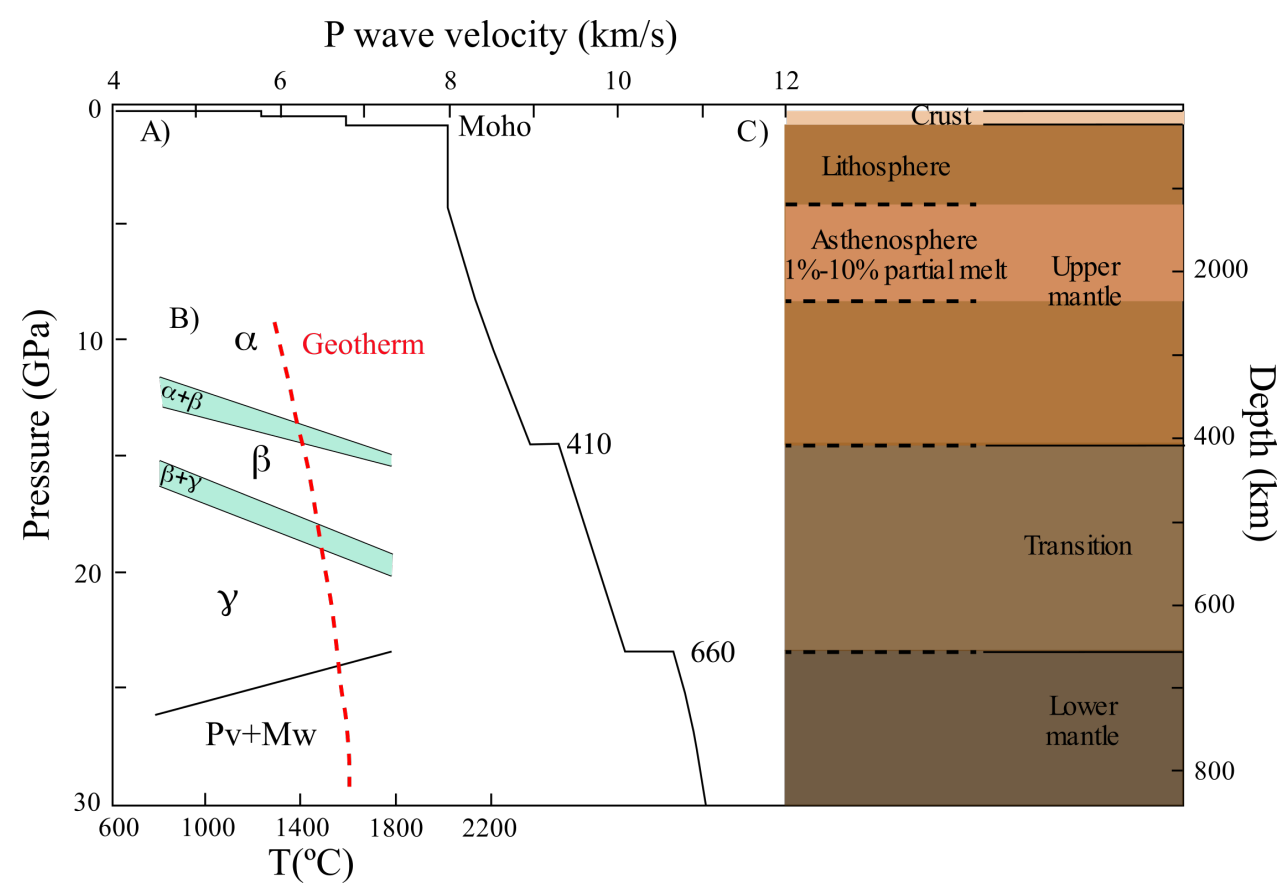

Figure 24: Phase transitions in the MTZ and their respective Clapeyron slopes. Figure courtesy of F. Mancilla.

than usual, for instance, when there is a cold sinking slab. On the contrary, the $410 \mathrm{~km}$ discontinuity deepens but the $660 \mathrm{~km}$ becomes shallower when there is a positive temperature anomaly, meaning the MTZ will be thinner when temperatures are warmer than usual.

Results of the grid stacking indicate the MTZ below the Phoenix plate has a normal thickness, showing only a thickness difference $(\triangle M T Z)$ of $-0.4 \mathrm{~s}$ with respect to a theoretical unperturbed MTZ in spite of the lack of coherence of the pulses. Cells located in the $\mathrm{SSB}$, in contrast, display a clearly thickened MTZ, with $\triangle M T Z$ being $2.8 \mathrm{~s}$ in cell B and $1.6 \mathrm{~s}$ in cell $\mathrm{C}$, thus suggesting the presence of the Phoenix slab. The arrivals of P410s and P660s are very difficult to detect in the RFs belonging to the AP: only cell E displays a clear P410s arrival, although no P660s pulse is observed in the stack. The stacks of cell D show two maximums which may correspond to P410s and P660s, even though no coherent pulses can be clearly seen. The potential P410s pulse agrees well with that in cell E, but the P660s pulse cannot be compared. With those arrivals the MTZ below the AP appears thinner than usual, with $\triangle M T Z=-4.4 \mathrm{~s}$. If it is assumed that the thickness in cell $\mathrm{D}$ is a reliable result, then a hot region beneath the AP is expected.

Nevertheless, the MTZ discontinuities may also be affected by chemical anomalies. For instance, an increase in water content causes the $410 \mathrm{~km}$ discontinuity to become shallower and the $660 \mathrm{~km}$ discontinuity to become deeper (Smyth and Jacobsen, 2006). Water is usually carried by subducting slabs, so the effect of the negative temperature anomaly may be reinforced. Additionally, an enrichment of $\mathrm{Mg}$ relative to Fe results in a deeper $410 \mathrm{~km}$ discontinuity: this may happen when a sinking slab suffers partial melting, a process that depletes Fe (Fei and Bertka, 1999). The effect may be amplified when there is slab rollback (Schmerr and Garnero, 2007), as is thought happens beneath the Bransfield Strait (Robertson Maurice et al., 2003; Dziak et al., 2010; Park et al., 2012). The work 

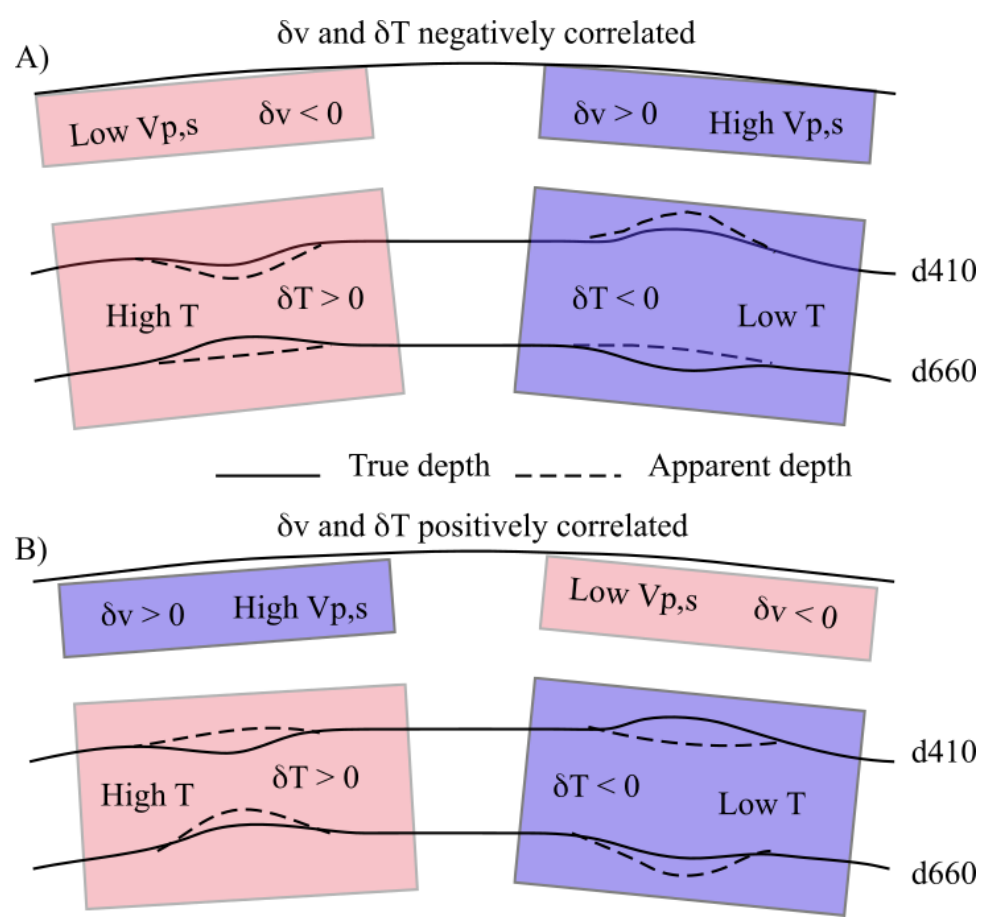

Figure 25: Combined effects of thermal anomalies and seismic velocities on the apparent depth (in dashed lines) of the MTZ discontinuities. Figure courtesy of F. Mancilla.

of Schmerr and Garnero (2007) provides a good example of the complex interactions between thermal and chemical anomalies in the MTZ, which may even lead to double seismic interfaces. The double pulse seen in the P660s stack of cell B and the P410s stack of cell E could be examples of such complex interactions. In cell B the pulse is too close to P660s to belong to P520s and may be caused by interaction with the slab, while it is unknown what the second pulse in cell E might represent, so further investigations on the mantle structure are required.

The MTZ thickness seems to agree with velocity anomalies in the seismic tomography of Park et al. (2012), although it does not sample such depths. Park et al. (2012) observed a high velocity anomaly below the SSB, which they interpret as an almost vertical cold sinking slab of the former Phoenix plate. If the slab does reach deeper regions of the mantle it could explain the thickened MTZ. Moreover, the tomography shows a low velocity anomaly under the AP that indicates a warmer mantle region and a possibly thinner MTZ, although our results in the AP do not provide clear evidence supporting this.

Cells B and C, which belong to the SSB, also feature another positive pulse located between delay times of 35 to $40 \mathrm{~s}$. Those pulses are too far away from P410s to represent a double discontinuity; instead, we suggest it may correspond to P300s, which would be a wave converted at the $300 \mathrm{~km}$ discontinuity. This seismic interface is commonly present below active island arcs and is associated to the presence of eclogites undergoing silica phase transitions in the upper mantle (Williams and Revenaugh, 2005; Schmerr et al., 2013). Therefore, it is an additional evidence for the presence of the Phoenix slab.

Another major feature in our results is the lag of P410s and P660s with respect to the theoretical arrival times, as obtained with the IASP91 Earth model. P410s and P660s in 
the SSB and AP appear always displaced towards larger delay times, indicating an apparently deeper MTZ. This, however, does not necessarily mean the MTZ is found at a greater depth; in this case the thickness variations alone cannot explain the time lag, so it must be caused partly by the disagreement of the IASP91 Earth model with the local seismic velocities. Such effects are represented in Figure 25. As we know from the RFs $(a=2.5)$, there is a negative pulse below the Moho that probably represents a converted wave at a gradient-like negative velocity contrast that may indicate the presence of a low velocity zone. This layer is not present in the Earth model, so the seismic interfaces may appear apparently deeper much like the case that Martínez-Arévalo et al. (2013) report in the Canary Islands. Therefore, beneath the SSB the case could be similar to B in Figure 25, with a low velocity anomaly in the upper mantle above a thickened MTZ. In the AP the case would be closer to A, with a low velocity zone above a thinned MTZ. The supposedly deep-rooted low velocity anomaly detected by Park et al. (2012) under the Bransfield Strait (and especially below the AP) could also contribute to the time lag of the converted phases.

On the contrary, P410s and P660s in the Phoenix plate display a negative time lag respective to the theoretical arrivals, so the MTZ appears to be slightly shallower in spite of having a regular thickness. All summation traces in this study display to some extent the negative pulse which is interpreted as a low velocity zone but, if all RFs are affected by this velocity anomaly, something else has to be affecting the RFs in cell A. We interpret there is a high velocity layer below the SSB (most likely the cold and dense Phoenix slab) which counteracts the effect of the low velocity zone and is responsible of the thickened MTZ under the Strait, as is shown in Figure 26. Moreover, due to the dominant NW backazimuth direction cells B, C, D, and E are almost exclusively sampled by the stations

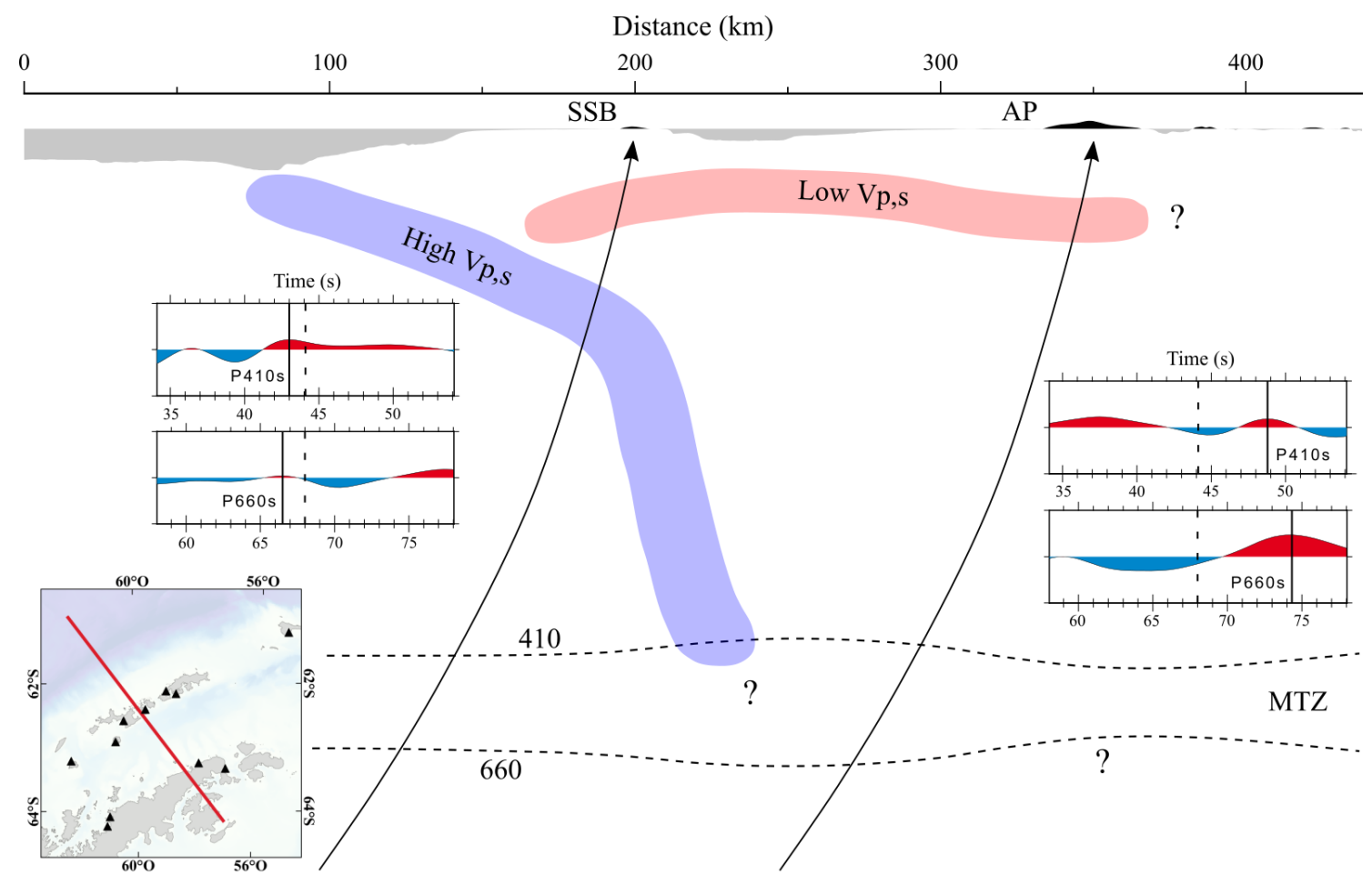

Figure 26: Interpretation of the velocity anomalies above the MTZ on a NW-SE profile crossing the SST, the SSB, and the AP (not to scale). 
in the AP, so the seismic rays avoid interaction with the slab. Previous studies suggest the slab dips gently upon contact with the SSB (Robertson Maurice et al., 2003) but rapidly becomes almost vertical (Park et al., 2012), which also helps explain why only cell A is affected.

\section{Conclusions}

RF analysis in the Bransfield Strait is limited by the lack of data, the geographical configuration of the SSI archipelago and the AP, and the bad backazimuthal and spatial coverage to date. However, the RFs within each of the two continental blocks display distinctive and consistent patterns which are coherent with the corresponding tectonic features.

$H-\kappa$ stacking shows the crustal thickness in the SSB is much more heterogeneous than in the AP, and the crust appears thinned especially in the area surrounding Deception Island $(\sim 15 \mathrm{~km})$, reflecting the active extensional tectonics of the region. The $V_{P} / V_{S}$ ratio is also highly variable in the SSB and may reach high values also in the stations close to Deception Island ( $>2)$, indicating the presence of melts and/or a highly fractured medium. In the southwestern and northeastern boundaries of the SSB (Low and Elephant islands) and in the AP the crustal thickness is always $>30 \mathrm{~km}$ and $V_{P} / V_{S}$ is commonly around 1.8 or below, indicating a more standard continental crust.

A LVZ has been identified below the Moho both in the SSB and the AP, possibly reflecting the presence of melts due to decompression caused by the active rifting. In the SSB this LVZ may be the source of the melts which are inferred to be generating magmatic underplating below LOWI, DECP/DCP, LVN, PRAT, and FREI. Another potential seismic discontinuity has been identified below the LVZ in the SSB, which probably corresponds to the sinking Phoenix slab. The slab could also contribute to the partial melting in the mantle wedge due to its dehydration, which is a well-known source of magmatism in such tectonic regimes and is in accordance with the intermediate seismicity in the region.

The MTZ in the study area shows variable thickness. North of the SSB, in the Phoenix plate, the MTZ displays a regular thickness, but it appears clearly thickened below the SSI and the Bransfield Basin due to the effect of the cold Phoenix slab, which is thought to sink very steeply. Data in the AP suggests the MTZ is thinner than usual, but the results are inconclusive due to the lack of clear converted phases. Double $440 \mathrm{~km}$ and $660 \mathrm{~km}$ discontinuities have also been detected, which could indicate the presence of chemical anomalies and further exemplify the complexity of the region. The arrival times of P410s and P660s are not only affected by the depth of the interfaces, but also by shallower velocity anomalies which make the times disagree with those obtained with a standard Earth model. This disagreement, alongside the potential presence of the $300 \mathrm{~km}$ discontinuity below the Bransfield Strait, provides further evidence that there is a steeply dipping slab below a laterally broad LVZ.

A more extensive dataset and a denser seismic network would be necessary to constrain to a larger extent the structural characteristics of the crust and upper mantle described in this study. Our results may be taken as preliminary, as additional data will be 
obtained during the 2019-2020 antarctic summer thanks to the temporal seismometers installed by the BRAnsfield VOlcano SEISmology (BRAVOSEIS) project scientists (IAG, Universidad de Granada). Future studies should include harmonic decomposition analysis to understand the effects of anisotropy and the possible dipping interfaces, as well as joint inversion with surface wave tomography to discern the crustal structure in the Bransfield Strait.

\section{References}

Almendros, J., J. M. Ibáñez, G. Alguacil, E. Del Pezzo, and R. Ortiz, Array tracking of the volcanic tremor source at Deception Island, Antarctica, Geophysical Research Letters, 24(23), 3069-3072, doi:10.1029/97g103096, 1997.

Ammon, C. J., G. E. Randall, and G. Zandt, On the nonuniqueness of receiver function inversions, Journal of Geophysical Research, 95(B10), 15,303, doi:10.1029/jb095ib10p15303, 1990.

Barker, D. H., G. L. Christeson, J. A. Austin, and I. W. Dalziel, Backarc basin evolution and cordilleran orogenesis: Insights from new ocean-bottom seismograph refraction profiling in Bransfield Strait, Antarctica, Geology, 31(2), 107, doi:10.1130/00917613(2003)031<0107:bbeaco>2.0.co;2, 2003.

Biryol, C. B., S. J. Lee, J. M. Lees, and M. J. Shore, Lithospheric structure of an incipient rift basin: Results from receiver function analysis of Bransfield Strait, NW Antarctic Peninsula, Polar Science, 16, 47-58, doi:10.1016/j.polar.2018.02.003, 2018.

Bormann, P., B. Engdahl, and R. Kind, Seismic Wave Propagation and Earth models, in New Manual of Seismological Observatory Practice (NMSOP), edited by P. Bormann, pp. 1-70, Deutsches GeoForschungsZentrum GFZ, doi:10.2312/GFZ.NMSOP_r1_ch2, 2009.

Christensen, N. I., and W. D. Mooney, Seismic velocity structure and composition of the continental crust: A global view, Journal of Geophysical Research: Solid Earth, 100(B6), 9761-9788, doi:10.1029/95jb00259, 1995.

Christeson, G. L., D. H. N. Barker, J. A. Austin, and I. W. D. Dalziel, Deep crustal structure of Bransfield Strait: Initiation of a back arc basin by rift reactivation and propagation, Journal of Geophysical Research: Solid Earth, 108(B10), doi:10.1029/2003jb002468, 2003.

Crotwell, H. P., T. J. Owens, and J. Ritsema, The TauP Toolkit: Flexible Seismic Travel-time and Ray-path Utilities, Seismological Research Letters, 70(2), 154-160, doi:10.1785/gssrl.70.2.154, 1999.

Dalziel, I. W., L. A. Lawver, I. O. Norton, and L. M. Gahagan, The Scotia Arc: Genesis, Evolution, Global Significance, Annual Review of Earth and Planetary Sciences, 41(1), 767-793, doi:10.1146/annurev-earth-050212-124155, 2013.

Davoli, R., Análisis de la sismicidad en el Estrecho de Bransfield durante el año 2018 y el principio del año 2019, Master's thesis, Instituto Andaluz de Geofísica, Universidad de Granada, 2019. 
Dietrich, R., A. Rülke, J. Ihde, K. Lindner, H. Miller, W. Niemeier, H.-W. Schenke, and G. Seeber, Plate kinematics and deformation status of the Antarctic Peninsula based on GPS, Global and Planetary Change, 42(1-4), 313-321, doi:10.1016/j.gloplacha.2003.12.003, 2004.

Dziak, R. P., M. Park, W. S. Lee, H. Matsumoto, D. R. Bohnenstiehl, and J. H. Haxel, Tectonomagmatic activity and ice dynamics in the Bransfield Strait back-arc basin, Antarctica, Journal of Geophysical Research, 115(B1), doi:10.1029/2009jb006295, 2010.

Efron, B., and R. Tibshirani, Bootstrap Methods for Standard Errors, Confidence Intervals, and Other Measures of Statistical Accuracy, Statistical Science, 1(1), 54-75, 1986.

Fei, Y., and C. Bertka, Phase transitions in the Earth's mantle and mantle mineralogy, in Mantle Petrology: Field Observations and High Pressure Experimentation. A Tribute to Francis R. (Joe) Boyd, vol. 6, edited by Y. Fei, C. Bertka, and B. Mysen, pp. 189-207, The Geochemical Society, Special Publication N.6, 1999.

Fisk, M., Volcanism in the Bransfield Strait, Antarctica, Journal of South American Earth Sciences, 3(2-3), 91-101, doi:10.1016/0895-9811(90)90022-s, 1990.

Galindo-Zaldívar, J., L. Gamboa, A. Maldonado, S. Nakao, and Y. Bochu, Tectonic development of the Bransfield Basin and its prolongation to the South Scotia Ridge, northern Antarctic Peninsula, Marine Geology, 206(1-4), 267-282, doi:10.1016/j.margeo.2004.02.007, 2004.

González-Casado, J. M., J. L. Giner Robles, and J. López-Martínez, Bransfield Basin, Antarctic Peninsula: Not a normal backarc basin, Geology, 28(11), 1043, doi:10.1130/0091-7613(2000)28<1043:bbapna>2.0.co;2, 2000.

Gràcia, E., M. Canals, M. Farràn, M. J. Prieto, J. Sorribas, and Gebra Team, Morphostructure and evolution of the central and Eastern Bransfield Basins (NW Antarctic Peninsula), Marine Geophysical Researches, 18(2-4), 429-448, doi:10.1007/bf00286088, 1996.

Herrmann, R. B., Computer Programs in Seismology Volume II: EDABAC [Computer program], Department of Earth and Atmospheric Sciences, Saint Louis University, St. Louis, Missouri, USA, 1987.

Ibáñez, J. M., J. Morales, G. Alguacil, J. Almendros, R. Oritz, and E. Del Pezzo, Intermediate-focus earthquakes under South Shetland Islands (Antarctica), Geophysical Research Letters, 24(5), 531-534, doi:10.1029/97gl00314, 1997.

Jabaloy, A., J. C. Balanyá, A. Barnolas, J. Galindo-Zaldívar, F. J. Hernández-Molina, A. Maldonado, J. M. Martínez-Martínez, J. Rodríguez-Fernández, C. S. de Galdeano, L. Somoza, E. Suriñach, and J. T. Vázquez, The transition from an active to a passive margin (SW end of the South Shetland Trench, Antarctic Peninsula), Tectonophysics, 366(1-2), 55-81, doi:10.1016/s0040-1951(03)00060-x, 2003.

Jin, Y. K., J. Lee, J. K. Hong, and S. H. Nam, Is subduction ongoing in the South Shetland Trench, Antarctic Peninsula?: new constraints from crustal structures of outer trench wall, Geosciences Journal, 13(1), 59-67, doi:10.1007/s12303-009-0005-5, 2009. 
Keller, R. A., Geochemistry of back arc basin volcanism in Bransfield Strait, Antarctica: Subducted contributions and along-axis variations, Journal of Geophysical Research, 107(B8), doi:10.1029/2001jb000444, 2002.

Kennett, B. L. N., and E. R. Engdahl, Traveltimes for global earthquake location and phase identification, Geophysical Journal International, 105(2), 429-465, doi:10.1111/j.1365-246x.1991.tb06724.x, 1991.

Kikuchi, M., and H. Kanamori, Inversion of complex body waves, Bulletin of the Seismological Society of America, 72(2), 491-506, 1982.

Langston, C. A., Structure under Mount Rainier, Washington, inferred from teleseismic body waves, Journal of Geophysical Research, 84(B9), 4749, doi:10.1029/jb084ib09p04749, 1979.

Larter, R. D., A. P. Cunningham, P. F. Barker, K. Gohl, and F. O. Nitsche, Tectonic evolution of the Pacific margin of Antarctica 1. Late Cretaceous tectonic reconstructions, Journal of Geophysical Research: Solid Earth, 107(B12), EPM 5-1-EPM 5-19, doi:10.1029/2000jb000052, 2002.

Lawver, L., B. Sloan, D. Barker, M. Ghidella, R. Von Herzen, R. Keller, G. Klinkhammer, and C. Chin, Distributed, active extension in Bransfield basin Antarctic Peninsula: Evidence from multibeam bathymetry, GSA Today, 6(11), 1-6, 1996.

Leahy, G. M., J. A. Collins, C. J. Wolfe, G. Laske, and S. C. Solomon, Underplating of the Hawaiian Swell: evidence from teleseismic receiver functions, Geophysical Journal International, 183(1), 313-329, doi:10.1111/j.1365-246x.2010.04720.x, 2010.

Ligorría, J., and C. Ammon, Iterative deconvolution and receiver-function estimation, Bulletin of the Seismological Society of America, 89(5), 1395-1400, 1999.

Livermore, R., J. C. Balanyá, A. Maldonado, J. M. Martínez, J. Rodríguez-Fernández, C. Sanz de Galdeano, J. G. Zaldívar, A. Jabaloy, A. Barnolas, L. Somoza, J. HernándezMolina, E. Suriñach, and C. Viseras, Autopsy on a dead spreading center: The Phoenix Ridge, Drake Passage, Antarctica, Geology, 28(7), 607, doi:10.1130/00917613(2000)28<607:aoadsc >2.0.co;2, 2000.

Lodge, A., S. Nippress, A. Rietbrock, A. García-Yeguas, and J. Ibáñez, Evidence for magmatic underplating and partial melt beneath the Canary Islands derived using teleseismic receiver functions, Physics of the Earth and Planetary Interiors, 212-213, 44-54, doi:10.1016/j.pepi.2012.09.004, 2012.

Lombardi, D., J. Braunmiller, E. Kissling, and D. Giardini, Moho depth and Poisson's ratio in the Western-Central Alps from receiver functions, Geophysical Journal International, 173(1), 249-264, doi:10.1111/j.1365-246x.2007.03706.x, 2008.

Maldonado, A., F. Bohoyo, J. Galindo-Zaldívar, F. J. Hernández-Molina, F. J. Lobo, E. Lodolo, Y. M. Martos, L. F. Pérez, A. A. Schreider, and L. Somoza, A model of oceanic development by ridge jumping: Opening of the Scotia Sea, Global and Planetary Change, 123, 152-173, doi:10.1016/j.gloplacha.2014.06.010, 2014. 
Mancilla, F., D. Stich, J. Morales, J. Julià, J. Diaz, A. Pazos, D. Córdoba, J. A. Pulgar, P. Ibarra, M. Harnafi, and F. González-Lodeiro, Crustal thickness variations in northern Morocco, Journal of Geophysical Research: Solid Earth, 117(B2), n/a-n/a, doi:10.1029/2011jb008608, 2012.

Martínez-Arévalo, C., F. Mancilla, G. Helffrich, and A. García, Seismic evidence of a regional sublithospheric low velocity layer beneath the Canary Islands, Tectonophysics, 608, 586-599, doi:10.1016/j.tecto.2013.08.021, 2013.

Muller, G., Approximate Treatment of Elastic Body Waves in Media with Spherical Symmetry, Geophysical Journal International, 23(4), 435-449, doi:10.1111/j.1365246x.1971.tb01835.x, 1971.

Park, Y., K.-H. Kim, J. Lee, H. J. Yoo, and M. P. Plasencia L., P-wave velocity structure beneath the northern Antarctic Peninsula: evidence of a steeply subducting slab and a deep-rooted low-velocity anomaly beneath the central Bransfield Basin, Geophysical Journal International, pp. no-no, doi:10.1111/j.1365-246x.2012.05684.x, 2012.

Robertson Maurice, S. D., D. A. Wiens, P. J. Shore, E. Vera, and L. M. Dorman, Seismicity and tectonics of the South Shetland Islands and Bransfield Strait from a regional broadband seismograph deployment, Journal of Geophysical Research: Solid Earth, 108(B10), doi:10.1029/2003jb002416, 2003.

Ryan, W. B. F., S. M. Carbotte, J. O. Coplan, S. O'Hara, A. Melkonian, R. Arko, R. A. Weissel, V. Ferrini, A. Goodwillie, F. Nitsche, J. Bonczkowski, and R. Zemsky, Global Multi-Resolution Topography synthesis, Geochemistry, Geophysics, Geosystems, 10(3), n/a-n/a, doi:10.1029/2008GC002332, 2009.

Schmerr, N., Imaging Mantle Heterogeneity with Upper Mantle Seismic Discontinuities, in The Earth's Heterogeneous Mantle: A Geophysical, Geodynamical, and Geochemical Perspective, edited by A. Khan and F. Deschamps, pp. 79-104, Springer International Publishing, doi:10.1007/978-3-319-15627-9_3, 2015.

Schmerr, N., and E. J. Garnero, Upper Mantle Discontinuity Topography from Thermal and Chemical Heterogeneity, Science, 318(5850), 623-626, doi:10.1126/science.1145962, 2007.

Schmerr, N. C., B. M. Kelly, and M. S. Thorne, Broadband array observations of the $300 \mathrm{~km}$ seismic discontinuity, Geophysical Research Letters, 40(5), 841-846, doi:10.1002/grl.50257, 2013.

Smellie, J. L., The 1969 subglacial eruption on Deception Island (Antarctica): events and processes during an eruption beneath a thin glacier and implications for volcanic hazards, Geological Society, London, Special Publications, 202(1), 59-79, doi:10.1144/gsl.sp.2002.202.01.04, 2002.

Smellie, J. L., R. Pankhurst, M. R. A. Thomson, and R. E. S. Davies, The geology of the South Shetland Islands: VI. Stratigraphy, geochemistry and evolution, British Antarctic Survey Scientific Reports, 87, 85 pp, 1984.

Smyth, J. R., and S. D. Jacobsen, Nominally anhydrous minerals and Earth's deep water cycle, in Earth's Deep Water Cycle, vol. 168, edited by S. D. Jacobsen and S. Van Der Lee, pp. 1-11, American Geophysical Union, doi:10.1029/gm168, 2006. 
Thomas, C., R. Livermore, and F. Pollitz, Motion of the Scotia Sea plates, Geophysical Journal International, 155(3), 789-804, doi:10.1111/j.1365-246x.2003.02069.x, 2003.

Vinnik, L., Detection of waves converted from P to SV in the mantle, Physics of the Earth and Planetary Interiors, 15(1), 39-45, doi:10.1016/0031-9201(77)90008-5, 1977.

Vuan, A., Joint Inversion of Receiver Function of Teleseismic Body Waves and Local Group Velocity Dispersion Curves beneath ESPZ and PMSA Stations (Antarctic Peninsula), Terra Antarctica, 8(2), 49-54, 2001.

Williams, Q., and J. Revenaugh, Ancient subduction, mantle eclogite, and the $300 \mathrm{~km}$ seismic discontinuity, Geology, 33(1), 1, doi:10.1130/g20968.1, 2005.

Yegorova, T., V. Bakhmutov, T. Janik, and M. Grad, Joint geophysical and petrological models for the lithosphere structure of the Antarctic Peninsula continental margin, Geophysical Journal International, 184(1), 90-110, doi:10.1111/j.1365246x.2010.04867.x, 2010.

Zhu, L., and H. Kanamori, Moho depth variation in southern California from teleseismic receiver functions, Journal of Geophysical Research: Solid Earth, 105(B2), 29692980, doi:10.1029/1999jb900322, 2000. 
A Computer programs 


\section{hkstacking.c}

Pàgina 1 de 3

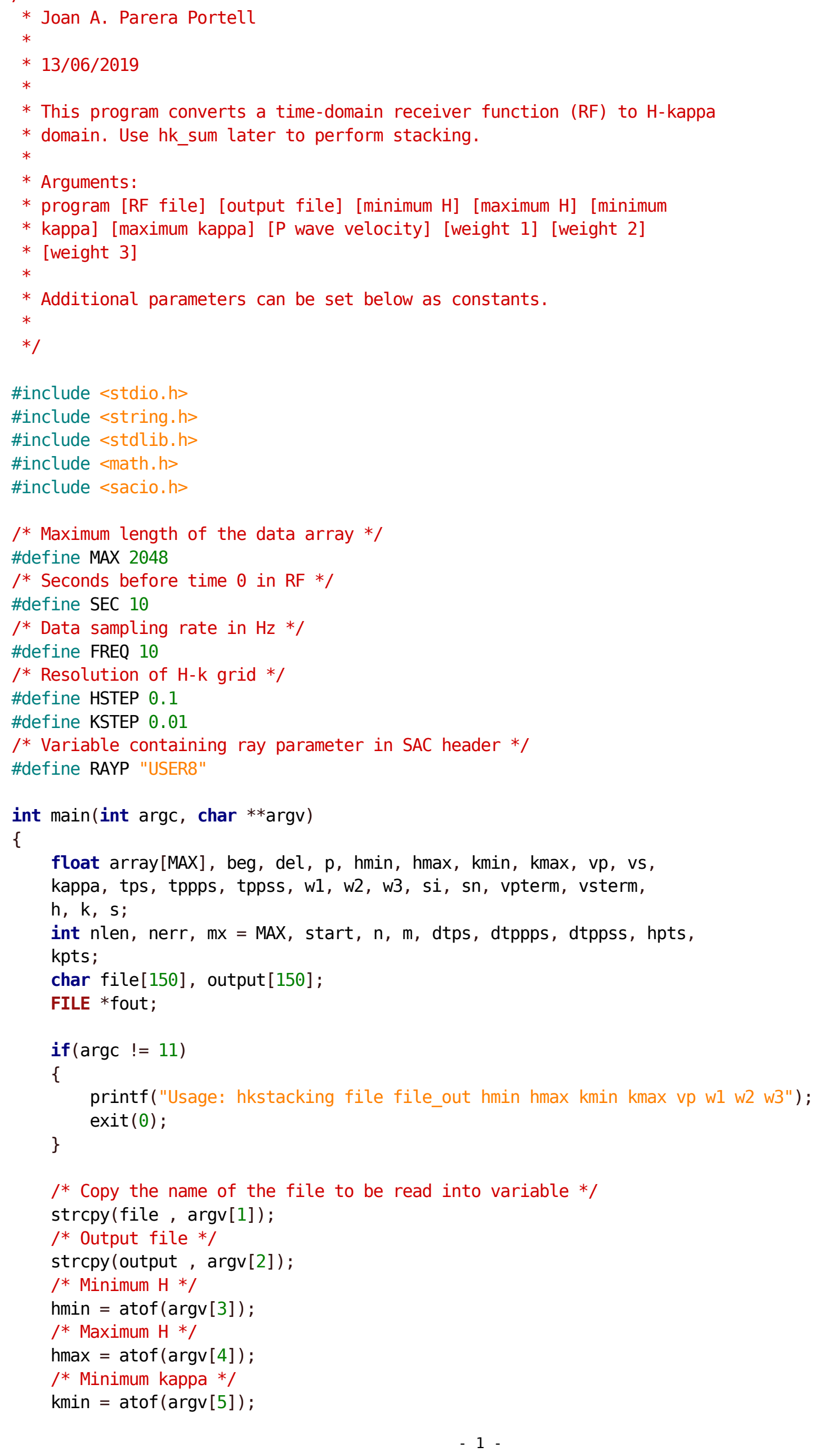




\section{hkstacking.c \\ Pàgina 2 de 3}

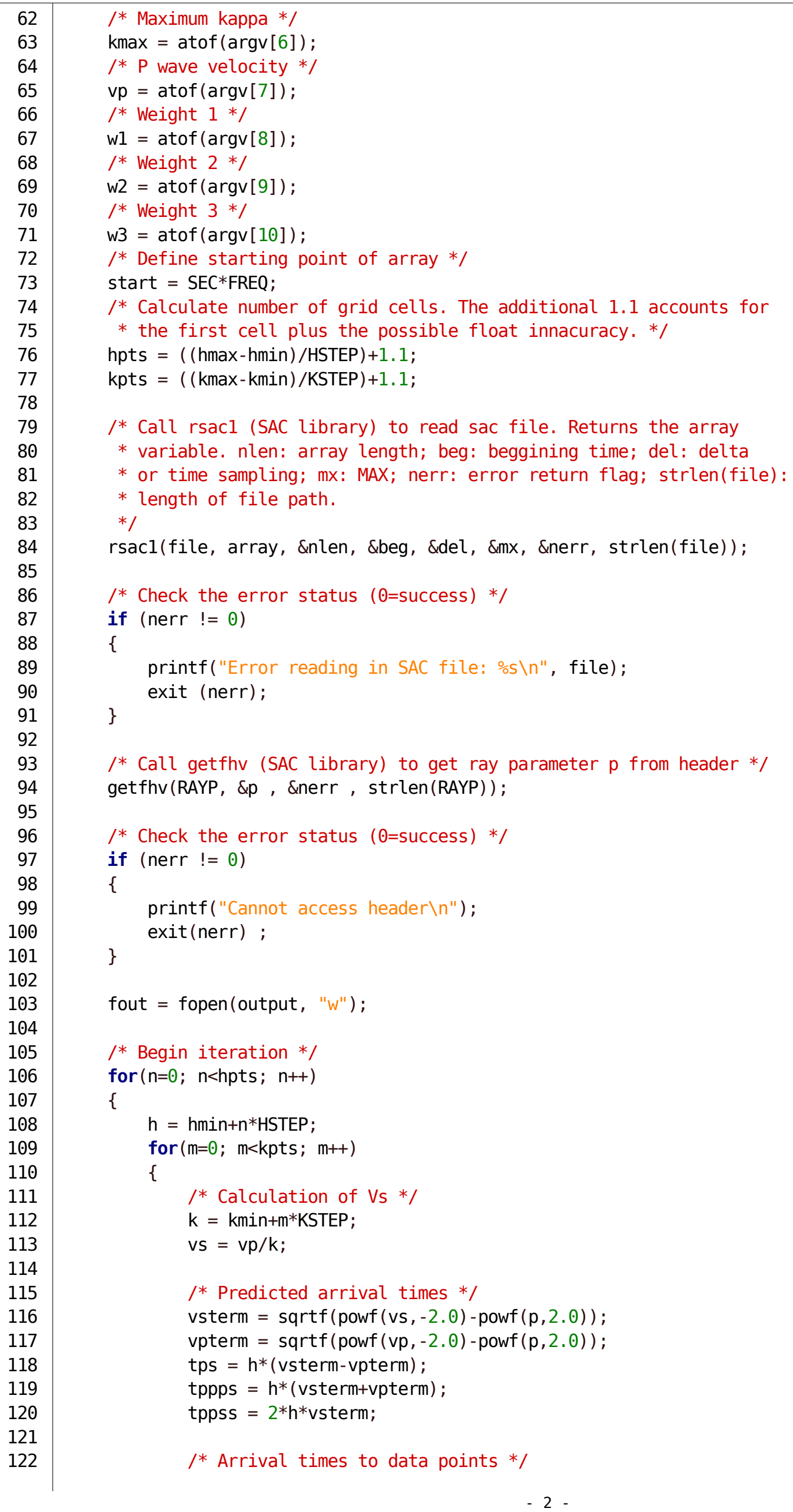


hkstacking.c

Pàgina 3 de 3

123

124

125

126

127

128

129

130

131

132

133

134

135

136

137

138 dtps $=$ (int) start+tps*FREQ;

dtppps $=$ (int) start+tppps*FREQ;

dtppss $=$ (int) start+tppss*FREQ;

/* Conversion to $\mathrm{H}-\mathrm{k} *$ /

$\mathrm{s}=\mathrm{w} 1 * \operatorname{array}[\mathrm{dtps}]+\mathrm{w} 2 * \operatorname{array}[\mathrm{dtppps}]-\mathrm{w} 3 * \operatorname{array}[\mathrm{dtppss}]$;

/* Write results to file */

fprintf(fout, "\%2.2f,\%1.3f,\%1.5f\n", h, k, s);

\}

\}

fclose(fout);

return $\theta$;

\} 
hk_sum.c

Pàgina 1 de 2

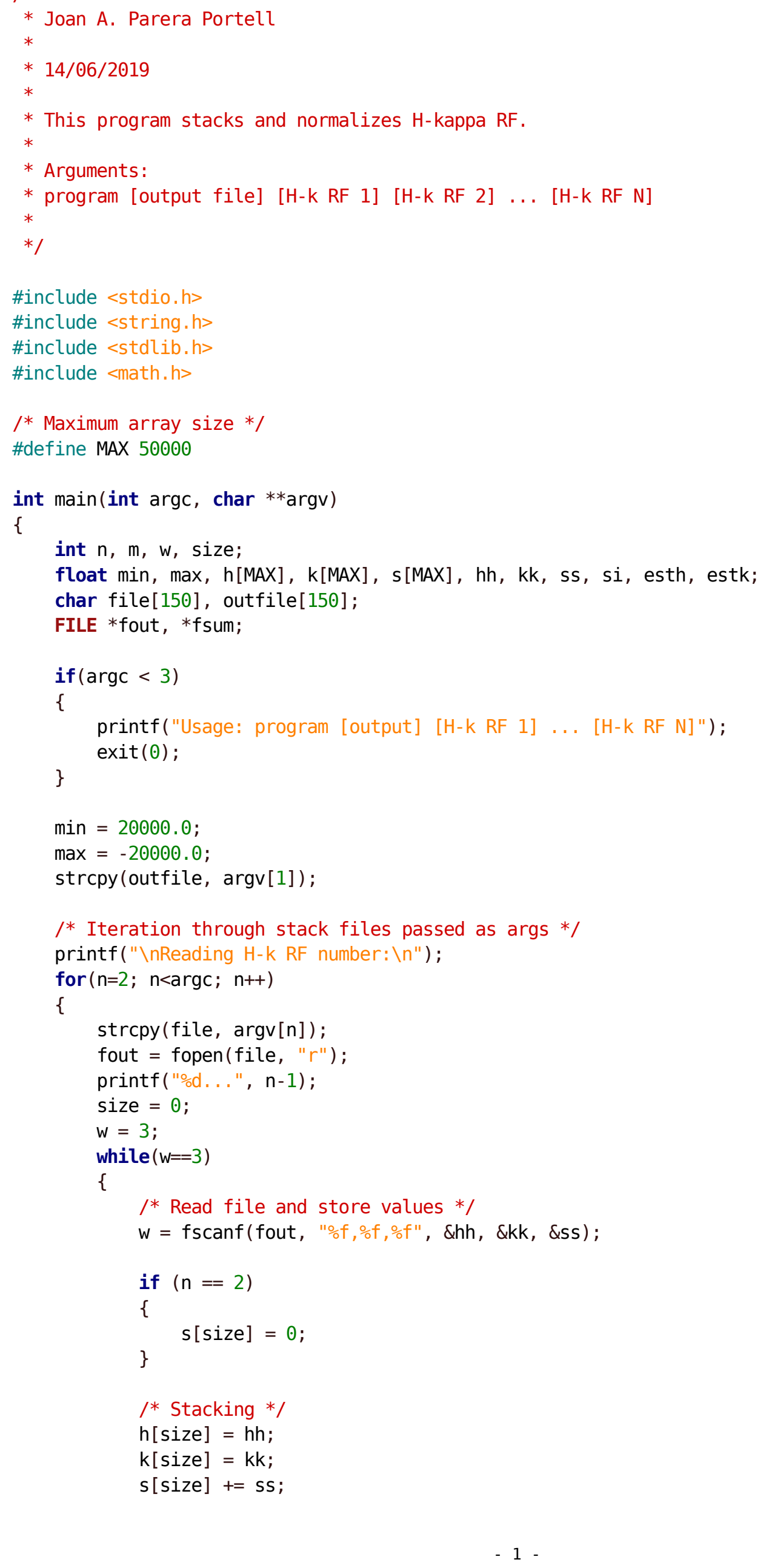


hk_sum.c

Pàgina 2 de 2

\section{2}

63

64

65

66

67

68

69

70

71

72

73

74

75

76

77

78

79

80

84

85

86

87

88

89

90

91

92

93
/* Find if the stack value is maximum */

if $(s[s i z e]>\max )$

\{

$\max =\mathrm{s}[$ size $]$

\}

/* Find if the stack value is minimum */

if $(\mathrm{s}[\mathrm{size}]<\min )$

\{

$\min =\mathrm{s}[$ size $]$

\}

size++ ;

\}

\}

fclose(fout);

size- - ;

/* Normalize stack and write to output file */

fsum = fopen (outfile, "w");

for $(\mathrm{n}=0 ; \mathrm{n}<\mathrm{size} ; \mathrm{n++})$

\{

$\operatorname{si}=(s[n]+\operatorname{sqrtf}(\operatorname{powf}(\min , 2.0))) /(\max +\operatorname{sqrtf}(\operatorname{powf}(\min , 2.0)))$;

\}

fprintf(fsum, "\%2.2f,\%1.3f,\%1.5f\n", h[n], k[n], si);

printf("\nH-k stacking done! \n");

fclose(fsum);

return $\odot$; 
bootstrap.c

Pàgina 1 de 3

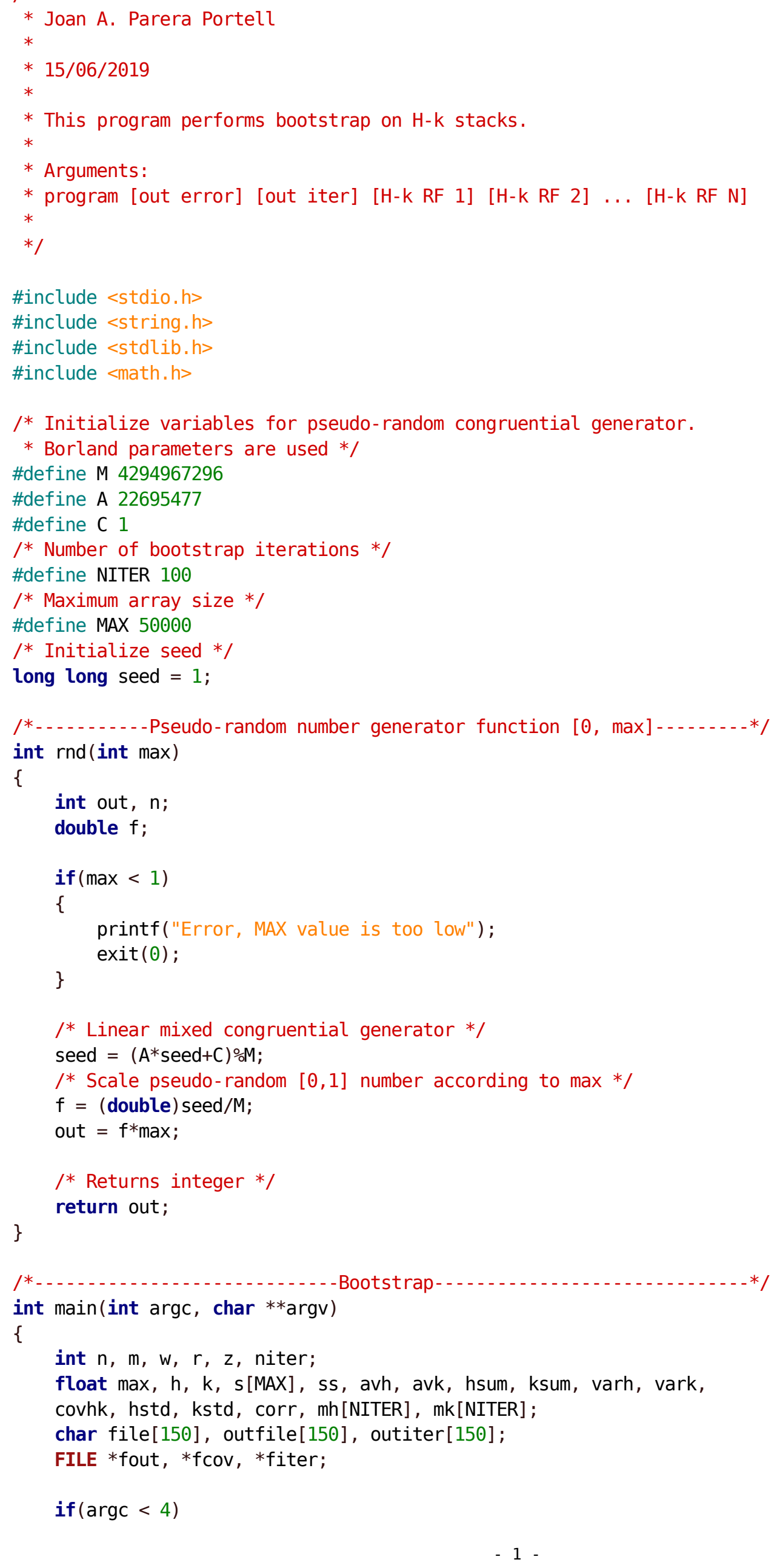


bootstrap.c

Pàgina 2 de 3

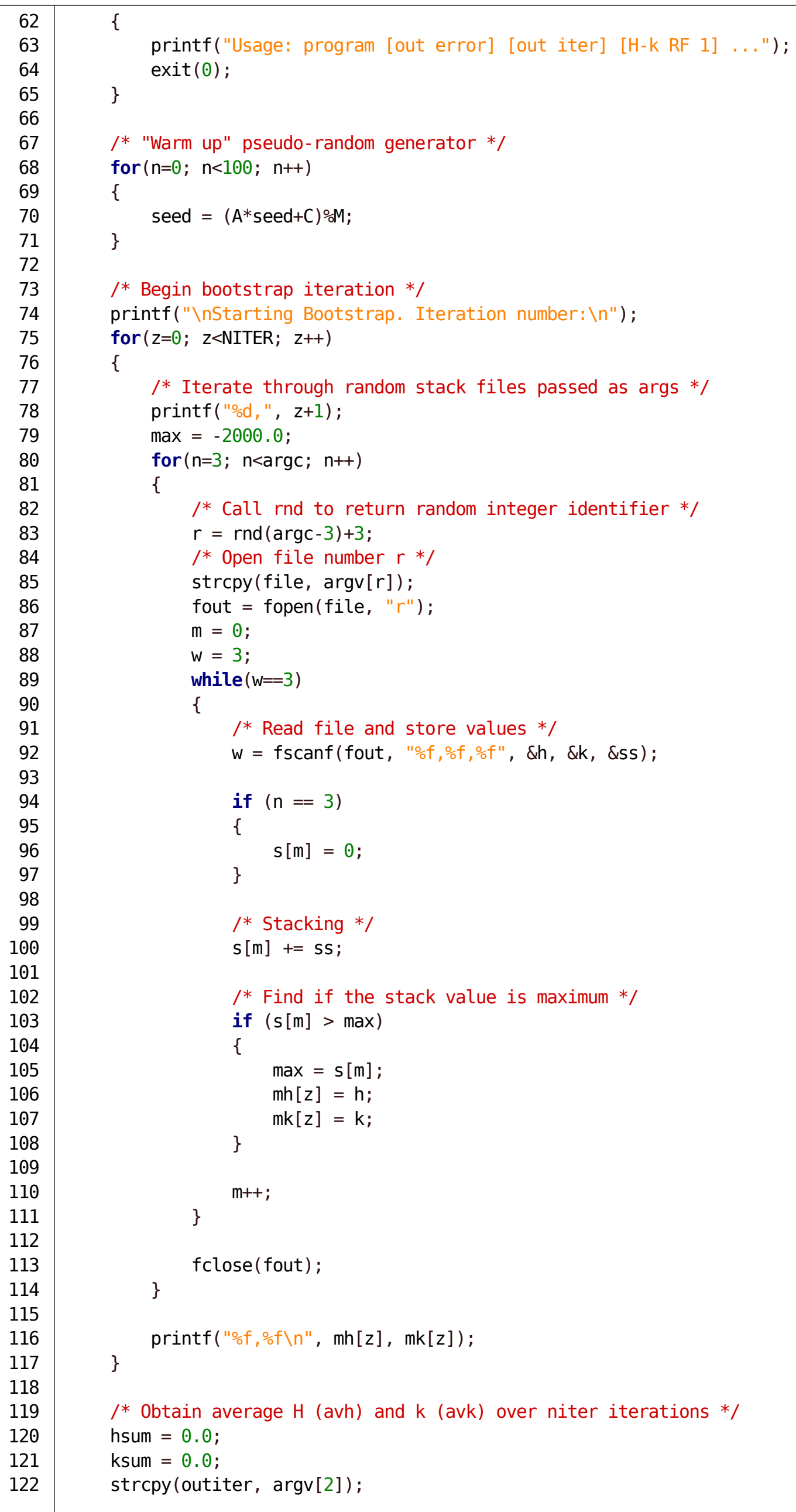


bootstrap.c

Pàgina 3 de 3

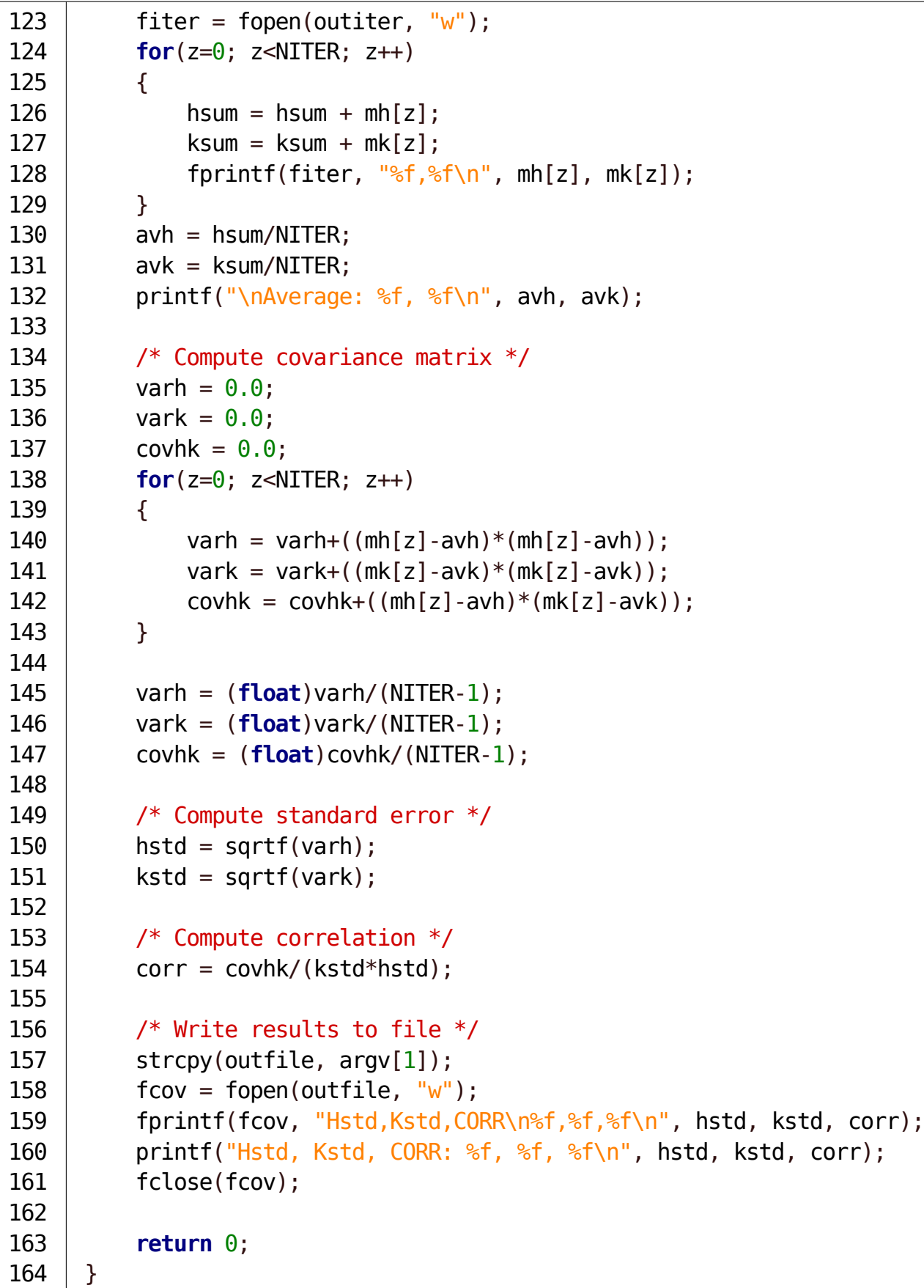




\section{hk_plot.py}

Pàgina 1 de 2

1 \# -*- coding: utf-8 -*-

2

3 Joan A. Parera Portell

$15 / 06 / 2019$

This script plots H-K stacks.

Usage: python3 hk_plot.py [in file] [out plot] [Hmin] [Hmax] [kmin] [kmax] [bootstrap]

$$
\text { " " " " }
$$

\section{import sys}

import math as $\mathrm{m}$

import numpy as $n p$

import pandas as pd

import scipy.interpolate as $\mathrm{sp}$

import matplotlib.pyplot as plt

from matplotlib.patches import Ellipse as ep

from matplotlib.ticker import AutoMinorLocator

from matplotlib import rcParams

rcParams ['font.size'] $=15$

rcParams ['font. family'] = 'serif'

if len(sys.argv) < 8:

print("Usage: python3 hk_plot.py [in file] [out plot] [Hmin] [Hmax] [kmin] [kmax] [bootstrap]")

$$
\text { \#- }
$$
-Read input

infile $=$ sys.argv[1]

outfile = sys.argv[2]

hmin $=$ float $($ sys $\cdot \operatorname{argv}[3])$

hmax $=$ float $($ sys $\cdot \arg v[4])$

$\mathrm{kmin}=$ float $($ sys $\cdot \operatorname{argv}[5])$

$\operatorname{kmax}=$ float $($ sys $\cdot \arg [6])$

boot $=$ sys.argv[7]

\# Read files as tables and calculate covariance

suma $=$ pd.read_csv(infile, $\operatorname{sep}="$, ", names $=\left[" h ", "{ }^{\prime}\right.$ ", "s"])

bootstrap $=$ pd. read $\operatorname{csv}($ boot, $\operatorname{sep}="$ ", ", header $=0$ )

hstd $=$ float (bootstrap ["Hstd"])

kstd $=$ float (bootstrap ["Kstd"])

corr = float (bootstrap ["CORR"])

covar $=$ corr*hstd*kstd

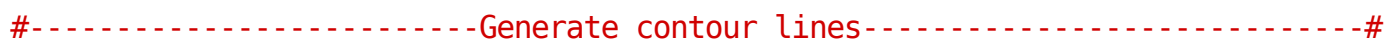

$y i=n p$. linspace $(k m i n, k m a x, 150)$

$x i=n p . l i n s p a c e(h m i n, h m a x, 150)$

$x, y=n p$. meshgrid $(x i, y i)$

zc = sp.griddata ( (suma["h"], suma["k"]) , suma["s"], $(x, y)$, method="linear")

\#-

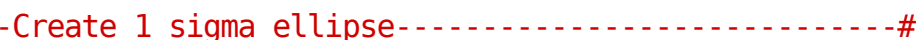

\# Locate data point of maximmum $\mathrm{S}$

maxs_index = suma. loc [ $\operatorname{suma}[" \mathrm{~s} "]==\operatorname{suma}[" \mathrm{~s} "] \cdot \max ()]$. index [0]

\# Get $\mathrm{H}$ and $\mathrm{k}$ (center of ellipse) at data point of maximum $\mathrm{S}$

$\mathrm{h}=$ float (suma $[" \mathrm{~h} "][\operatorname{maxs}$ index])

$\mathrm{k}=$ float (suma ["k"] [maxs index])

\# Calculate covariance matrix

cov mat $=$ np.array $([$ hstd**2, covar $],[\operatorname{covar}, \operatorname{kstd} * * 2]])$

eigvalues, eigvectors $=\mathrm{np}$.linalg.eig(cov_mat) 


\section{hk plot.py}

\section{Pàgina 2 de 2}

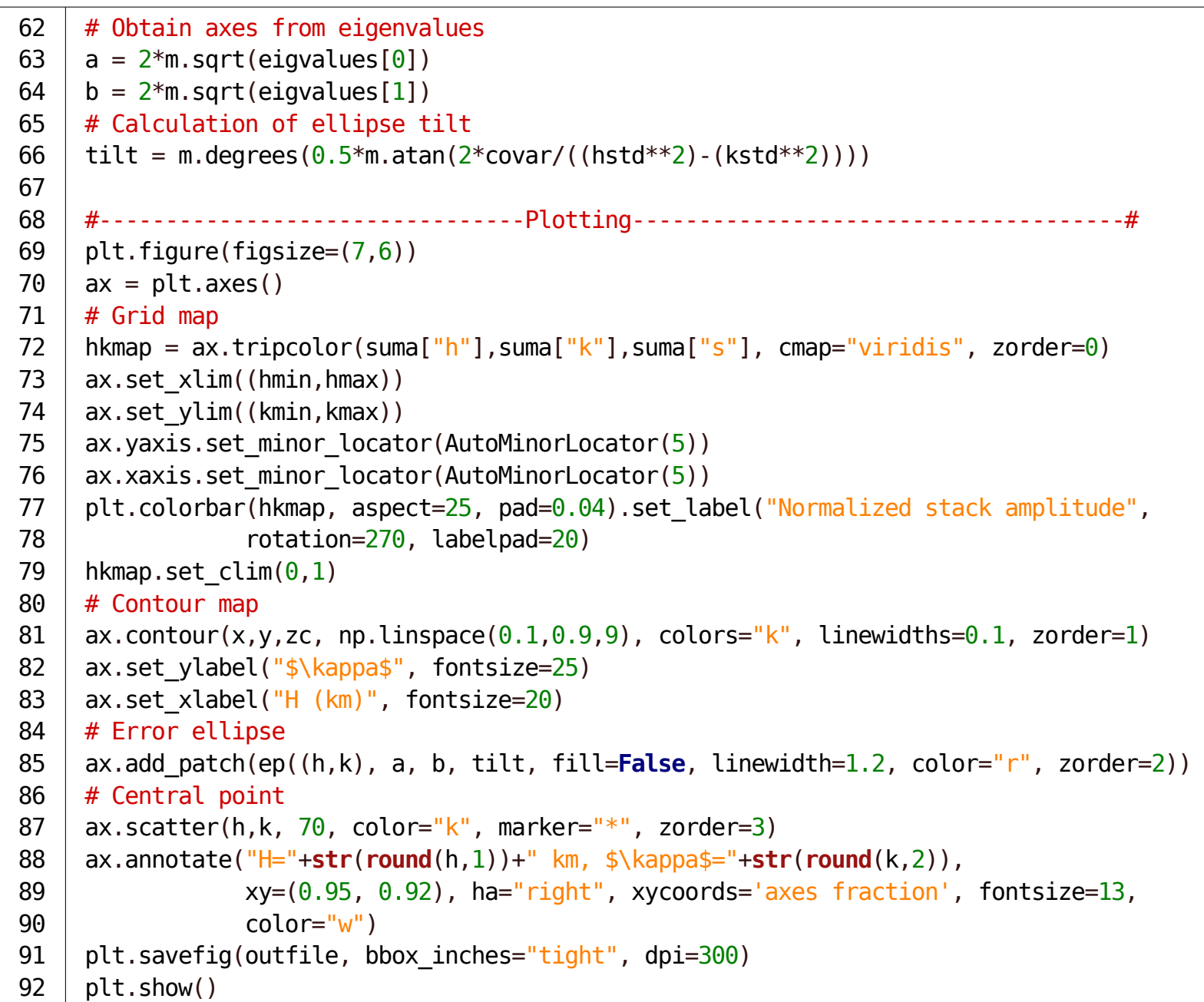


do_hk.sh

Pàgina 1 de 2

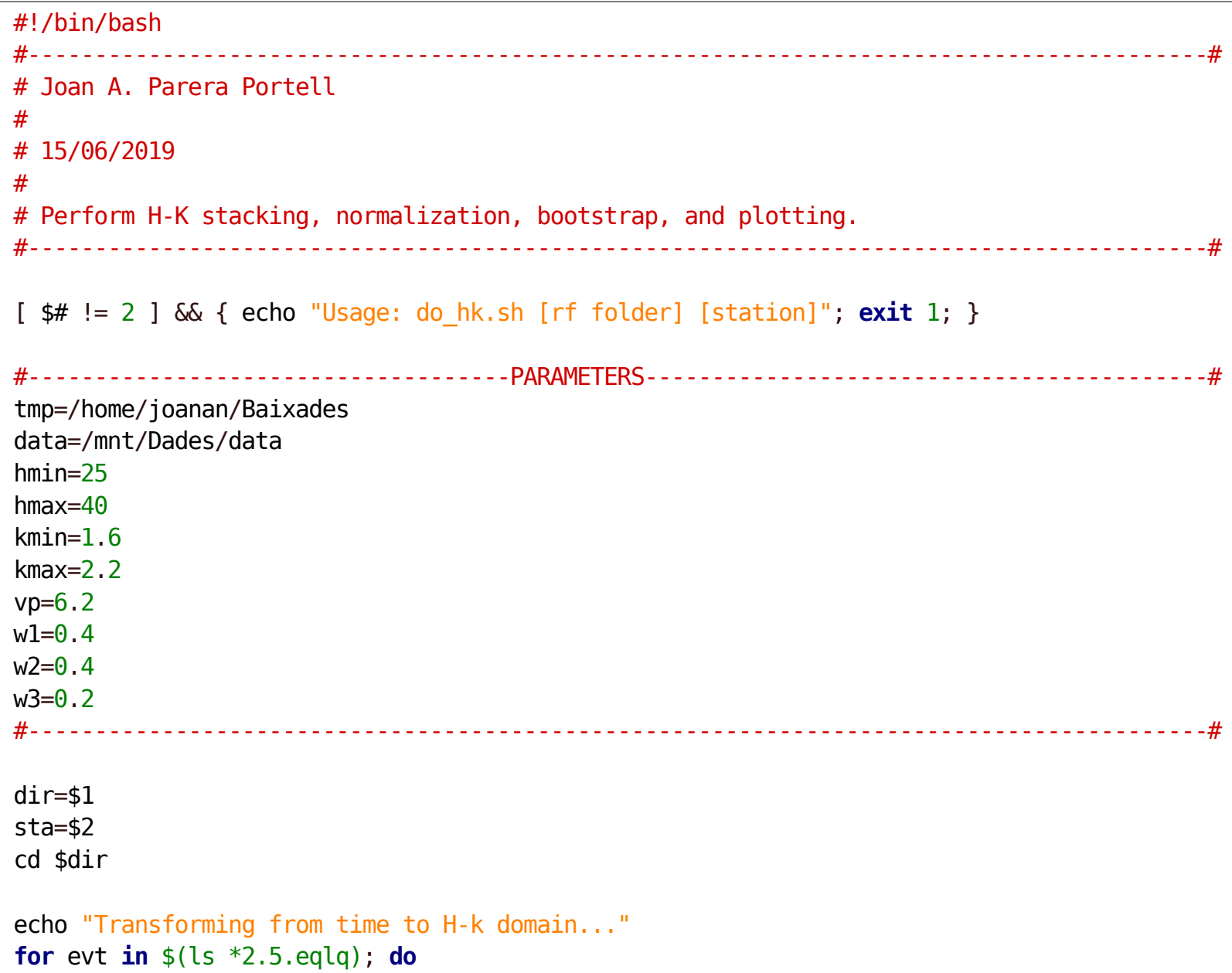


do_hk.sh

Pàgina 2 de 2

62 echo "Vp: \$vp" > \$params

63 echo "W1: $\$ w 1 ">$ \$params

64 echo "W2: \$W2" > \$params

65 echo "W3: \$W3" > \$params

66 echo "Plotting..."

67

68

in $=\$\{$ data $\} / \$\{$ sta $\} /$ hkstack $/ \$\{$ sta $\}$ hk.txt

out $=\$\{$ data $\} / \$\{$ sta $\} /$ hkstack $/ \$\{$ sta $\}$ hk.png

70 boot $=\$\{$ data $\} / \$\{$ sta $\} /$ hkstack $/ \$\{$ sta $\}$ bootstrap.txt

71 \# Call Python script to plot the normalized stack

72 python3 /bin/hk_plot.py \$in \$out \$hmin \$hmax \$kmin \$kmax \$boot

74 


\section{B Time-domain stacks}

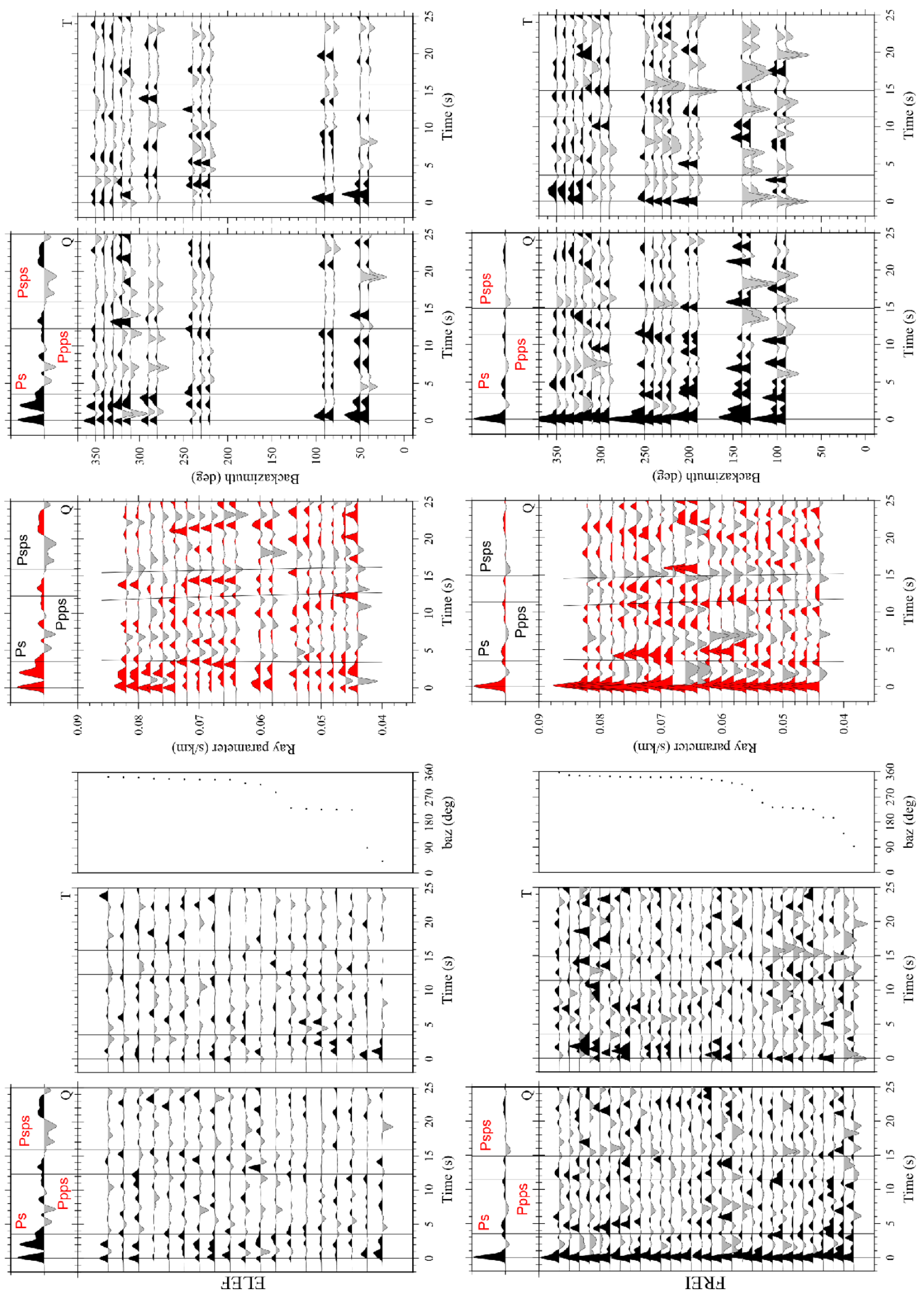

Figure 27: RFs ordered by backazimuth (left), stacks by ray parameter (centre), and stacks by backazimuth (right) of ELEF and FREI. 

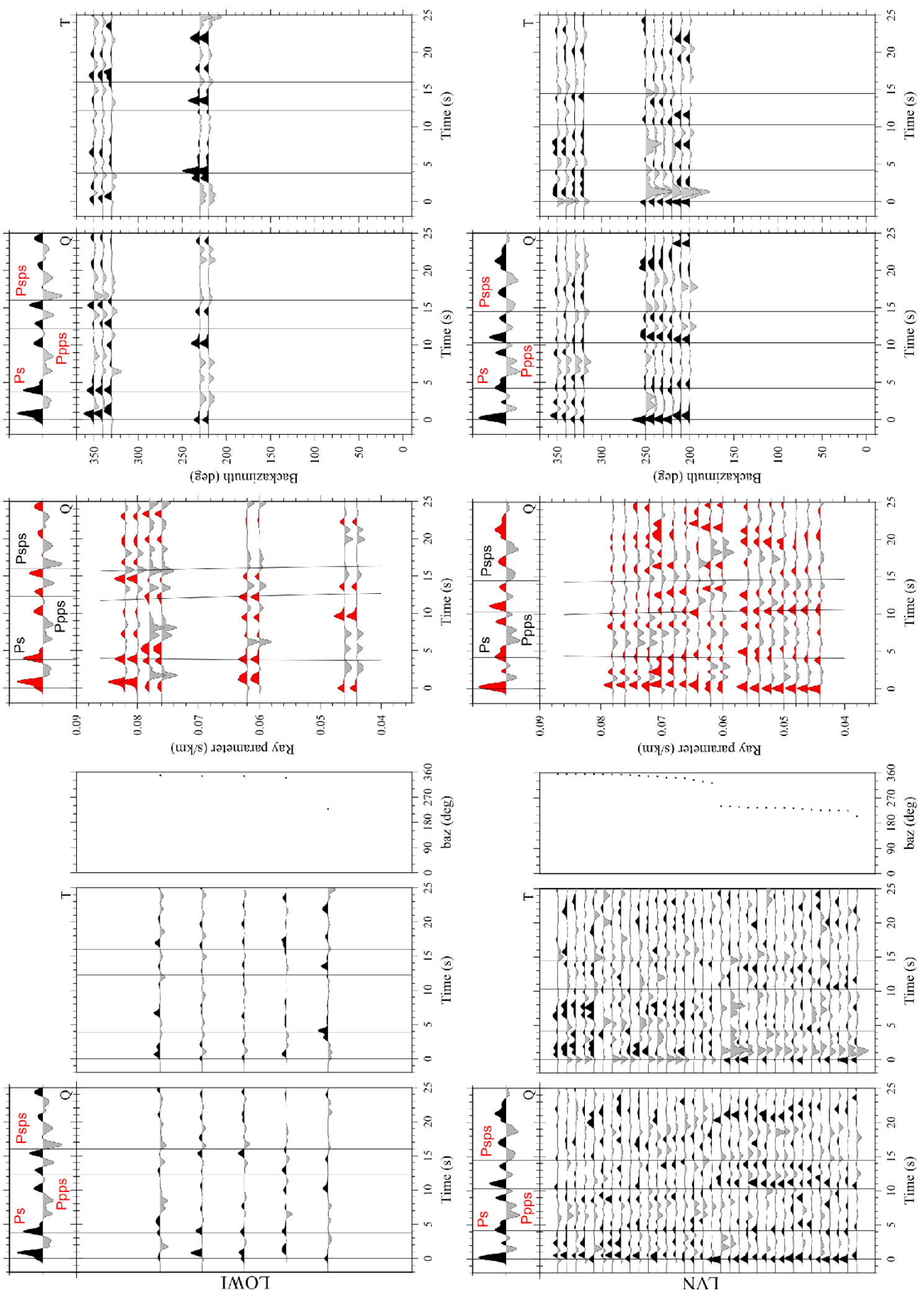

Figure 28: RFs ordered by backazimuth (left), stacks by ray parameter (centre), and stacks by backazimuth (right) of LOWI and LVN. 

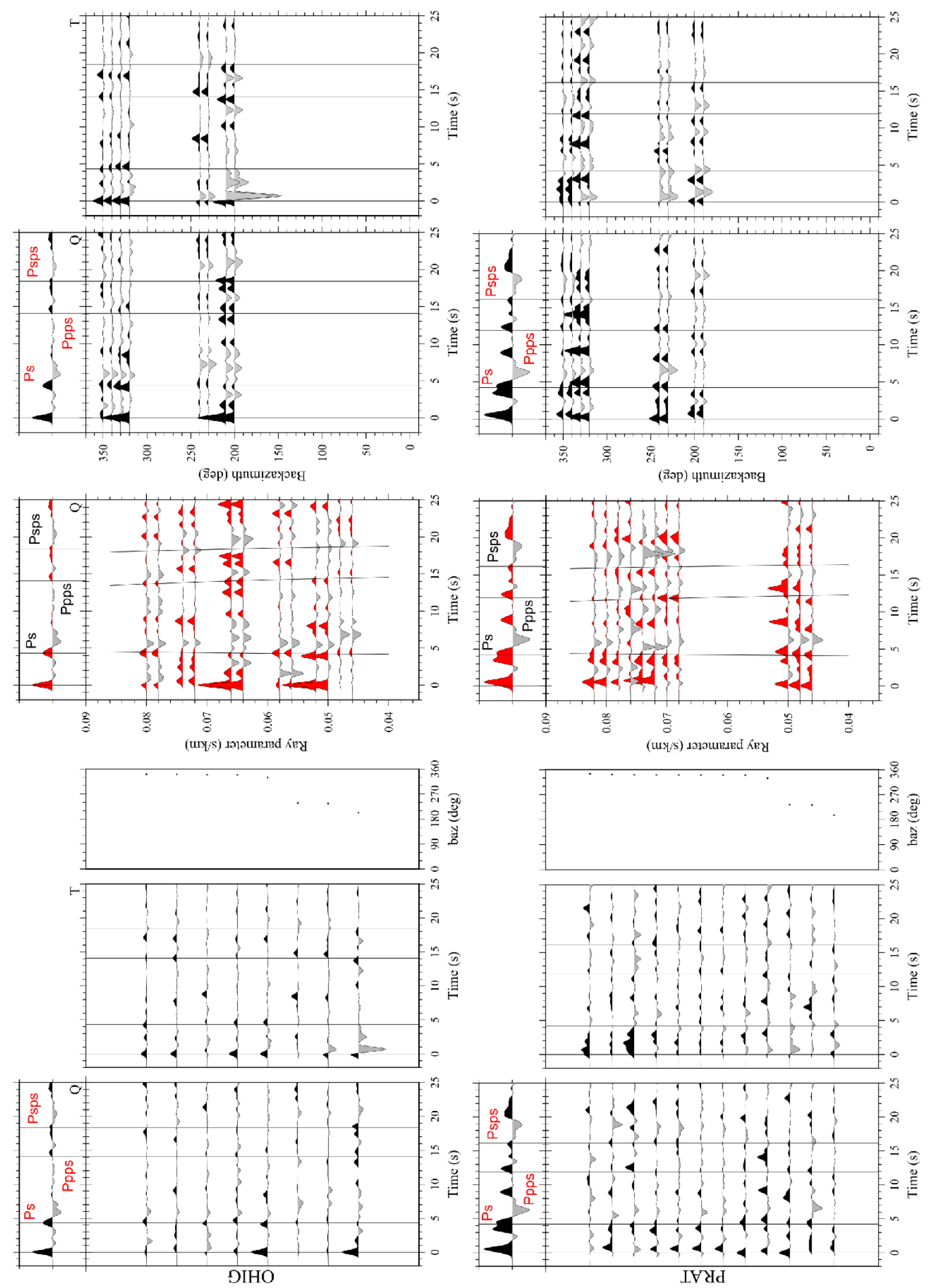

Figure 29: RFs ordered by backazimuth (left), stacks by ray parameter (centre), and stacks by backazimuth (right) of OHIG and PRAT. 

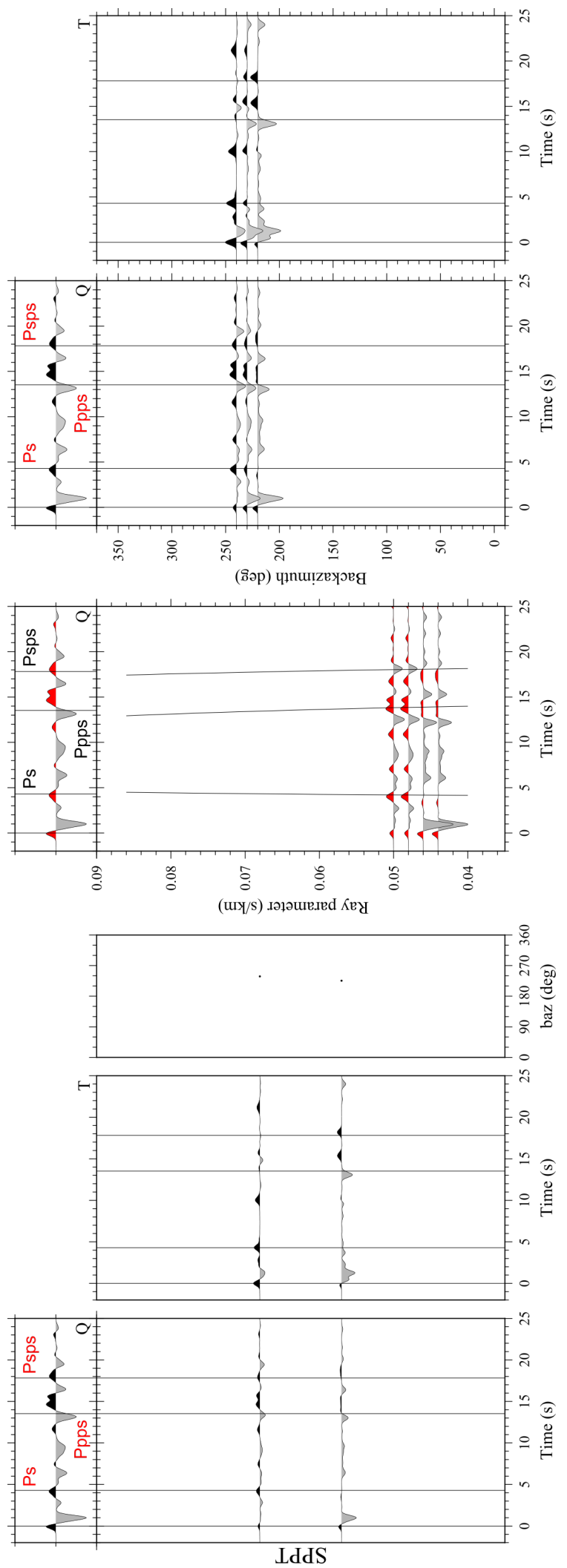

Figure 30: RFs ordered by backazimuth (left), stacks by ray parameter (centre), and stacks by backazimuth (right) of SPPT. 

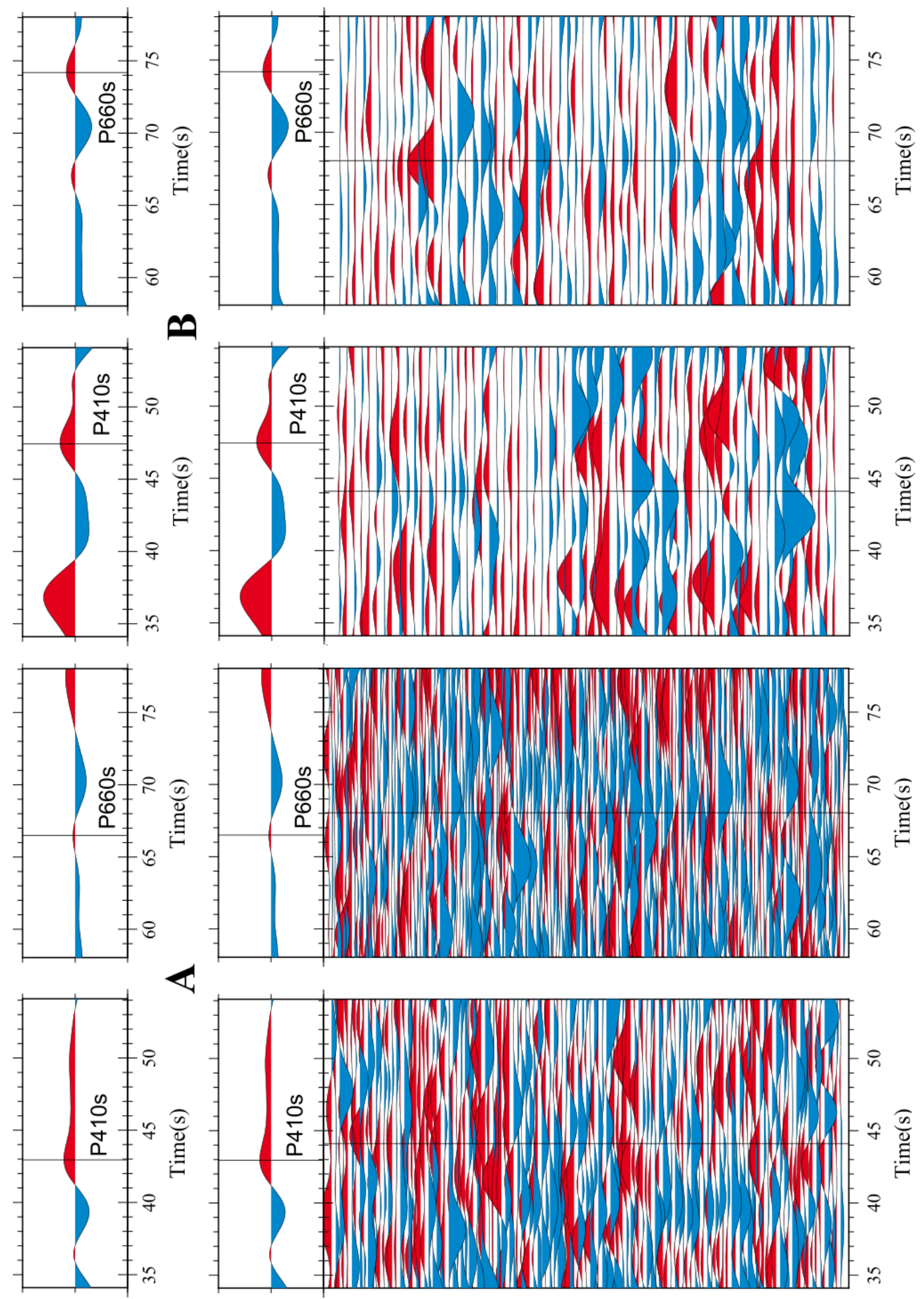

Figure 31: Grid stacks of cells A (left) and B (right). 


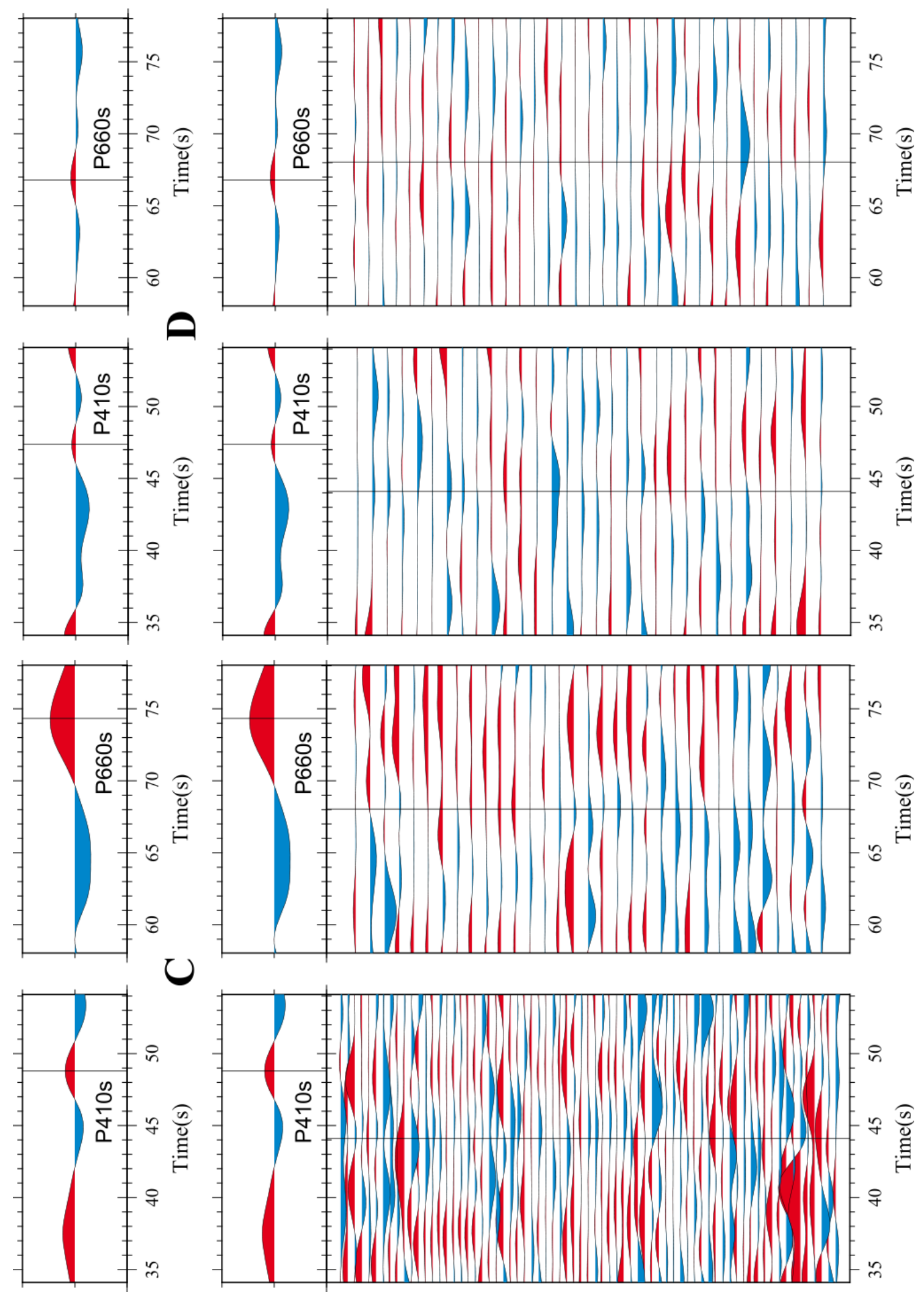

Figure 32: Grid stacks of cells C (left) and D (right). 


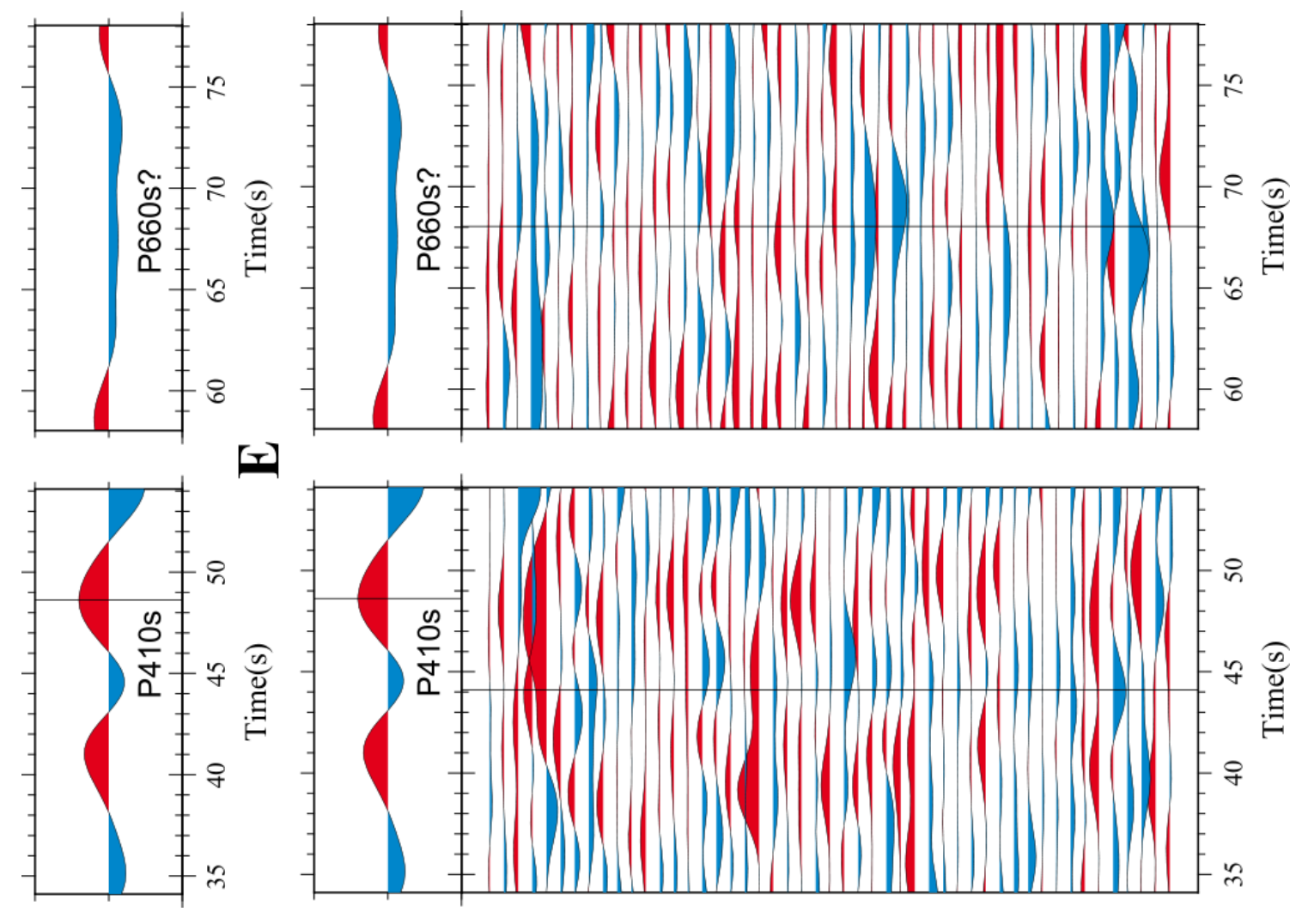

Figure 33: Grid stack of cell E. 


\section{C $H-\kappa$ stacks}

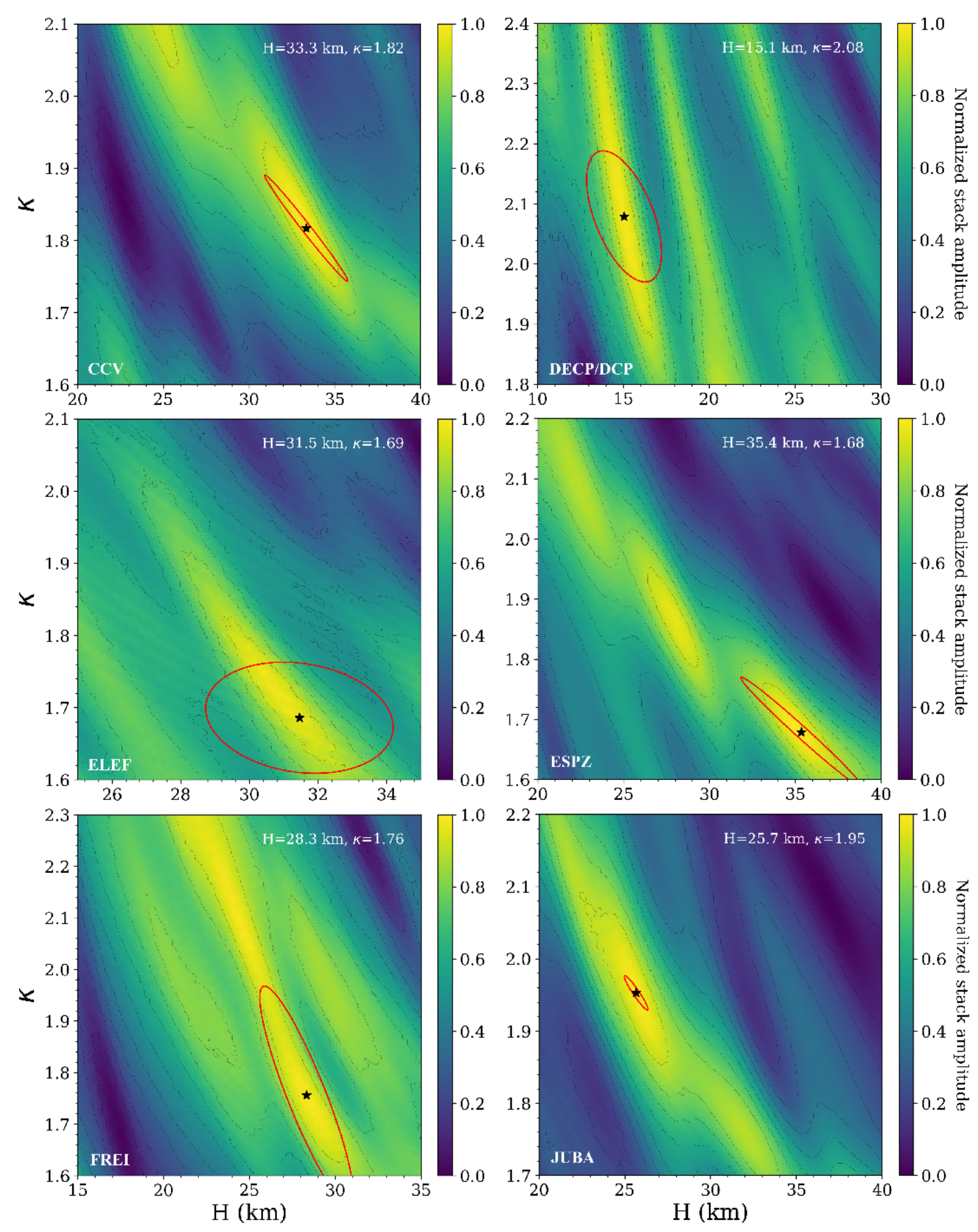

Figure 34: $H-\kappa$ stacks of CCV, DECP/DCP, ELEF, ESPZ, FREI, and JUBA. $1 \sigma$ ellipses are shown in red. 

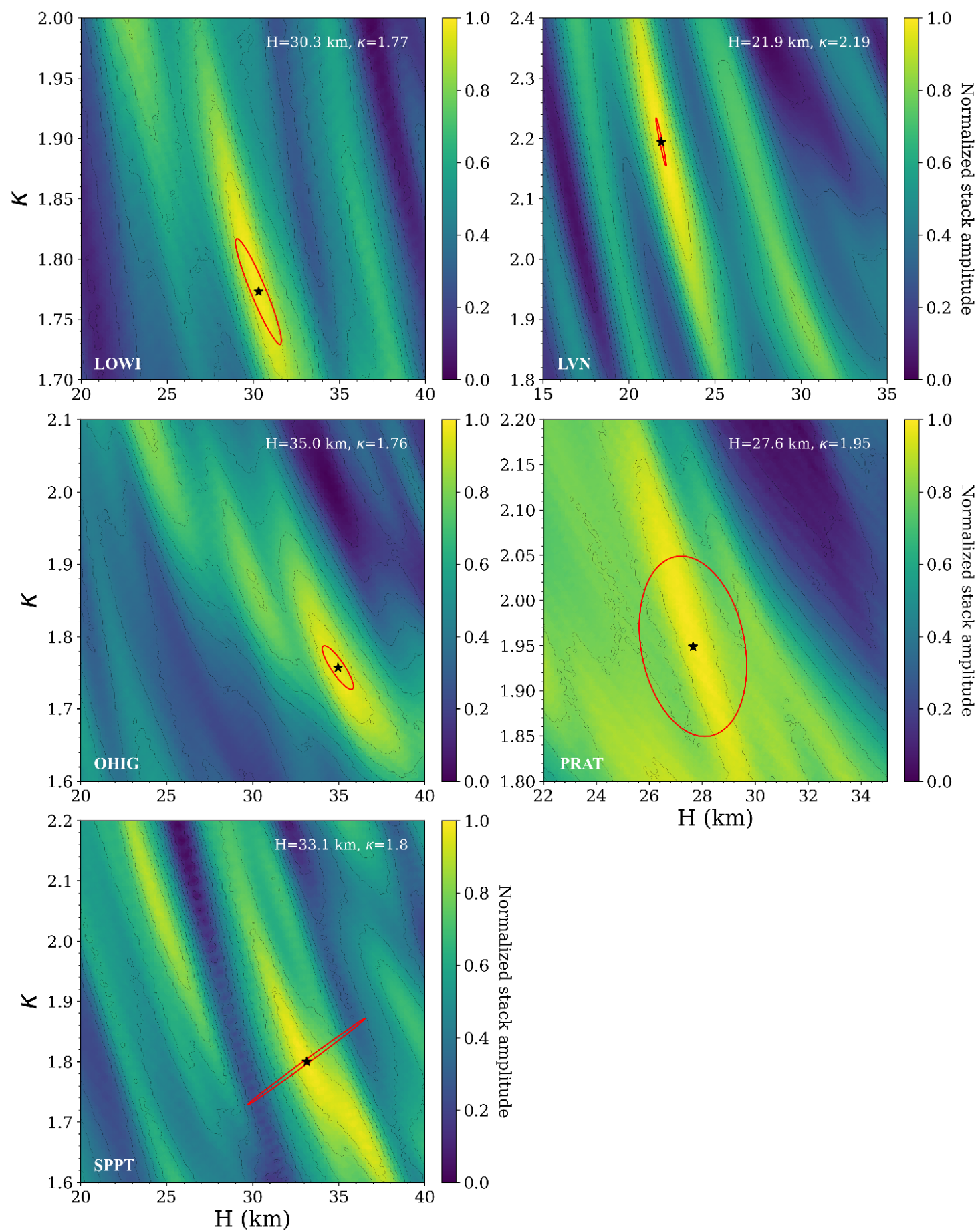

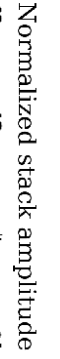

Figure 35: $H-\kappa$ stacks of LOWI, LVN, OHIG, PRAT, and SPPT. $1 \sigma$ ellipses are shown in red. 